Portland State University

PDXScholar

\title{
Nuwuvi (Southern Paiute) Ecological Knowledge of Piñon-Juniper Woodlands: Implications for Conservation and Sustainable Resource Use in Two Southern Nevada Protected Areas
}

Brian John Lefler

Portland State University

Follow this and additional works at: https://pdxscholar.library.pdx.edu/open_access_etds

Part of the Anthropology Commons, Ecology and Evolutionary Biology Commons, and the Indigenous Studies Commons

Let us know how access to this document benefits you.

\section{Recommended Citation}

Lefler, Brian John, "Nuwuvi (Southern Paiute) Ecological Knowledge of Piñon-Juniper Woodlands: Implications for Conservation and Sustainable Resource Use in Two Southern Nevada Protected Areas" (2014). Dissertations and Theses. Paper 2007.

https://doi.org/10.15760/etd.2006

This Thesis is brought to you for free and open access. It has been accepted for inclusion in Dissertations and Theses by an authorized administrator of PDXScholar. Please contact us if we can make this document more accessible: pdxscholar@pdx.edu. 
Nuwuvi (Southern Paiute) Ecological Knowledge of Piñon-Juniper Woodlands:

Implications for Conservation and Sustainable Resource Use in Two Southern Nevada

Protected Areas

Brian John Lefler

A thesis submitted in partial fulfillment of the requirements for the degree of

Master of Science

In

Anthropology

Thesis Committee:

Jeremy Spoon, Chair

Michele Gamburd

Kenneth Ames

Douglas Deur

Portland State University

2014 
(C) Brian John Lefler 


\begin{abstract}
Nuwuvi (Southern Paiute) have inhabited the southern Great Basin for thousands of years, and consider Nuvagantu (where snow sits) in the Spring Mountains landscape to be the locus of their creation as a people. Their ancestral territory spans parts of Nevada, Utah, Arizona, and California. My research identifies and describes the heterogeneous character of Nuwuvi ecological knowledge (NEK) of piñon-juniper woodland ecosystems within two federal protected areas (PAs) in southeastern Nevada, the Spring Mountains National Recreation Area (SMNRA) and the Desert National Wildlife Refuge (DNWR), as remembered and practiced to varying degrees by 22 select Nuwuvi knowledge holders. I focus my investigation on four primary aspects of NEK. First, drawing from data obtained through ethnoecological research, I discuss how Nuwuvi ecological knowledge evolved through protracted observation and learning from past resource depletions, and adapted to various environmental and socio-economic drivers of change induced since Euro-American incursion. Second, I argue that Nuwuvi management practices operate largely within a framework of non-equilibrium ecology, marked by low to intermediate disturbances and guided by Nuwuvi conceptions of environmental health and balance. These practices favor landscape heterogeneity and patchiness, and engender ecosystem renewal, expanded ecotones, and increased biodiversity. I then consider the third and fourth aspects of NEK as two case studies that consider NEK at the individual, species, population, habitat, and landscape scales. These case studies operationalize NEK as a relevant body of knowledge and techniques conducive to collaborative resource stewardship initiatives with federal land management agency partners. In the first case study I suggest that the Great Basin piñon pines are
\end{abstract}


Nuwuvi cultural keystone species (CKS), evaluating their central importance to Nuwuvi according to several criteria including number of uses, role in ritual and story, and uniqueness relative to other species. In the second case study I contend that local social institutions regulated Nuwuvi resource use in the past and in some cases continued to do so at the time of study. These local social institutions included a system of resource extraction and habitat entrance taboos that may have mitigated impacts and supported sustainable resource use and conservation. The implications of this research are that Nuwuvi ecological knowledge, disturbance-based adaptive management practices, and resource and habitat taboos are relevant to contemporary land management concerns in piñon-juniper woodlands, offering complementary approaches to adaptive management as practiced in the SMNRA and the DNWR despite divergent epistemological foundations. My research contributed to the Nuwuvi Knowledge-to-Action Project, an applied government-to-government consultation, collaborative resource stewardship, and cultural revitalization project facilitated by The Mountain Institute among seven Nuwuvi Nations, the U.S. Forest Service, and the U.S. Fish and Wildlife Service.

Keywords: Nuwuvi (Southern Paiute), piñon-juniper, local ecological knowledge (LEK), protected areas, indigenous peoples, ethnoecology, environmental anthropology, applied anthropology, adaptive management, conservation, Great Basin 


\section{Dedication}

To my own elders, ancestors, and the cultural landscapes from whence they came in the Ozark highlands of Missouri and the heathlands and mountains of Éire:

Harold "Boots" Elmont Lefler

Ruth Marie Bandermann Lefler

Patrick (Pádraig) Francis Byrne

Mary Jane Chapman Byrne

Ruthie Chapman

Margaret Ann Hutchison

And all of the others

Through the unfortunate early loss of your wisdom and guidance in my life I came to recognize how truly precious the intergenerational transfer of family stories, local knowledge and practices, rules for right livelihood, sense of lineage, and shared culture and identity are to a person. These realizations have inspired my academic and personal trajectories, including the work herein. I am forever grateful for your continued influences and presences in my life. 


\section{Acknowledgements}

First, to my advisor, Jeremy Spoon: thank you for the opportunity to contribute to such an amazing project and for keeping me on track when the vastness and richness of the data overwhelmed my senses. And to Richard Arnold, who adeptly bridged multiple worlds and guided my entrée into research with Native communities.

To my Nuwuvi consultants who shall remain anonymous because of confidentiality agreements: thank you for welcoming a small-town Kansas boy into your homes and homelands. Your knowledge and stories touched my life and opened my eyes to other ways of seeing. I hope to talk to you again soon around the kitchen table.

To the Nuwuvi Working Group: thank you for your assistance with locating and allowing access to the elders of your communities and for your guidance in respectfully navigating Indian Country: Richard Arnold (Pahrump Paiute Tribe), Kenny Anderson (Las Vegas Paiute Tribe), Lalovi Miller (Moapa Paiute Tribe), Dorena Martineau (Paiute Indian Tribes of Utah), Charley Bullets and Glendora Homer (Kaibab Paiute Indian Tribe), Ron Escobar (Chemehuevi Indian Tribe), and Betty Cornelius (Colorado River Indian Tribes).

A thank you to the staff of the Spring Mountains National Recreation Area and the Desert National Wildlife Refuge for supporting such an innovative project and sharing your perspectives: Judy Suing, Marissa Anderson, Jennifer Brickey, Kevin DesRoberts, Amy Sprunger, and Lindsay Smythe. I offer a hearty thank you to David Charlet for a different and much-needed perspective on piñon-juniper historical ecology.

A big thank you to all of my research funders: the Southern Nevada Public Lands Management Act (SNPLMA), which funded the bulk of my field work; the Newman Fund at Portland State University (PSU), whose research grant enhanced my interview materials and methodology; and the PSU AAA Travel Grant which supported the presentation of my research at the 2013 Society for Applied Anthropology conference in Denver, Colorado.

I offer my appreciation to my committee members for helping me refine this work, and to my fellow researchers at the Office of Applied Anthropological Research who provided stimulating discussions and camaraderie: Kendra Wendel, Michael Kilman, Rachel Lahoff, April Eagan, Cerinda Survant, Karla Hambelton, and Chris Milton. We've seen some things together my friends! Also, Connie Cash, Kendra Mote and Alexis Davis your kind help re-transcribing my interviews is not forgotten.

Finally, a thank you to the cornerstone of my life, my family: John, Sheila, Colleen, Scott, Sean, Nick, Levi, Ocotillo, Huckleberry, and Kyra; and to my extended community of friends, especially Chelsea, Kendra, Kalle, Neil, and Leah. I offer an enormous thank you for your support. Your warm words of encouragement truly helped me follow this project to completion. I am eternally grateful. 


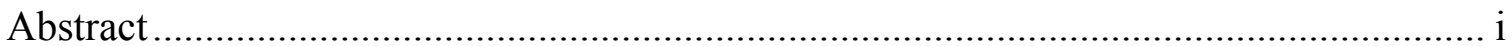

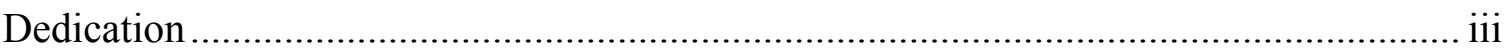

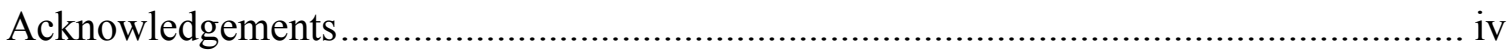

List of Tables ...................................................................................................... vii

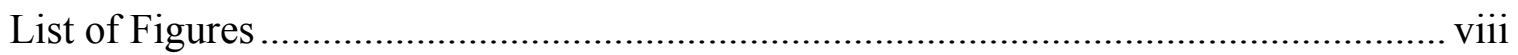

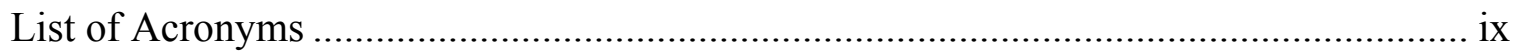

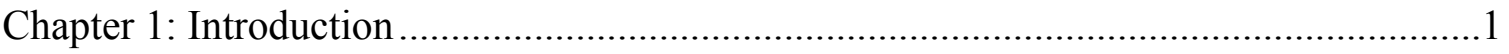

Chapter 2: Nuwuvi and their Desert Home................................................................21

Chapter 3: Knowledge Persistence and Change in the Great Basin ................................33

Chapter 4: Causing Disturbance to Balance the Land:

Nuwuvi Adaptive Management and Non-Equilibrium Ecology ....................................50

Chapter 5: Nuwuvi Cultural Keystone Species:

The Case for the Great Basin Piñon Pines ............................................................................ 78

Chapter 6: Whistling at Night with Twisted Lips:

The Conservation Value of Nuwuvi Local Social Institutions .......................................93

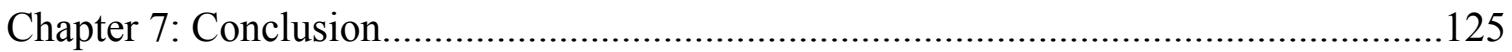

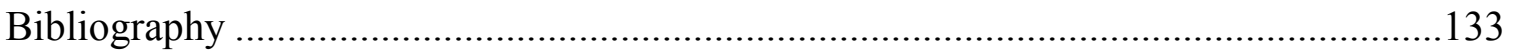

Appendix A: Nuwuvi Consultant Informed Consent Script ......................................156

Appendix B: Ethnoecological Interview Questions for Nuwuvi Consultants .................157

Appendix C: Select Focal Piñon-Juniper Woodland Botanical Species..........................159

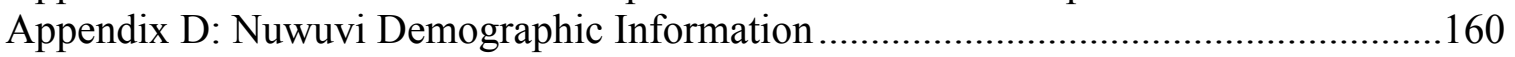

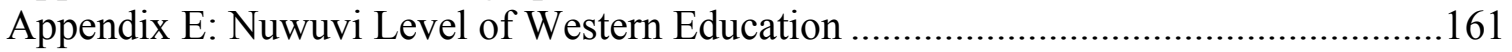

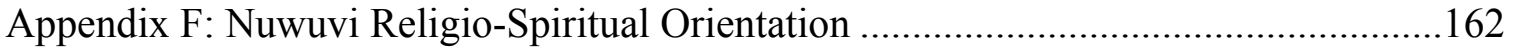

Appendix G: Nuwuvi Disturbance-Based Management Practices in

Piñon-Juniper Woodlands ......................................................................163

Appendix H: Reported Nuwuvi Vegetative Propagation Methods for Select Taxa ........164

Appendix I: Special Status Faunal Species Potentially Benefitting from

Nuwuvi Taboos in Piñon-Juniper Woodlands 
Appendix J: Special Status Botanical Species Potentially Benefitting from Nuwuvi Taboos Piñon Juniper Woodlands 166

Appendix K: Summary of Recommendations for Collaborative Resource

Stewardship Projects in Piñon-Juniper Woodlands ....................................167 


\section{List of Tables}

Table 4.1 Evaluation of the Great Basin Piñon Pines as Cultural Keystone Species

Table 5.1 Nuwuvi Piñon-Juniper Resource and Habitat Taboos and their Hypothesized Conservation Functions

Table 5.2 Reported Sanctions for Non-Compliance with Taboos 


\section{List of Figures}

Figure 1.1: Map of SMNRA and DNWR Within the Nuwuvi Ancestral Territory.

Figure 1.2: View of the Spring Mountains Across the Las Vegas Valley from the Adjacent Sheep Range, Nevada. January 2012

Figure 1.3: $\quad$ Southerly View From atop Hayford Peak, Sheep Range, Nevada, January 2012

Figure 2.1: Nuwuvi Ancestral Territory and Current Reservations

Figure 2.2: $\quad$ Single-Leaf Piñon (Pinus monophylla). Sheep Range, Nevada, January 2012

Figure 2.3: $\quad$ Utah Juniper (Juniperus osteosperma), Sheep Range, Nevada, January 2012

Figure 3.1: The Preferred Pine Nut Container for Many Nuwuvi at the Time of Research, Sheep Range, Nevada October 2012

Figure 4.1: Uncured Pine Nut Whipping Poles of Freshly Cut Alder (Alnus incana), Lander County, Nevada 2011

Figure 4.2: $\quad$ Oozing Chainsaw Scars Resulting from Fuel Reduction Treatments. Lee Canyon, SMNRA, Nye County, Nevada. 2011

Figure 4.3 Vegetative Phenophase of Water Cress (Nasturtium officinale) in Slack Water of Stream, Beatty, Nevada 2011

Figure 5.1: $\quad$ Pine Nuts (Pinus monophylla) in Cone, Sheep Range, Nevada 2012 


\section{List of Acronyms}

BIA - Bureau of Indian Affairs

CKS - Cultural Keystone Species

CRIT - Colorado River Indian Tribes

DNWR - Desert National Wildlife Refuge

ESA - Endangered Species Act of 1973 as amended

LDS - Church of Jesus Christ of Latter Day Saints (Mormonism)

LEK - Local Ecological Knowledge

NEK - Nuwuvi Ecological Knowledge

NEPA - National Environmental Policy Act of 1969 as amended

NHPA - National Historic Preservation Act of 1966 as amended

NTFPs - Non-Timber Forest Products: mushrooms, floral greens, nuts, berries, and other woodland resources unassociated with logging

NWG - Nuwuvi Working Group

OAAR - Office of Applied Anthropological Anthropology

PA(s) - Protected Area(s)

PITU - Paiute Indian Tribes of Utah

PSU - Portland State University

SMNRA - Spring Mountains National Recreation Area

SNPLMA - Southern Nevada Public Lands Management Act

TCPs - Traditional Cultural Properties

TMI - The Mountain Institute

USFS - United States Forest Service

USFWS - United States Fish and Wildlife Service 


\section{Chapter 1 \\ Introduction}

I don't understand these botanists and these scientists. They need to ask an old Indian about what they know. We got no more old Indians. We're going!

- Las Vegas Paiute Elder

\section{Research Problem}

Worldwide, researchers and land managers are seeking out indigenous knowledge and stewardship practices to supplement Western science-based approaches to land management in an era of unprecedented and escalating environmental change (Berkes et al. 2000; Huntington 2000; Ross et al. 2011). Indigenous peoples have ecological knowledge acquired and learned over thousands of years. This knowledge is adaptive ${ }^{1}$ and informs resource use decisions, in many cases resulting in environmentally sustainable outcomes. ${ }^{2}$ Not surprisingly, many of the world's national parks and other protected areas (PAs) are overlaid on ancestral territories of indigenous groups, whose members continue to steward the cultural and natural resources found within. ${ }^{3}$ Managers of some of these PAs bar indigenous settlement and resource use-a direct consequence of the original Western protected area model that considered humans as divided from the natural world and their environmental practices or disturbances as negative and disruptive

\footnotetext{
${ }^{1}$ I use the term adaptive to describe alterations in knowledge and practice that incorporate learning, experimentation, and innovation and adjust human and natural systems in response to expected or actual stimuli to prevent harm and exploit opportunities (Armitage 2005; Berkes and Folke 1998; Berkes et al. 2000; FCCC 2001).

${ }^{2}$ Sustainability is a problematic buzzword variously applied to social, economic, and environmental situations and subjectively defined according to one's personal values, socioeconomic background, and other factors (Lélé and Norgaard 1996:355-356; Spoon 2013:211-212). Recognizing these impediments, and viewing sustainability as a process rather than a product (Berkes et al. 2003:2), I use the term herein to refer to indigenous adaptive practices that may have resulted from mistakes and resource depletions in the past, and may even involve moderate environmental disturbances, yet have the capacity to provide consistent resource availability while supporting ecological values such as biodiversity and resilience. ${ }^{3}$ By 2005, 20 million $\mathrm{km}^{2}$, or $12.2 \%$ of the Earth's terrestrial surface was demarcated as PA (Chape et al. 2004:447).
} 
to ecosystem health (Adams and Hutton 2007; Keller and Turek 1998; Mancillas 2000;

Spence 1999). My research supports a fundamental shift away from such socially unjust paradigms of "fortress conservation" and advocates forms of protected area management that include local and indigenous peoples as collaborators, resource advisors, and even co-decision makers. ${ }^{4}$ This shift necessitates a concomitant ideological shift away from preservationist policies that criminalize traditional resource use to those that not only tolerate environmentally sustainable levels of traditional resource extraction, but that also view such practices as necessary components of successful resource management, representing co-evolved disturbance-based ecological relationships developed between humans and biota over long periods of time. While this research is grounded in Great Basin piñon-juniper woodlands, its relevance extends to other plant communities and protected areas in arid lands and mountainous regions and indeed, to protected areas worldwide where indigenous people still manage resources or ascribe cultural significance.

In the southern Great Basin, Nuwuvi" or "the people," consider themselves to be the original caretakers of their ancestral territory, much of which is now governed by five primary federal agencies as protected areas. ${ }^{6}$ From the long tenure in their homeland, which Nuwuvi believe to be since the beginning of time, Nuwuvi have developed a rich

\footnotetext{
${ }^{4}$ Fortress conservation aims to preserve wildlife in protected areas by forcefully excluding local peoples who have traditionally subsisted on resources in those areas (Brockington 2002).

${ }^{5}$ Although the term Southern Paiute is often applied to this ethnic/culture group, the word is of Mormon advent (Kelly 1934:548-549). Nuwuvi call themselves variously Nuwuvi, Niwiwi, Ninwin, Niwi, or Nuwu depending on dialect (Kelly 1934; Laird 1976:3; Stoffle and Zedeño 2001). I use Nuwuvi due to its popular usage among its contemporary designatees.

${ }^{6}$ The U.S. Forest Service (USFS), U.S. Fish and Wildlife Service (USFWS), Bureau of Land Management (BLM), Department of Defense (DOD), and the Department of Energy (DOE) manage the largest tracts of public land in the Nuwuvi ancestral territory (see Figure 1.1 for a map of the Nuwuvi ancestral territory).
} 
knowledge of environmental processes. Nuwuvi also developed informal social institutions for regulating sustainable resource use and management practices that introduce moderate disturbances to engender ecosystem renewal while maintaining a mosaic of habitats and successional stages. Nuwuvi ecological knowledge (NEK) thus offers complementary, even vital information and strategies for PAs and other federal lands to adapt to the unprecedented environmental changes afoot in southern Nevada, including urban expansion and population growth, increased nitrogen deposition, energy and water development, insect and disease epidemics, invasive species, and altered fire regimes (Pendleton et al. 2013). These are compounded by elevated carbon dioxide concentrations and linked changes in temperature, precipitation, and nutrient cycles occurring at the global scale (Smith et al. 2009). These stressors threaten the ecological integrity of the region, including Nevada's 3,800 documented botanical and faunal species, 173 of which are endemic to the state (Abele 2011:3). In sum, fifteen percent of Nevada's species are considered at risk (Stein 2002).

Nuwuvi knowledge holders also expressed grave concerns about language and culture loss because of an aging and waning population of expert knowledge holders, decreased interest among youth, and multiple socio-economic and legal impediments to resource access and intergenerational knowledge transfer. Collaborative resource stewardship addresses these concerns by providing opportunities for cultural revitalization, ${ }^{7}$ including reintroduction of management practices, Native language use, hands-on learning, ritual, and intergenerational knowledge exchange.

\footnotetext{
${ }^{7}$ Cultural revitalization is defined divergently among anthropologists and indigenous groups. My usage of the term highlights celebrations and maintenance of distinct cultural identities in the wake of government
} 
During interviews, consultants spoke of declining ecological health and reduced interactions with piñon -juniper woodlands while federal agency personnel highlighted global and regional drivers of change that threaten biodiversity and the function of this ecosystem. To address these concerns, this thesis examines NEK, management practices, and environmental taboos related to piñon-juniper ecosystems, evaluating their relevance to sustainable resource use, conservation, adaptation to climate change, and the potential for collaborative resource stewardship in two southern Nevada PAs. The two selected PAs, the U.S. Forest Service (USFS) Spring Mountains National Recreation Area (SMNRA) and the U.S. Fish and Wildlife Service (USFWS) Desert National Wildlife Refuge (DNWR) lie within the Nuwuvi ancestral territory and represent significant sites for past and continuing Nuwuvi spiritual practices, knowledge transmission, and resource stewardship.

I interviewed 22 expert knowledge holders from seven Nuwuvi Nations, eliciting knowledge associated generally with piñon -juniper woodlands, and specifically within the SMNRA and the DNWR. Drawing from a theoretical framing of political ecology, ethnobiology, and local ecological knowledge (LEK), I explain both persisting and shifting elements of NEK by examining social, economic, political, environmental, and historic drivers of change. I argue that these drivers have fractured NEK into the heterogeneous and syncretic forms I encountered at the time of research. While my analysis of Nuwuvi ecological knowledge attends to change over time, it lacks the full temporal depth possible from a thorough archaeological overview of prehistory. Because

policies of assimilation and repression, integrating both tradition and innovation while linking the past, present, and future (Willow 2010). 
of time and page limit constraints, I focus my current analysis on information revealed by my primary interview data and the ethnographic record. My primary data consists of knowledge held, practiced, and remembered by select Nuwuvi knowledge holders. Some of these memories extend back as far as the 1930s during these elders' childhoods, and contain stories, knowledge, and practices conveyed across multiple generations from even further in the past.

I divide this thesis into 7 chapters. I begin in Chapter 1 by providing an overview of the project, discussing the research questions guiding my inquiry, the theories that I draw from to explain my findings, and my methods of data collection and analysis. In Chapter 2 I introduce Nuwuvi, describe the physiographic and ecological foundations of piñon-juniper woodlands in their aboriginal homeland in the Great Basin, and discuss their representation in the ethnographic record. I turn my attention in Chapter 3 to NEK of piñon-juniper woodlands. I examine the various ways in which NEK is generated while explaining factors driving its heterogeneity, syncretism, and adaptation through time. In Chapter 4 I discuss physical and spiritual techniques for managing resources towards Nuwuvi conceptions of balance. ${ }^{8}$ I argue that Nuwuvi land management practices aligned with a non-equilibrium view of ecology, marked by moderate disturbances including patch burning, spring maintenance, pruning, and leaf litter

\footnotetext{
${ }^{8}$ Although religious, supernatural, shamanistic, animistic, and other terms have been employed in the Anthropology of Religion corpus, I utilize the term spiritual and its derivatives throughout this manuscript to honor Nuwuvi consultants' word preferences and to align with other recent ethnographic work in the region (e.g., Spoon et al. 2011, 2012b, 2013; Spoon and Arnold 2012). Out of respect to my Nuwuvi consultants, I also restrict my discussions of particular identified medicinal plants, rituals, spiritual beings, and other related subject matter due to a growing sensitivity to sharing such knowledge. Curious readers may look to previous research on Nuwuvi spirituality by Hultkrantz (1986), Kelly (1939), Spoon and Arnold (2012), and Stoffle et al. (2004).
} 
removal. I argue in Chapter 5 for the status of the Great Basin piñon pines (Pinus monophylla and P. edulis) as Nuwuvi cultural keystone species (CKS), evaluating them according to several criteria. Recognizing the holistic nature of the Nuwuvi worldview that conceives of all biotic and abiotic landscape elements as necessary and significant, I suggest a central yet shifting role of piñon pines in Nuwuvi culture at various points in time. In Chapter 6 I discuss Nuwuvi local social institutions or taboos that regulate human-environment interactions by limiting habitat entrance and resource extraction. I speculate that certain Nuwuvi taboos served multiple conservation functions in piñonjuniper woodlands. I conclude in Chapter 7 with a summary of the research, linking it to the broader global context. Ultimately I advocate a paradigm shift away from fortress conservation and indigenous exclusion in protected area management. I include a summary of recommendations oriented toward land managers for creating collaborative stewardship projects in piñon-juniper woodlands (see Appendix K).

\section{Research Questions}

My research investigated three primary questions aimed at illuminating Nuwuvi ecological knowledge of piñon-juniper woodlands in the Spring Mountains National Recreation Area (SMNRA) and the Desert National Wildlife Refuge (DNWR). I developed these questions to elicit relevant knowledge domains while linking NEK to adaptive management, sustainable resource use, and conservation in southern Nevada protected areas. The research questions are as follows: 
1) What is the character of knowledge and related management practices held by select Nuwuvi expert knowledge holders regarding plants and landscapes within piñon-juniper woodlands in the SMNRA and DNWR in southern Nevada?

2) What aspects of Nuwuvi belief systems and associated local social institutions mediate human-environment interactions within piñon-juniper woodlands in the SMNRA and the DNWR in southeastern Nevada?

3) Do any aspects of Nuwuvi ecological knowledge, management practices, belief systems, and informal social institutions result in conservation outcomes?

\section{Theoretical Framework}

\section{Political Ecology}

My analysis of Nuwuvi knowledge of and relationships with piñon-juniper woodlands draws from political ecology, an interdisciplinary body of theory that links the social and natural sciences while examining political, social, cultural, spatial, and historical factors (Biersack 2006:28). Political ecology examines how differential distributions of power create and affect human-environment interactions, including the control and access of resources (Biersack 2006; Escobar 1996). In my discussion of Nuwuvi, this extends to previous systems of land tenure, including extended familymanaged piñon groves and individually managed springs and eagle aeries, which I discuss in Chapter 6. I further these considerations through the historic and contemporary periods, discussing Nuwuvi impediments to resource access because of private, state, and federal land ownership and regulation and other structural constraints. 
Vayda and Walters (1999) argue that political ecology overemphasizes the political dimensions of human-environment interactions as a reaction to the earlier position of cultural ecology, which viewed culture groups as largely static and homogenous entities governed by the limitations of their environs (e.g., Steward 1938, 1955). I acknowledge their critique by noting the real influences of environmental forces or ecological realities (Forsyth 2003) such as climate change and massive land conversion as significant variables that impact Nuwuvi human-environment relations. Collectively, I use these theoretical framings in the present research to examine how the unequal distribution of power and various social, economic, political, environmental and historic drivers of change influence the heterogeneous, syncretic, dynamic, and adaptive character of Nuwuvi ecological knowledge, disturbance based management practices, and informal social institutions such as resource and habitat taboos.

Political ecology also argues that nature is socially and discursively produced (Biersack 2006:4; Escobar 1999), a perspective I take while discussing Nuwuvi and Western perceptions of nature and both converging and diverging approaches to resource management in protected areas, which stem from these epistemological foundations. I also draw from Forsyth's (2003) critical political ecology, which questions the hegemony of Western orthodox science explanations of environmental phenomena. I use this lens in Chapter 4 to examine the Western paradigms of equilibrium and non-equilibrium ecology, which compete to explain interactions and processes in ecological systems. I also employ this critical approach to challenge the hegemony of "natural laws" from orthodox Western science by providing space for alternate Nuwuvi perceptions and interpretations of phenomena, including mechanisms of ecological knowledge generation 
(Chapter 3), conceptions of environmental health and balance (Chapter 4), and spiritual reasons for avoiding certain habitats and limiting resource extraction (Chapter 6).

\section{Ethnobiology, Ethnoecology, and Local Ecological Knowledge (LEK)}

The last several decades have seen a proliferation of interest in the ecological knowledge and management practices of place-based peoples. Hosts of scholars have shown the significant and frequently positive (in terms of biodiversity, ecosystem recharge, and resilience) effects that certain indigenous anthropogenic activities have had on a variety of ecosystems through time and around the world (Alcorn 1981; Anderson 2005; Berkes et al. 2000; Deur and Turner 2005; Posey 1985). Anthropology has a long history of investigating indigenous knowledge systems, although a focus on biological knowledge emerged later. This research has primarily been carried out in the interdisciplinary subfields of ethnobiology and ethnoecology. Whereas ethnobiology explores human cognitive ordering, use, and evolutionary interaction with biota; ethnoecology scales out to the landscape level, considering linkages between biotic and abiotic features, environmental processes, and the interplay between social and ecological systems (Spoon 2008:70; Stepp 2005:211).

This knowledge base held by local and indigenous peoples has been termed both local ecological knowledge (LEK) and traditional ecological knowledge (TEK). I employ Berkes' definition of TEK as “a cumulative body of knowledge, practice, and belief, evolving by adaptive processes and handed down through generations by cultural transmission, about the relationship of living beings. with one another and with their environment" (2008:7). For some scholars, the word tradition conjures associations with 
static and antiquated practices frozen in time, causing them to avoid the term altogether, opting instead for LEK, which explicitly avoids a time dimension. Tradition can, however, invoke a sense of continuity that is a critical aspect of knowledge conveyance across generations. Indeed, LEK is best conceived of as "a living body of knowledge" (Sheehan and Glenn 2000:100), that is "time-tested and wise" (Berkes 2008:4). LEK also at times incorporates information gained from exposure to or mixing with other cultures, resulting in increased resilience and adaptive capacity for change (Begossi 1998). Such knowledge change and intra-group variation nuances black and white dichotomous delineations of Western and indigenous knowledge (Agrawal 1995; Watson and Huntington 2008). Turnbull (1997:552-553) suggests conceiving of all knowledge production (including Western science) as situated and contingent, occurring in localized knowledge spaces and consisting of heterogeneous knowledge assemblages of knowledge, beliefs, practices, values, and social mechanisms.

Ecological knowledge and understanding arises by way of multiple mechanisms. Key among these processes is incremental learning gained from protracted observation and lived experience in a place combined with lessons learned through resource crises and depletions (see Chapter 4) (Berkes and Turner 2006; Turner and Berkes 2006a). Although many cultures have practiced conservation-based resource management strategies at various points in time, the literature also indicates instances of maladaptive resource use (Diamond 2005; Krech 1999; Redman 1999). Successful conservationoriented management strategies include common property institutions that avoid Hardin's (1968) "tragedy of the commons" (Ostrom 1990), as well as taboo systems that act to regulate resource extraction (see Chapter 6) (Berkes 2008; Berkes et al. 2000; Colding 
and Folke 2001; Johannes 1978, 2002). Within the resource conservation political arena, some argue against entrusting resource management to customary resource users (Redford and Sanderson 2000; Terborgh 2000), insisting that conservation must not only be marked by practices that avoid habitat denigration, resource depletion, or species extirpation; but that such practices must also be intentionally designed to do so (Smith and Wishnie 2000:591). Such intentionality of conservation outcomes is arguably absent in many indigenous environmental management institutions and practices. The intent to produce ecologically beneficial outcomes suggested by this functionalist argument is extremely difficult to discover and measure. While there are likely both intentional and unintentional conservation benefits linked to Nuwuvi management institutions, in this manuscript I highlight practices and institutions with possible conservation outcomes regardless of whether they were intended to result or not.

\section{Research Design}

\section{The Research Sites}

The project sites—-the U.S. Forest Service (USFS) Spring Mountains National Recreation Area (SMNRA) and the U.S. Fish and Wildlife Service (USFWS) Desert National Wildlife Refuge (DNWR) — are situated in southern Nevada, at the southern extent of the Great Basin physiographic province, where climatic conditions transition to the hotter temperatures characteristic of the neighboring Mojave Desert to the south (Figure 1.1). Both PAs contain mountain ranges hosting mid-elevation piñon-juniper communities: the Spring Mountains in the SMNRA, and the Sheep Range in the DNWR. While consultants conveyed knowledge of piñon-juniper ecology and management in 
Figure 1.1: Map of SMNRA and DNWR Within the Nuwuvi Ancestral Territory (Wendel 2014, adapted from Spoon et al. 2013).

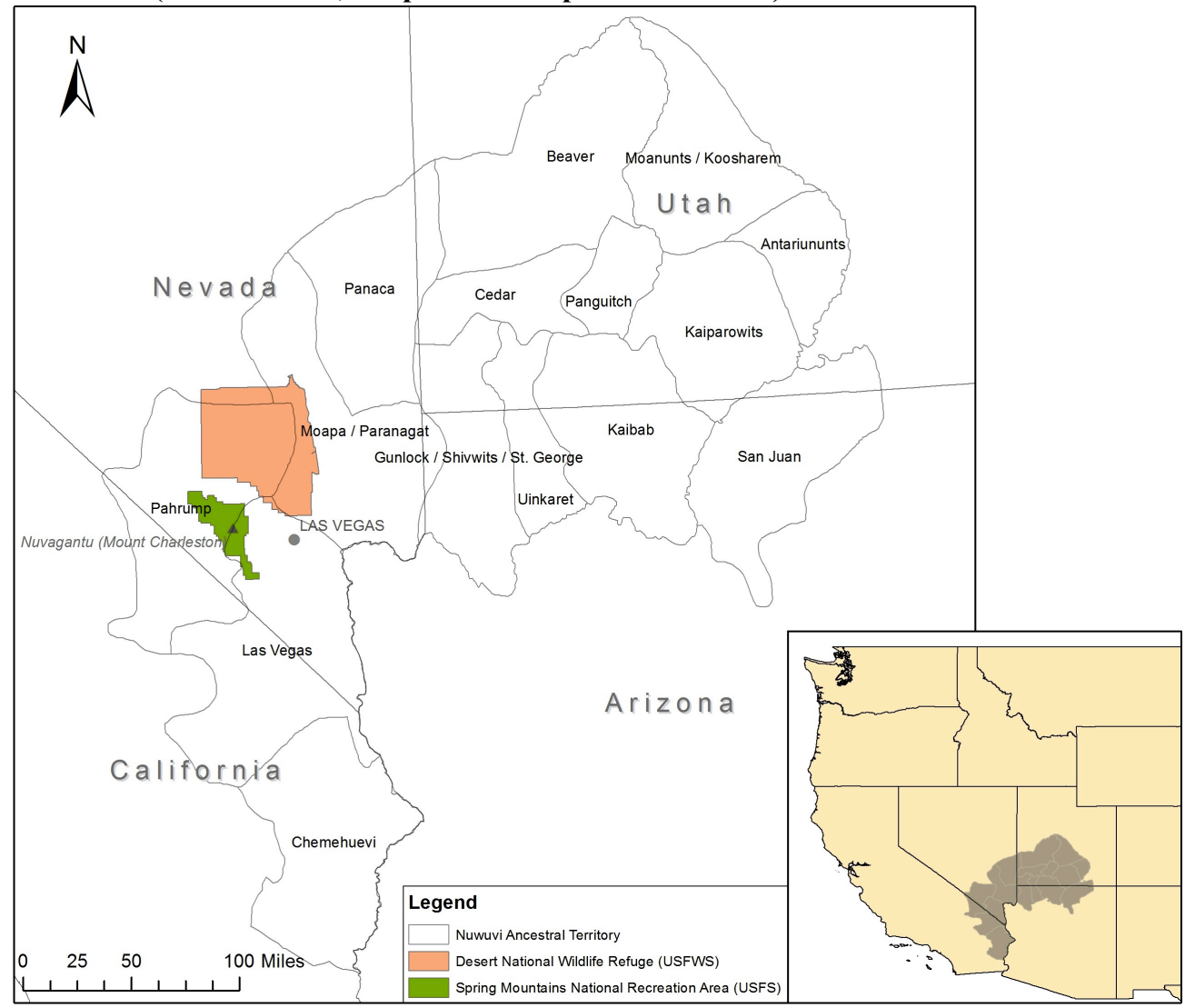

general, these two situated and culturally significant sites provided anchors for localized knowledge and stories to emerge.

The Spring Mountains National Recreation Area Act established the SMNRA in 1993, protecting 315,648 acres of mountainous terrain northwest of Las Vegas, Nevada, in Clark and Nye counties (USFS et al. 1998:3). Managed by the USFS Toiyabe National Forest, this PA was set aside to: (1) protect natural and other values that support public enjoyment and biological diversity; (2) apply USFS conservation and management strategies; and (3) provide recreation opportunities (USFS et al. 1998:6). Within the bounds of the SMNRA lie the Spring Mountains (historically termed the "Charleston Mountains"), a mountain chain running seventy-one miles in a predominantly north-south 
Figure 1.2 View of the Spring Mountains Across the Las Vegas Valley from the Adjacent Sheep Range, Nevada. January 2012 (Image: B. J. Lefler).

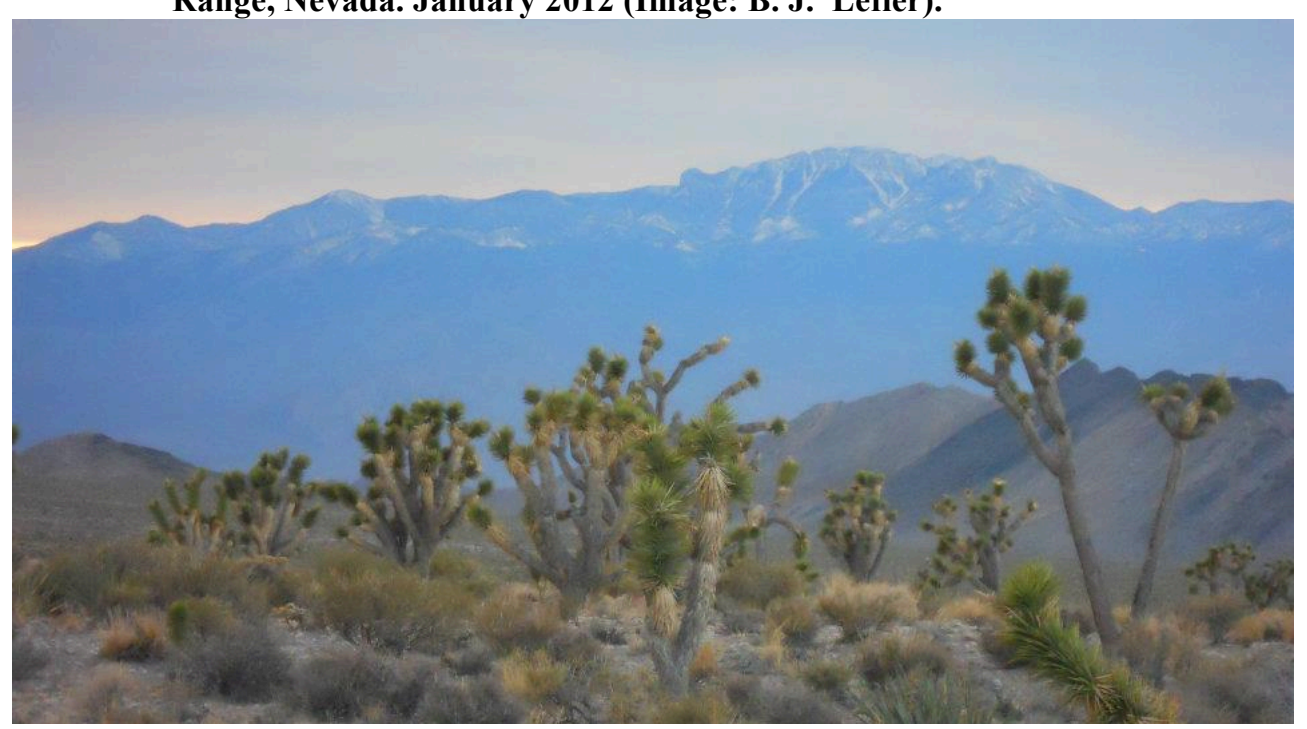

orientation (Niles and Leary 2007:1). The highest peak, and the location of the Nuwuvi creation story, is Nüvant (Charleston Peak) (Kroeber 1976:596), standing 3,632 meters high. Temperatures vary widely depending on elevation, time of day, and season with lows of $-15^{\circ} \mathrm{C}$ during winter nights and highs of $109^{\circ} \mathrm{C}$ during summer days (Niles and Leary 2007:3). Piñon-juniper communities composed of single-leaf piñon (Pinus monophylla Torr. \& Frem.) and Utah juniper (Juniperus osteosperma Torr.) occur between 1,250-2,500 meters elevation. Because of geographic factors and a range of elevation zones, the SMNRA acts as a biological sky island, containing a diverse flora and fauna including 15 vascular plants, one mammal, and nine invertebrate species endemic to the Spring Mountains (USFS et al. 1998:3).

The DNWR lies to the east and northeast of the SMNRA and encompasses 1.6 million acres north of Las Vegas, in Clark County, Nevada (USFWS 2009:S-1). It is the largest non-military protected area in Nevada, and the largest USFWS refuge in the continental United States. Originally set aside in 1936 by President Franklin Roosevelt, 
Figure 1.3: Southerly View From Atop Hayford Peak, Sheep Range, Nevada, January 2012 (Image: B. J. Lefler)

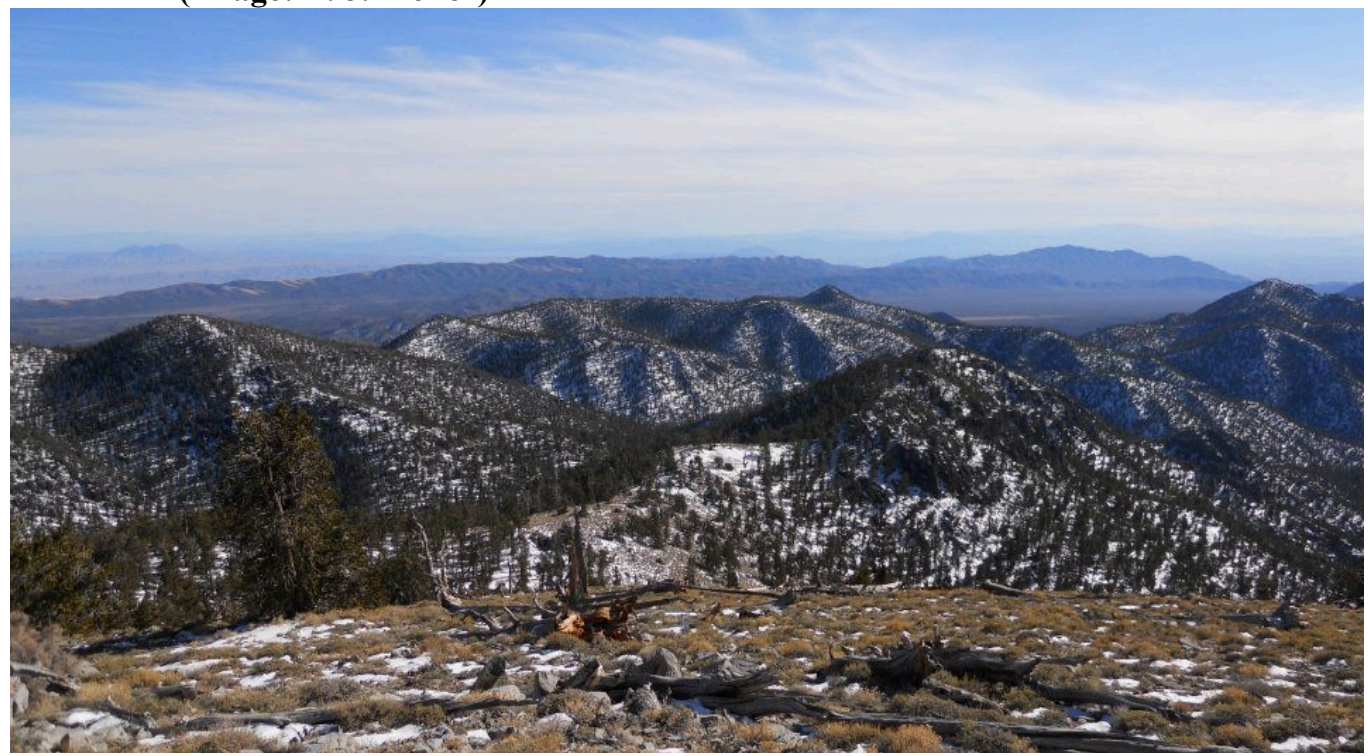

the present incarnation and boundaries date back to 1966 (2009:S-10). The DNWR contains several desert mountain ranges including the Desert, East Desert, Spotted, Las Vegas, Pintwater and Sheep. The Sheep Mountain Range, marked at its highest point by Hayford Peak at 3,020 meters (Bair and Tiehm 2003:2), was the focal mountain range within DNWR for this research. Jennifer Brickey, Botanist at the SMNRA, noted four endemic vascular plant species shared by the Sheep and Spring Mountains (email to author August 28, 2012). Piñon-juniper communities occur in the montane vegetation zone between approximately 1,830 and 2,285 meters and consist of single-leaf piñon and Utah juniper with some occurrence of Rocky Mountain juniper (J. scopulorum Sarg.) in the upper portions of this community (Bair and Tiehm 2003:3-4).

\section{Sampling}

Contemporary Nuwuvi live in both urban centers and rural locations and on and off designated reservations (Spoon and Arnold 2012:479). Reservation lands now 
represent but a fraction of the original Nuwuvi territory (see Figure 2.1), and one of the seven tribes participating in my research, the Pahrump Paiute, still lacks federal recognition and reservation land (Chmara-Huff 2006). In the last 100 years, the Nuwuvi population has been reduced to a fraction of its pre-Euro-American contact numbers, and as of 2005, numbers individuals (BIA 2005; Spoon and Arnold 2012:479).

My sample of Nuwuvi consultants - ranging in age from 52 to 85 - consisted of between three and four primary expert knowledge holders from the seven participant Nuwuvi nations for a total 3,391 of 22 consultants. An additional three family members spontaneously joined certain interviews, enriching the data by filling in knowledge gaps and stimulating additional discussions. Participating Nuwuvi Nations included the Las Vegas Paiute Tribe, the Moapa Band of Paiute Indians, The Paiute Indian Tribes of Utah (PITU), Chemehuevi members of the Colorado River Indian Tribes (CRIT), the Kaibab Band of Paiute Indians, the Pahrump Paiute Indian Tribe, and the Chemehuevi Indian Tribe. ${ }^{9}$ Seven Nuwuvi Working Group (NWG) members - tribally designated representatives of each of the seven Nations participating in the NKTA projectrecommended three to four expert knowledge holders from their own respective Nations as consultants for my Nuwuvi sample ${ }^{10}$. I define expert knowledge holders as individuals, often elders (typically 40 years old and older), who are known within their community to

\footnotetext{
${ }^{9}$ The Twenty-Nine Palms Band of Mission Indians (Chemehuevi), and the San Juan Southern Paiute Tribe of Arizona are also Nuwuvi Nations, but did not participate in the NKTP.

10 NKTA, directed by Dr. Jeremy Spoon and Richard Arnold, was a unique partnership among seven Nuwuvi Nations, the U.S. Forest Service (USFS), the U.S. Fish and Wildlife Service (USFWS), the nongovernmental organization (NGO) The Mountain Institute (TMI), and the Office of Applied Anthropological Research (OAAR) at Portland State University (PSU); and was made possible through funds made available by the Southern Nevada Public Lands Management Act (SNPLMA).
} 
be reservoirs of cultural, spiritual, or ecological knowledge handed down to them through story, song, observation, or instruction, or gained through direct personal experience.

\section{Data Collection}

My research process generated qualitative data obtained from transcribed interviews with Nuwuvi consultants. I collected this ethnographic data during a threemonth fieldwork period between January and March of 2012. I conducted interviews with Native knowledge holders using the English language and in participants' homes, offices, and public places, both on and off reservations. After initially developing my research instruments, I refined them during meetings with the NKTA project Co-Director Jeremy Spoon to ensure that they were tailored to relevant knowledge domains and project goals. The knowledge domains I selected included plants, landscape features, ecological interactions, beliefs, and management practices in piñon-juniper woodlands in both PAs. I selected these domains because of their prime significance to Nuwuvi humanenvironment interactions. I also selected certain features, such as rock writing (pictographs and petroglyphs) and caves, because of their relevance to agency legislative obligations to consult with tribes regarding the management of cultural resources under the National Environmental Protection Act of 1969 as amended and Section 106 of the National Historic Preservation Act of 1966 as amended.

Prior to the primary interview phase, I conducted free-listing exercises independently with both a Nuwuvi expert knowledge holder and a conservation biologist who had worked extensively in the DNWR to generate a core list of relevant botanical taxa (see Appendix C) and landscape features (including cultural sites) occurring in 
piñon-juniper woodland ecosystems in both PAs. The Native knowledge holder recommended taxa and landscape features based on their cultural significance, excluding certain culturally sensitive plants. The conservation biologist suggested plants based on criteria related to their significance to ecosystem function and structure. I crosschecked these collectively identified taxa and features against ethnographic references of Nuwuvi ethnobotany (Fowler 1986, Kelly and Fowler 1986, Rhode 2002, Stoffle et al. 1999) and plant lists for both protected areas (Ackerman 2003; Niles and Leary 2007).

I used a series of botanical and landscape photographs for elicitation exercises with Nuwuvi consultants. Where possible, I took these photographs at various locations in the SMNRA and the DNWR. I identified botanical species using botanical keys found in A Utah Flora (Welsh et al. 2003) and the multi-volume Intermountain Flora (Cronquist et al. 1972), triangulating results with published plant lists for each mountain range (see Ackerman 2003; Niles and Leary 2007). This stock of images consisted of multiple angles, perspectives, and zoom levels of each plant to highlight various botanical features and the plant's context in the larger landscape. I also photographed both the Spring and Sheep Mountain Ranges at the landscape level in addition to close up shots of springs, caves, and other features in both ranges to help trigger recognition and elicit stories from consultants. I displayed these photos for informants on an Apple iPad ${ }^{\mathrm{TM}}$. During interviews I kept four gazetteers of detailed topographic maps of Nevada, Utah, Arizona, and California on hand in addition to a U.S. Geological Survey (USGS) raised relief quadrangle map of the Las Vegas area that included the SMNRA and the DNWR. I used these maps to stimulate story elicitation and to help knowledge holders communicate locations of events, stories, physiographic features, cultural sites, and biota. 
I began interviews by asking consultants demographic questions concerning their age, Nation, religion/spiritual affiliation, education, and work experience in order to contextualize subsequently elicited ecological knowledge. Demographic tables in Appendix G summarize these results. A secondary tier of questions elicited ethnoecological knowledge (see Appendix D). I drew inspiration for developing relevant questions from both Spoon (2008) and Cunningham (2001), asking consultants about landscape classifications, changes in land use, effects of harvesting, and differences in plants based on geographic location, aspect, and elevation. I began by asking for names, locations, and stories regarding target plant taxa and features, then scaled up to the landscape level to address both ecological and biophysical interactions and interconnectivity among biota and landscape features. Next, I garnered information regarding human interaction, relationship, and management of the land at both the species and landscape level. Finally, I solicited opinions regarding current management approaches utilized by federal agencies and suggestions for improvement, cooperation, and co-stewardship (see Spoon et al. 2013). Although I developed semi-structured interview questions prior to fieldwork, I regarded research questions as emergent, incorporating topics that arose during the course of interviews into subsequent interview sessions (Fontana and Frey 1994).

\section{Data Analysis}

My interviews with Nuwuvi consultants lasted approximately $2-2.5$ hours each, for a total of 44 hours and 39 minutes, which I recorded on a Sony ${ }^{\mathrm{TM}}$ PCM-M10 Portable 
Audio Recorder. I created full transcripts of Nuwuvi interviews using ExpressScribe ${ }^{\mathrm{TM}}$ software in conjunction with an Infinity ${ }^{\mathrm{TM}}$ IN-USB-2 transcription pedal.

I used grounded theory (Glaser and Strauss 1967) to qualitatively analyze data collected from interviews. The essence of this approach involved identifying themes within transcripts and coding them for the presence or absence of the themes. This was largely an inductive process, allowing understanding of larger patterns to emerge from close study of the data and transforming an amorphous text into a set of variables though the coding process (Bernard 2006:492-493). I identified themes by reading through the interview transcripts multiple times, highlighting and categorizing patterned themes as they emerged, and determining presence or absence of those themes within each transcript in an iterative process. When possible I followed in vivo coding (Strauss and Corbin 1990), by using actual phrases elicited by interviewees to name thematic categories. I also used emergent coded themes to develop the organizational structure for this manuscript, with some important and recurrent themes resulting in chapters devoted to illuminating their substance. For instance, the theme caretakers of the land catalyzed Chapter 4, while piñon pines as culturally salient species inspired Chapter 5 . Wherever possible in this manuscript, I utilize exemplar quotes to allow my consultants the opportunity to describe their perspectives, beliefs, and practices in their own words.

\section{Ethical Considerations}

Prior to the onset of research, the Human Subjects Research Review Committee at Portland State University reviewed my thesis proposal and informed consent documents to ensure project compliance with university policies and protections of human subjects. 
At the beginning of each ethnographic interview I presented each consultant with a copy of an informed consent document, which I read aloud. All of the consultants mentioned in this thesis accepted the terms. Copies of this document are provided in Appendix A. Another critical element of ethical research design involves returning the research to the Nuwuvi community by: (1) presenting my research findings during and NKTA meeting in December 2012, attended by members of the NWG and representatives from the USFS and the USFWS; and (2) mailing copies of the project report (Spoon et al. 2013), interview recordings, and transcripts to consultants.

\section{Conclusion}

This research contributes to the literature on indigenous peoples and protected areas, ethnoecology, and local ecological knowledge. Additionally, my particular focus on Nuwuvi ecological knowledge, management practices, and taboos associated with piñon-juniper woodlands identifies entry points for collaborative resource stewardship projects between Nuwuvi and federal agencies in the southern Great Basin (see also Appendix K). Data are drawn primarily from qualitative, ethnoecological interviews with Nuwuvi expert knowledge holders from seven Nuwuvi Nations. In the next chapter I introduce Nuwuvi, describing the biophysical character of their Great Basin home and their changing use and relationship with piñon-juniper woodlands over time. 


\section{Chapter 2 \\ Nuwuvi and their Desert Home}

My great-grandfather said this was his mountain. That's what I

told them, Mt. Charleston,...He told us one time, if I die, when I'm gone, that Mt. Charleston will tip over.

- Pahrump Paiute Elder

\section{Introduction}

The Nuwuvi ancestral territory — far from the desolate and resource-impoverished wasteland described by early explorers - is a rich and storied land to its indigenous peoples, providing everything that a grocery store, pharmacy, and church offer, according to one consultant. Nuwuvi believe the land itself is alive and sentient, a view that constitutes the epistemological foundation of Nuwuvi culture (Stoffle et al. 2004:18). The region's peaks, springs, and other places acted as mnemonic repositories of genealogies, stories, and events in their history as a people, with a relational time depth unfathomable to non-indigenous groups. Collectively, Nuwuvi ranged through several physiographic regions including the Great Basin section of the Basin and Range province, Colorado Plateau, Canyonlands, and Mojave Desert; each offering different ecological communities for resource exploitation (Kelly and Fowler 1986:370). The Nuwuvi homeland spans portions of southern Nevada, southwestern Utah, northeastern Arizona, and southern California. Contemporary Nuwuvi land holdings are but a fraction of their aboriginal territory (Figure 2.1).

In the ensuing pages, I describe the Nuwuvi ancestral territory, focusing on the Great Basin and piñon-juniper woodlands. I begin with a discussion of the physiography of the region, the ecology of piñon-juniper woodlands, and management concerns in this 
Figure 2.1 Nuwuvi Ancestral Territory and Current Reservations (Spoon et al. 2013).

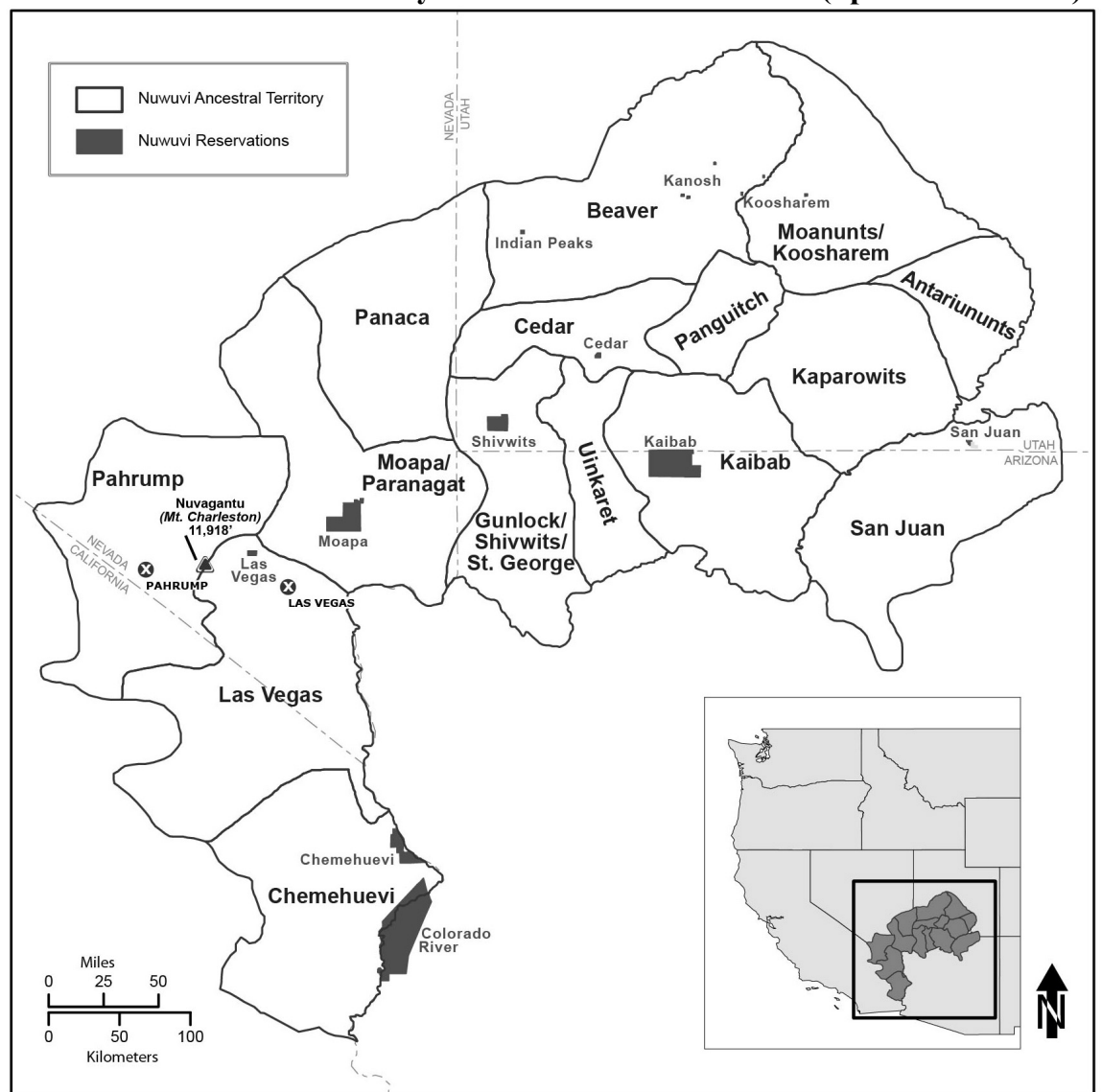

ecosystem. I then shift my discussion to Nuwuvi themselves, providing an overview of pre- and postcontact subsistence patterns. I close with a synopsis of previous ethnographic work that has occurred in the region and a discussion of Nuwuvi indigeneity.

\section{Great Basin Piñon-Juniper Woodlands: Ecological Foundations}

As the location of the project sites, the Great Basin is of greatest import to the present research. Arid desert valleys interspersed with approximately 200 major northsouth running mountain ranges define Great Basin topography, and consist of 
sedimentary and igneous geological parent material rising to heights of up to 4,267 meters (Tueller et al. 1979:2).

Piñon-juniper woodlands - the third largest vegetation type in the United States and the focal ecosystem of my research - occur across 47 million acres in the western U.S., with 17.6 million acres in the Great Basin alone (Lanner 1996; Tueller et al. 1979). Piñon-juniper ecosystems constitute 12\% of Nevada (Ostoja et al. 2013:102) and are distributed between 1,500 to 2,500 meters elevation in the SMNRA and DNWR (CCDCP and DRI 2008:53). This ecosystem consists of three predominant tree species in the Great Basin: single-leaf piñon (Pinus monophylla), Utah juniper (Juniperus osteosperma (Torr.) Little), and western juniper (J. occidentalis Hook.); with Colorado piñon (Pinus edulis Englm.) eventually replacing the single-leaf piñon in the eastern portion of the region (Chambers 2001:27). Single-leaf piñon is the only piñon pine occurring in the SMNRA and the DNWR. Ecologists grade this plant community into three forms, including tree-dominated piñon-juniper woodlands, grass-understoried piñon-juniper savannas, and wooded shrublands (Romme et al. 2008). For the purposes of my research, I consider all of these piñon-juniper communities collectively, as my Nuwuvi consultants neither differentiated between these grades of piñon-juniper communities, nor between piñon-juniper and adjacent zonal ecosystems. Elders were, however, very aware of plant associations, elevations, soil types, and other constraints of species distribution, despite the apparent lack of plant community or ecosystem as an ethnobiological cognitive category (see Berlin 1992; Hunn 1982). 
Figure 2.2 Single-Leaf Piñon (Pinus monophylla). Sheep Range, Nevada, January 2012

(Image: B. J. Lefler)

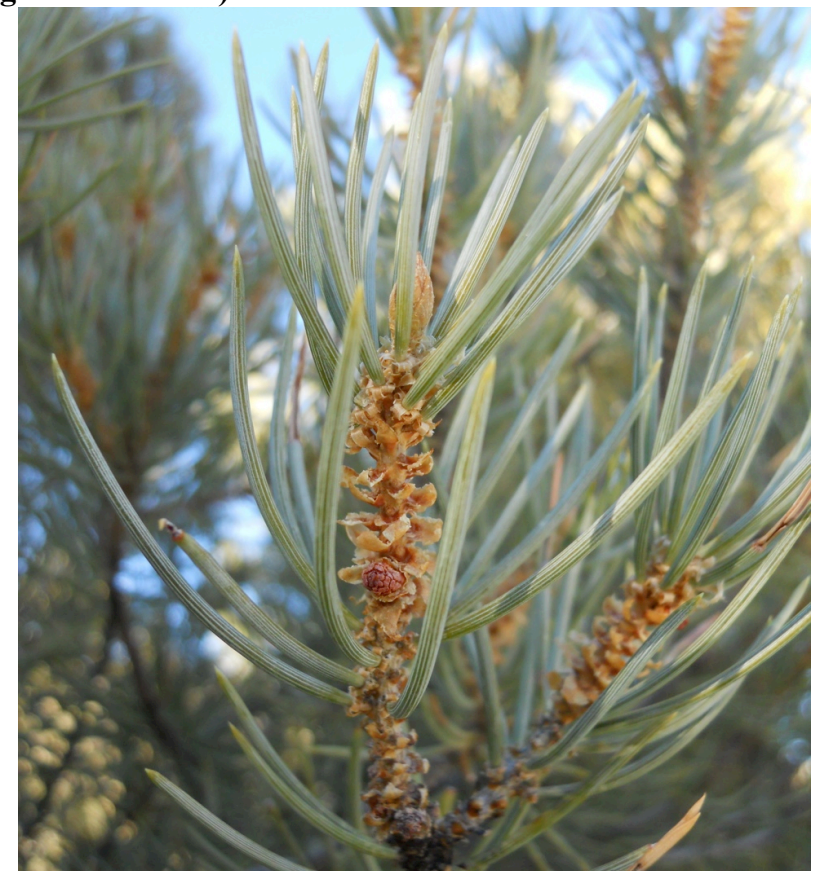

Single-leaf piñon seeds are dispersed by corvids that include piñon jays

(Gymnorhinus cyanocephalus) and Clark's nutcrackers (Nucifraga columbiana Wilson), and rodents including kangaroo rats (Dipodomys spp. Gray), deer mice (Peromyscus spp. Gloger), pocket mice (Perognathus spp. Wied-Neuwied), and piñon mice (Peromyscus truei Shufedlt) (Chambers 2001:28). The location and number of seeds in each planting cache varies by animal. Jays place one seed per hole, nutcrackers up to ten, both avoiding dense vegetation. Rodents plant between one and twelve seeds under shrubs at the edge of their canopies as well as in the shrub interspaces (2001:28). Seeds that are not retrieved by these animals or discovered by others, may germinate and produce seedlings. Although infrequently mentioned in the literature, humans likely played a role in both intentional and unintentional piñon dispersal (Waring 2011:98; Zouhar 2001) through intentional planting and incidental sowing during harvesting activities and transport. 
Figure 2.3 Utah Juniper (Juniperus osteosperma), Sheep Range, Nevada, January 2012 (Image: B. J. Lefler)

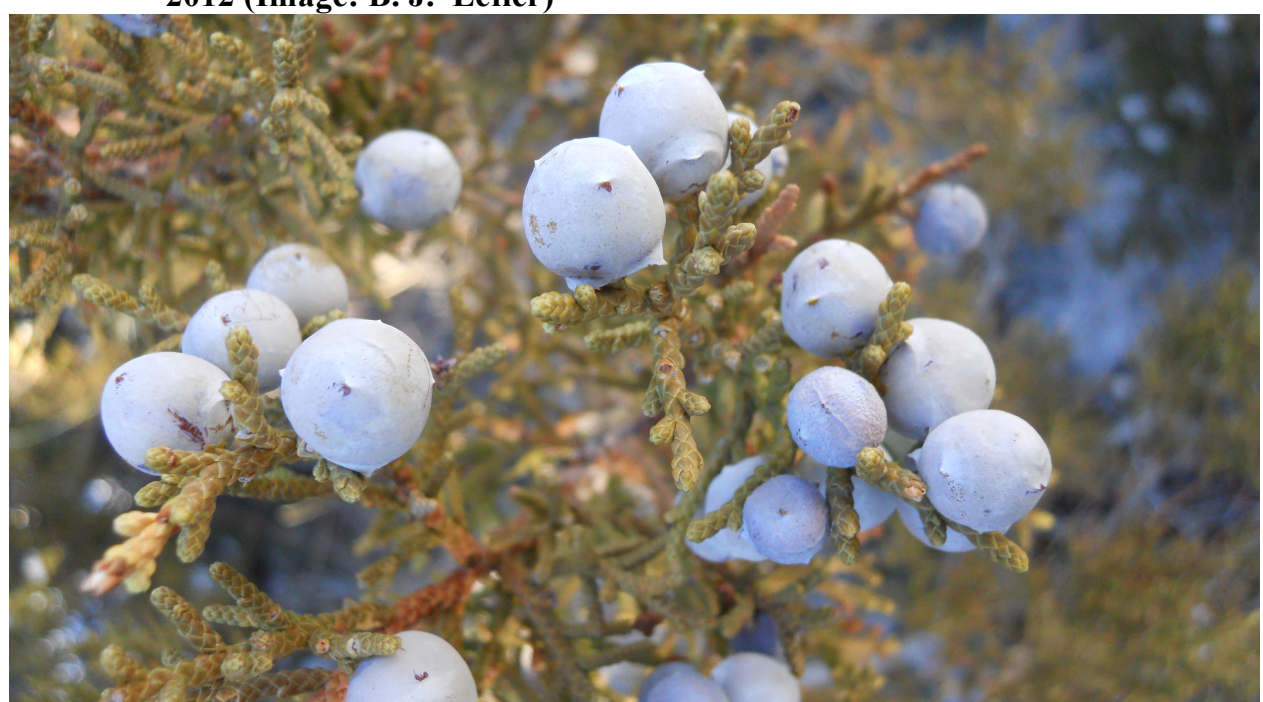

Currently, piñon-juniper woodlands are expanding their range. Supporters of the piñon-juniper encroachment hypothesis portray piñon and its co-dominant juniper as weedy invaders, which threaten the endangered greater sage grouse by expanding beyond their natural range into the adjacent sagebrush steppe (Connelly et al. 2004; Miller and Tausch 2000; Miller and Wigand 1994). Other scholars, however, suggest that piñonjuniper ecosystems are simply reestablishing their former distribution after widespread deforestation from historic logging, mining, and railroad activities (Charlet 2008; Lanner and Frazier 2011). In the 1950s, fears of historic rangeland conversion from piñonjuniper encroachment resulted in massive chaining campaigns that finally abated in the 1980s. ${ }^{11}$ Such divergent interpretations and reactions to piñon-juniper expansion, and the involvement of ranching and conservation lobbies in the interpretation of this

\footnotetext{
11 "Chaining", or "cabling" entailed dragging a ship's anchor chain between two bulldozers, uprooting trees in broad swaths to expand pasturage (Gillihan 2006:12). Between 1960 and 1972 alone, over three hundred thousand acres of piñon-juniper woodlands were chained (Lanner 1981).
} 
phenomenon are evidence of the ways that Western science is wielded to achieve various political aims (Forsyth 2003).

Piñon-juniper woodlands are also experiencing increased tree density and canopy closure, resulting in reduced understory plant species abundance and diversity (Bauer and Weisberg 2009; Miller et al. 2008). These closed-canopy woodlands do not provide adequate structurally diverse habitat for piñon jays (Ostoja et al. 2013:103). Habitat reduction for this piñon pine disperser is an obvious concern threatening the persistence and regeneration of piñon-juniper woodlands. Stand in-fill also affects other animals, including the desert bighorn sheep (Ovis canadensis nelson Merr.), because of habitat requirements for rocky, open areas in piñon-juniper woodlands. Desert bighorn sheep suffered severe population reductions beginning in the late $19^{\text {th }}$ century but currently exist in greater numbers in the DNWR than in many other Great Basin ranges (USFWS 2009:1-14). I contend that these shifts in piñon-juniper ecology are not only potentially attributable to reduced fire frequency (Bauer and Weisberg 2009), but also to the abatement of Nuwuvi stewardship practices, which managed for multiple age classes, patchiness, and landscape heterogeneity (see Chapter 4).

\section{Nuwuvi in Prehistory}

Before the coming of Euro-Americans and other ethnic and cultural groups, with their broad scale erasure of Native land-ordering patterns (Trusler and Johnson 2008:564), Nuwuvi accessed and managed a variety of resources at multiple temporal and spatial scales. Despite a fixation on their nomadic tendencies by both settlers and early ethnographers (e.g., Steward 1938, 1955), Nuwuvi regularly returned to various 
points on the landscape where they planted and irrigated riparian and spring-fed gardens, tended fields of edible grasses, and managed orchards bearing pine nuts and mesquite beans (Prosopis glandulosa var. torreyana (L.D. Benson) M.C. Johnst.) (Fowler 1995; Knack 2001; Von Till Warren 2007).

The Great Basin is comparatively low in faunal density but exhibits a high degree of speciation. Elevation gradients display a faunal distribution pattern, with smaller rodents and lizards inhabiting the lower regions and larger mammals found at higher elevations (Fowler 1972:20). Despite the apparent homogeneity of the region, the various landforms created a variety of habitats and attendant resources for Nuwuvi use. In prehistoric and early historic times Nuwuvi subsisted on a variety of animal species that differed among Nuwuvi groups, but included pronghorn antelope (Antilocapra americana Ord), mountain sheep, birds, insects, larvae, fish (purportedly avoided by Chemehuevi groups), desert tortoise (Gopherus agassizii Cooper), lizards, rats, squirrels, rabbits, bear, and elk (Kelly and Fowler 1986:370; Laird 1976:5). Plants provided more consistent foodstuffs and included: pine nuts (Pinus monophylla and P. edulis), mesquite beans (Prosopsis spp.), agave (Agave spp.), yucca fruits (Yucca spp.), cacti shoots (Opuntia spp.), and various berries, roots, and seeds. Some of these taxa were tended and managed to varying degrees, which I discuss in further detail in Chapter 4. Nuwuvi cultivated both food and non-food plants such as maize, squash, tepary bean, sunflower, morning glory, amaranth, devil's claw, gourd, lambs quarter, and tobacco; later they incorporated nonnative crops such as potato, sorghum, wheat, watermelon, muskmelon, cowpea, and black-eyed pea (Fowler 1995; Kelly and Fowler 1986:371; Laird 1976:5; Stoffle and Dobyns 1982:73; Von Till Warren 2007). A simplified and generalized representation of 
the prehistoric seasonal round consisted of pine nuts harvesting, communal deer hunts, and harvesting horticultural crops in the fall; reliance on cached foods and harvests of juniper berries, agave, and cacti in the winter; rabbit hunting, field preparation, and root harvesting in the spring; and crop planting in addition to seed, mesquite bean, and berry gathering in the summer (Holt 2006; Steward 1938; Von Till Warren 2007).

\section{Ethnographic Legacy}

The first recorded encounter between Euro-Americans explorers and Nuwuvi occurred in 1776 with Spanish Franciscan priests Father Escalante and Father Dominguez. Subsequent interactions were recorded by William Nye in 1864, by Lieutenant George Wheeler in 1871, and by Major Powell and Lieutenant Ingalls at the turn of the $20^{\text {th }}$ century during a U.S. Geological Survey expedition (Fowler and Fowler 1971; Stoffle and Zedeño 2001:228-229). These explorers documented Nuwuvi lifeways in journals and reports.

Much of the available literature on pre-contact Nuwuvi stems from early ethnographers who followed highly descriptive approaches and documented Native lifeways in a static, timeless manner, even though the effects of Euro-American contact had been underway for over a century, and despite periodic resources crises and adaptations that had occurred since time immemorial (Berkes et al. 2000; Berkes and Turner 2006). Julian Steward's (1955) seminal work introduced the school of Cultural Ecology, which continues to hold sway in American anthropology. This approach emphasized the importance of environmental influences in shaping the development of culture and subsistence strategies. Later critiqued as an overemphasis on external forces 
at the expense of individual and group agency, the legacy of Steward's work in the Great Basin (see also Steward 1938) continues to persist in many of the sparse contemporary ethnographic works on this cultural region.

Edward Sapir (1930) provided the first major linguistic analysis of the Nuwuvi language, in addition to subsequent ethnographic contributions (see Bright 1992). One of the most detailed accounts of Nuwuvi spiritual traditions came from Isabel Kelly's (1939) study of Nuwuvi shamanism, while another work documented Nuwuvi lifeways and social structures (Kelly 1934). Scholars disagree about both Nuwuvi social structurewhether consisting of bands or extended families - and the number of pre-contact and early historic period groups. Some suggest that 16 bands existed including Chemehuevi, Las Vegas, Moapa, Pahranagat, Panaca, Beaver, Cedar, Gunlock, Saint George, Shivwits, Uinkaret, Kaibab, Panguitch, Kaiparowits, Antarianunts, and San Juan (Kelly and Fowler 1986:368). These groups merged, diverged, and in some cases disappeared in the wake of disease epidemics, slave raids, relocation programs, and cycles of reservation creation and termination, as conflicting eras of federal policy attempted to both assimilate Nuwuvi into the broader U.S. sociocultural fabric (Knack 2001) and isolate them on reservations through ethnic spacing (Biolsi 2007).

Carobeth Laird (1976) provided the most thorough ethnography of the Chemehuevi, while Catherine Fowler $(1972,1995)$ and Richard Stoffle and his colleagues (e.g., Stoffle et al. 1989, 1990, 1999) have contributed significantly to understandings of Nuwuvi ethnobiology. The large volume of ethnographic treatments of Nuwuvi in the $19^{\text {th }}$ through the mid- $20^{\text {th }}$ centuries primarily focused on Nuwuvi precontact subsistence patterns, social organization, and spirituality. Recent work by 
Spoon and Arnold (2012) describes knowledge fragmentation in light of historic drivers

of change, while examining the interconnectivity of Nuwuvi place-based spirituality and ecological knowledge. The authors describe contemporary Nuwuvi spirituality as heterogeneously distributed and consisting of both traditional Native perspectives intermingled with more recent Euro-American religious influences, especially Christian denominations such as Mormonism (Church of Jesus Christ of Latter Day Saints (LDS)).

\section{Nuwuvi: An Indigenous People}

Anything that we do, we always tie back to our home...home is where you're from, where you're grounded....I think back... [on] my travels...on the East Coast for example....Sometimes it's...overly lush if that makes sense, where sometimes I would feel confined because I don't get the openness that I do over here in Nevada.

- Pahrump Paiute Elder

Nuwuvi consider the Great Basin and surrounding ecoregions to have been their home for millennia, if not since the beginning of time, and Native oral histories cite Nuvagantu (where snow sits) in the Spring Mountains landscape, Nevada, as the locus of Nuwuvi creation (Chmara-Huff 2006:14; Spoon and Arnold 2012:485-486; Stoffle and Zedeño 2001:229). A Las Vegas Paiute elder provided a synopsis of the creation story:

Well this here, [Mt.] Charleston, is the most important mountain we have, 'cause supposedly...that's where the Indian people originated from....

Coyote took them up....They lifted the lid on that [basket] and part of the Indians jumped out and then they spread all over....Then they put the lid back on there and he took them up to Mt. Charleston... and that's where all of the [Southern] Paiutes come from.

Indigeneity is a difficult and contested issue and simplistic definitions of indigenous peoples as people from a place (Clifford 2007) are insufficient given the 
complex and divergent histories of the world's various indigenous groups. Saugestad (Asch et al. 2004:264) reports four principles of indigeneity developed by the United Nations Working Group on Indigenous Populations (WGIP) that validate Nuwuvi as indigenous peoples, while avoiding arguments over their conclusive origin: (1) priority in time for the use and occupation of an area; (2) voluntary perpetuation of cultural distinctiveness; (3) self-identification and recognition by outside entities as a distinctive group; and (4) experiences with expulsion, marginalization, discrimination, or subjugation at some point in time. The WGIP also developed the UN Declaration on the Rights of Indigenous Peoples, which was adopted by the UN General Assembly in 2007. The document declares that indigenous peoples have several fundamental rights, including the right to: (1) self-determination; (2) protection from forcible removal from their lands; (3) practice and revitalize their cultural practices and maintain spiritual relationships with their territories; (4) consultation with the State on matters affecting them; and to (5) protect and conserve the environment in their territories, among others (Spoon 2008:67). Despite initially declining ratification of this document in 2007, the U.S. eventually ratified the Declaration under the Obama Administration (USDOS n.d.). Although legal ownership of the Nuwuvi traditional territory has largely shifted to federal, state, and private control ${ }^{12}$, Nuwuvi spiritual and cultural responsibilities as caretakers of the land, and their identity as an indigenous people persist. Contemporary Nuwuvi walk in multiple worlds, maintaining their collective identity as an indigenous people, while participating in the broader fabric of American culture. Many Nuwuvi continue to practice what they term "traditional" activities, including plant gathering,

\footnotetext{
${ }^{12}$ Nuwuvi still manage reservation lands and small private allotments within the ancestral territory.
} 
crafts, and cultural events such as pow wows and funeral cries, while generally experiencing a Western standard of living with material conveniences.

\section{Conclusion}

Despite bleak accounts of the Great Basin penned by early explorers, Nuwuvi derived a wide variety of resources from the land, from tended piñon groves and horticultural crops to a variety of faunal species. Nuwuvi explain that they have continuously inhabited the Great Basin since the beginning of time and they qualify as an indigenous group by United Nations standards. Piñon-juniper woodlands were one of the most significant habitats Nuwuvi visited during their transhumant ambulations, and are currently expanding their range and increasing stand density due in part to fire suppression and as I speculate, because of reductions in Nuwuvi management. While early ethnography focused on subsistence and social groups (e.g., Fowler and Fowler 1971; Kelly 1934; Steward 1955), recent work has shifted to considerations of Nuwuvi ethnobiology, place based knowledge, and spirituality (e.g., Fowler 1995; Spoon and Arnold 2012; Stoffle et al. 2004). I add to this literature in the next chapter, discussing the formation, transmission, and adaptation of Nuwuvi ecological knowledge and understanding. 


\section{Chapter 3 \\ Knowledge Persistence and Change in the Great Basin}

I'm sure in the old days there probably were [places where only certain people should go]. But today I don't know of any place like that. That knowledge, that kind of knowledge... I didn't get that.

-Kaibab Paiute Elder

As I sat with an elder and his granddaughter on the Shivwits (PITU) Reservation in southeastern Utah, I marveled at the syncretic character of his knowledge and beliefs, which defiantly resisted seamless categorization as traditional beliefs, Christian dogma, Western science, or place-based learning. He patiently explained his spiritual views to me, effortlessly integrating characters from Nuwuvi traditional stories with Christian figures:

[Wolf and Coyote] are the demigods...to the real God....And [then] you got those two; you call him Satan and you call him Jesus Christ. Those are the two, and your God.

Despite my assumptions of a fundamental epistemological fissure between Christianity and traditional Nuwuvi spirituality, this conflict was apparently absent from my consultant's worldview:

I was brought up in the LDS [Mormon] church...it's the same belief [as traditional Nuwuvi spirituality] but different. But to me they're both the same.

As he revealed the story of his life-his education, work experience, travels, and exposure to different worldviews - these various factors, in addition to the larger drivers of change affecting Nuwuvi over the last few centuries, began to explain the hybrid character of his knowledge. 
In this chapter, I explore the processes by which Nuwuvi diachronically generated, transmitted, and adapted their ecological knowledge and understanding (NEK). I contend that accumulated observations of ecological phenomena over a long time horizon and lessons learned through mistakes and crises shape NEK in adaptive ways (Berkes et al. 2000; Berkes and Turner 2006; Turner and Berkes 2006a).

Knowledge holders also maintained that they learn from didactic cultural stories, dreams, and direct communication with spiritual beings and the animate environment. ${ }^{13}$ NEK consists of locally situated knowledge assemblages, consisting of hybridized constellations of knowledge, practices, and beliefs. I argue that various environmental and socio-economic drivers of change experienced since Euro American contact have disrupted knowledge transmission and fragmented earlier, more coherent, yet localized forms of NEK, resulting in its current heterogeneous distribution across the Nuwuvi population.

\section{Mechanisms of Knowledge Generation}

Berkes and Turner (2006:479) suggest two primary mechanisms by which ecological knowledge and conservation-oriented practices arise, conceptualized as a depletion crises model and an ecological understanding model. The first model explains the development of conservation practices as an adaptive response to periodic resource

\footnotetext{
${ }^{13}$ Animism has been defined as "religious beliefs involving the attribution of life or divinity to such natural phenomena as trees, thunder, or celestial bodies" (Hunter and Whitten 1976:12). The concept was first developed by E.B. Tyler (1874) and derogatorily applied to so-called "primitive" indigenous cultures, leading to its abandonment by many scholars. Stoffle et al. $(2004: 19,69)$ argue that the Nuwuvi concept of puha differs from animistic views, which explain natural objects as inert unless occupied by spirits. In contrast, Nuwuvi view spirits and the natural elements they may inhabit as equally alive and able to act.
} 
crises. From weathering these events, a group learns that resources are depletable and require the presence or omission of certain practices to persist at sustainable levels. Some knowledge holders contested this theory, stating that mistakes were not necessary and that Nuwuvi simply knew not to overharvest from cultural rules and teachings. Many elders spoke of their ancestors living harmoniously with nature, in a manner consistent with the "ecologically noble savage" (Hames 2007; Krech 1999; Kuper 2003) representation of Native peoples. As a Chemehuevi (CRIT) elder explained:

I've never heard Indian people go over-abundant, take too much, more than what you need. I never heard that. It's like the buffalos and all that...[they] never killed them all, killed them because you just want to kill them or we'll save for ten years from now and we'll have meat for ten years. No,...I never heard of that. Only take what they need for a season, whatever it is.

On the other hand, a Kaibab Paiute elder saw mistakes as a natural part of the learning process, matter-of-factly replying: "How else [are] you going to learn?.....Oops. Maybe we'll do it better next time." The depletion model holds that the limits of sustainable use are most easily found and understood by exceeding them at some point in time (Berkes and Turner 2006; Johannes 2002). Although none of my consultants made explicit mention of learning this way, several Nuwuvi disturbance-based management practices (see Chapter 4) and resource and habitat taboos (see Chapter 6) hint at resource depletions as a potential cause for their genesis. For instance, consultants employ knowledge of the negative consequences of overly aggressive hydrological modifications to inform the level of intensity used during spring management activities (see Chapter 4). Multi-year moratoria on antelope hunting in certain locations also likely developed from previous experiences with near-extirpation of herds (see Chapter 6). Ultimately this 
process worked in tandem with the following ecological understanding model as Nuwuvi holistically learned from the world around them.

The second, ecological understanding model suggested by Turner and Berkes (2006a:495-497), describes the development of a complex conservation ethic and understanding of ecological processes over a long time horizon by a culture group. They suggest this ecological understanding comes about by: (1) incremental learning from observation and interaction with the fluctuating environment over time; (2) the development of linked belief systems that support conservative resource use; (3) the creation of knowledge transmission mechanisms; and (4) the development of social institutions to regulate behaviors. The second and fourth attributes of Nuwuvi ecological understanding are the subject matter of Chapter 6 in this manuscript. Nuwuvi incremental learning, the first attribute, is rooted in the long-term residence of Nuwuvi in the Great Basin and surrounding ecoregions. This incremental learning has come about from observing episodic and periodic shifts in resource availability, plant phenology (Lantz and Turner 2003), animal behaviors, and other environmental phenomena, as well as through experimentation, monitoring, and evaluation. NEK also adapted to environmental changes catalyzed by Euro-American arrival in the region, including altered hydrology and shifts in vegetation induced by logging, mining, and cattle ranching (Knack 2001; Spoon and Arnold 2012; Wendel 2014). Nuwuvi diets shifted during this period in response to some of these activities, which caused a reduction in traditional food plant populations or obstructed access to them. New wild botanical species and cultivated horticultural plants also arrived in the region and were incorporated into Nuwuvi foodways (see my discussion of watercress in Chapter 4). 
This accumulated knowledge has been passed intergenerationally through oral history, at times codified in story, myth, and song (the third attribute of ecological understanding). Nuwuvi pedagogy generally consists of elders educating youth through didactic cultural stories and hands-on learning — simultaneously teaching morality, stewardship responsibilities, resource harvesting and management, spiritual protocols, and spatial/geographic recognition, among other skills. Although all of my consultants identified the importance of intergenerational knowledge transmission for the continuation and resilience of Nuwuvi culture, they noted a lack of interest in Nuwuvi culture among youth and also lamented the various structural impediments endangering this process. Among these barriers was the market economy—demanding long hours at grueling jobs in mining, construction, the service industry, and other job sectors. Other challenges included knowledge fragmentation resulting from the boarding school erawhich forcibly severed Nuwuvi connections to family, ancestral lands, cultural and spiritual practices and beliefs, and the Nuwuvi language (Spoon and Arnold 2012). Forced sedentism on reservations, privatization and regulation of traditional resource areas, and dietary shifts induced by the BIA food subsidy program and the dominant American food system further fragmented knowledge (Eagan 2013; Knack 2001). Because of these large-scale processes experienced to varying degrees across the Nuwuvi ancestral territory according to demographic factors such as age, gender, and residence, NEK is currently fragmented and heterogeneous in character (Spoon and Arnold 2012) and best perceived as knowledge assemblages (Turnbull 1997). Contingent and locally situated, these assemblages consist of hybridized constellations of knowledge, social institutions, beliefs, and practices. I address some of these syncretic assemblages later in 
this chapter and throughout this manuscript. I contend that changes in NEK and fissures in knowledge transmission because of these political and economic drivers have directly influenced the environmental health of piñon-juniper woodlands by destabilizing and unraveling Nuwuvi stewardship practices and shifting ecological dynamics. I discuss Nuwuvi this further in Chapter 4.

Forsyth's (2003) critical political ecology highlights the importance of including alternate explanations for phenomena in order to avoid unfairly favoring Western interpretations over other worldviews. While Berkes and Turner (2006) explain cultural stories as codified forms of knowledge rooted in long-term observation and experiences of crisis, many Nuwuvi believe these stories represent actual events in their history as a people. These didactic stories detail the adventures of spiritual beings such as Coyote and Wolf who make decisions with various moral and environmental consequences. Through both the virtue and mistakes of these beings, cultural stories instruct Nuwuvi in the proper and moral ways of interacting with each other and stewarding environment. Nuwuvi view taboos_-similarly explained by some scholars as codified knowledge (e.g., Berkes et al. 2000; Berkes and Turner 2006; Colding and Folke 2001; Turner and Berkes 2006a) — as rules for right livelihood, mandated by spiritual beings and transmitted through intergenerational instruction. Some taboos may originate in cultural stories and have associated punishments for transgressions, while others persist in vestigial form by cultural inertia and may no longer have explicit linked explanations (see Chapter 6).

Nuwuvi speak of yet another way that they acquire knowledge of proper environmental interaction - through personalized messages received directly from spiritual beings, caves, plants, and animals. Caves were frequently mentioned as a way 
for people to learn songs, gain the ability to speak with animals, or receive powerful gifts. Consultants reported that caves varied in their use, personality, and power, ranging from benign to extremely dangerous. Certain caves transmitted knowledge or power to select individuals through a variety of spiritual mechanisms. A PITU elder described a memory of his community members visiting such a cave:

And they went from here [Utah] with some guys from down in Moapa and they went across, down to Las Vegas. They were looking for that, they wanted to learn them songs they said. So they went into that cave down there.

Several consultants reported that instruction from the land continues into the present day for those who are receptive to these messages. A Chemehuevi elder from CRIT described this broader phenomenon:

The land can communicate if you're open to it and if you're sensitive to it....And it will show you, you know, how to behave towards it, to make it good and keep it in balance. The Indians, you know, to survive, they have to know all of this type of sensitive stuff.

In sum, knowledge derives from varied sources yet continues to change as it is passed intergenerationally. Drawing from my political ecology framework, I explain how the differential distribution of power across the landscape, including control and access to resources (Biersack 2006), in addition to various other drivers of change experienced to varying degrees by Nuwuvi groups, caused NEK to become highly fragmented, consisting of syncretic and locally contingent knowledge assemblages. I describe these drivers of change in greater detail in the sections that follow. 


\section{Drivers of Knowledge Change and Adaptation}

In the following section I discuss historically contingent environmental and socioeconomic drivers of knowledge change and fragmentation specific to the Great Basin and Nuwuvi. By the time the first ethnographic work was initiated, large-scale environmental changes were already catalyzed in the region, shifting the ecological foundations of NEK. These included climate change, non-native species encroachment, and landscape level vegetation shifts induced by mining, logging, and cattle ranching. Socio-political and economic factors including forced relocations, impeded land access, boarding schools, market integration, English language hegemony, exposure to other cultures and technologies, and individual experiences further stimulated knowledge change and adaptation (Knack 2001; Spoon and Arnold 2012). Although botanical knowledge may have originally been held by specialist plant doctors ${ }^{14}$, following ten epidemics that killed up to $90 \%$ of Nuwuvi between 1847 and 1856, knowledge shifted to a more dispersed form, with individuals holding portions of the whole cultural body of knowledge (Stoffle and Zedeño 1999:417). Perhaps paradoxically, Native usage of wild plants may have actually increased during this time period, as settlers drove Nuwuvi from their seasonal settlements, mesquite groves, and horticultural plots and into rugged upland areas until the late 1890s (1999:418). This loss of edible grass fields and cultivated crops necessitated an increased reliance on upland species.

An important factor affecting knowledge exchange and interaction with piñonjuniper woodlands is the location of an individual's place of residence in relation to this

\footnotetext{
${ }^{14}$ Doctor and traditional doctor were the preferred terms among many of my consultants when speaking about Nuwuvi spiritual healers and shamans.
} 
plant community. During the establishment of Nuwuvi reservations, the federal government sought lands in low elevation valleys, ideally situated next to streams to enable irrigation and riparian farming as part of the federal and Mormon agendas of turning the transhumant Nuwuvi into a sedentary, convertible, and self-supportive agrarian people (Knack 2001). Consequentially, the U.S. federal government established many Nuwuvi reservations in lower elevation plant communities rather than in piñonjuniper woodlands. Chemehuevis living in Parker, Arizona and in Havasu Lake, California live outside of the natural distribution of piñon-juniper woodlands (Little 1971), and must travel several hours north to go pine nut picking. As a result, and despite fond childhood memories of pine nut picking, Chemehuevi consultants reported both a decrease in knowledge and interest in piñon-juniper ecology, harvesting, and management within their tribal communities. Other Nuwuvi residing proximal to piñon groves reported higher rates of continued management and interaction with piñon-juniper woodlands. These include the Las Vegas Paiute Tribe, Moapa Band of Paiute Indians, Kaibab Paiute Tribe and the Paiute Indian Tribes of Utah. Although their reservations are situated in lower elevations, many members of these Nuwuvi Nations were able to access piñon-juniper woodlands within an hour by car. As a Kaibab Paiute elder related:

Indian people did gather a lot of pine nuts up here on the Kaibab Mountain....back up in there where all the trees are....people still even today go up there every once in a while....[It would] probably only take you 30 minutes to get to the foot of the mountain.

The Pahrump Paiute Tribe has a history that in several ways diverges from the other six Nations participating in my study. Despite their presence in ethnographies, historic documents, and government records, the federal government has not granted the Pahrump 
Paiute federal recognition or reservation lands. Instead, the Pahrump Paiute live in various urban and rural locations within and outside of their ancestral territory as "scattered Indians" (Chmara-Huff 2006:36). Some of these individuals have ties to family homesteads adjacent to pine nut groves in the Spring Mountains and therefore, may live closer to piñon-juniper plant communities than any other Nuwuvi Nation. Living in the mountains is itself a relict effect of historic influences, as mountain camps were only occupied seasonally or for short durations in prehistory. Part of this was because of the seasonality of the pine nut crop, while some Nuwuvi attribute it to the sacred status of mountains as a place to visit rather than live. One Chemehuevi (CRIT) elder interpreted this history:

I think that it wasn't until the white man or the government came in and started...collecting all the young Indian kids to send them away to boarding school, that a lot of people, because of that, to get away from that, they had no place to go. So they moved up into their sacred lands, which is a no-no. You know Indians don't live on sacred land. When they had that to be afraid of, when you're being intimidated and stuff like that, there was only one place to go and that was back to their sacred land. That's why a lot of Indians today, their families lived in the mountains. Before they all lived in the valleys. It was a sacred place... you only talked about. Legends were built in that mountain. When they came down they got threatened... [and] they had no alternative but to start migrating or moving back into that mountain.

Another driver of knowledge change stems from Nuwuvi integration in the market economy. My consultants worked in a variety of job sectors including: house cleaning, fast food, child care, casinos, tribal smoke shops, road construction, the military, mechanic shops, beauty shops, tribal government, and cattle ranches. A select few attained higher degrees, were consultants for cultural and natural resource projects, or worked for the National Park Service or other government agencies. With the 
exception of Las Vegas, many of the rural locations of Nuwuvi reservations resulted in scant employment and post-secondary education opportunities (see Appendix E). Many of these jobs were incredibly demanding, and because of low earning power, employees were frequently forced to work long hours with little time off to adequately provide for their families. For individuals living far from ancestral Nuwuvi pine nut picking grounds, the travel distance coupled with the prohibitive cost of fuel and the financial impact of missing work resulted in extremely limited opportunities for stewardship of piñon-juniper woodlands and hands-on intergenerational instruction in this ecosystem.

Religion and spirituality were yet other significant factors influencing ecological knowledge of piñon-juniper woodlands (see Appendix F). Rather predictably, those individuals raised in areas close to or within the state of Utah experienced the highest degree of influence from the LDS (Church of Jesus Christ of Latter Day Saints). Although it began in the eastern United States, the LDS moved to Utah under the charge of Brigham Young in the 1840s (Knack 2001:50-51). Utah continues to serve as the epicenter of the LDS in the present day. Not surprisingly, all Nuwuvi within close proximity heavily experienced the LDS penchant for proselytizing ever since Mormon arrival in the region. Tribal members of the Paiute Indian Tribes of Utah (PITU), the Moapa Band of Paiute Indians, and the Kaibab Paiute Tribe showed the highest level of Mormon influence. This incorporation occurred at multiple levels, including baptism in early childhood, attendance of church and church-sponsored community activities, conversion later in life, and current practice and self-identification as Mormon. Some consultants described their entrance into the LDS as voluntary, while others spoke of LDS members luring them as children with food, sweets, or entertaining community 
events. These descriptions paralleled LDS conversion programs initiated during early contact with Nuwuvi, when clothing, farming implements, and food were gifted in exchange for Nuwuvi involvement in Mormon activities and farm labor (Knack 2001). A Kaibab elder described her feelings about this conversion tactic:

We're not angry with the Mormons anymore or anything. You know, a lot of times, especially in the old days, when the Mormons first came around, Paiutes discovered that if you let these Mormon people baptize you, they're going to give you some food and they're going to give you a shirt. And so that's what they did. They'd line up to get them....That's how they got their clothing, because in that time when the Mormons came and took over everything and ran all their cattle out here, they ate up all the natural foods out there that the Indians would harvest and eat... Cattle just munched that right down and people were starving. That was probably one of the greatest losses of the Indian people that happened, when the Mormons came to the area for the first time.

Interestingly, not a single consultant from these three Nuwuvi Nations currently identified as strictly Mormon. Of those individuals still practicing or identifying as Mormon in these Nations, all ascribed to traditional Nuwuvi place-based spirituality as well, finding no apparent conflict in creating syncretic practices (see also Spoon and Arnold 2012). They remarked that the two spiritual orientations are either complementary or even inherently the same at a basic level. A stronger trend in current Nuwuvi spiritual practices, revealing a move away from Mormonism, manifested as increased participation in traditional ceremonies or practices and decreased participation in LDS events. On the Kaibab Paiute Reservation, the folding of a once-active LDS church marked this shift away from Mormonism and toward a resurgence in traditional spirituality at the grassroots level. As a Kaibab Paiute elder observed:

We even had a Mormon church in our village. Our community center was the old Mormon church. It was probably only a couple of families that weren't baptized or didn't get involved with the Mormons, but that's about 
all.... I don't know why they left. Maybe because the Indians started drifting away and they didn't have enough people to teach, because nobody's a Mormon anymore.

Some of my consultants had actively renounced Mormonism rather than simply ceasing involvement. They explained that their decision to leave the Church was linked to their late discovery and access to accurate accounts of the troubled Mormon-Nuwuvi history of which they were previously unaware. Other Judeo-Christian religions and denominations practiced at varying times by participants included: Catholicism, the Episcopal Church, non-denominational Christianity, and the Indian Nazarene Church (see Appendix F). One individual followed spiritual teachings from the Lakota Sioux and several individuals had participated in Native American Church activities.

Although difficult to separate in their current syncretic manifestations, several epistemological differences are apparent between Christianity and older forms of Nuwuvi spirituality. One of these differences involves the Christian dichotomy of good and evil. According to several consultants, "traditional” Nuwuvi spirituality does not categorize objects, places, or happenings as either good or evil. Instead, this worldview delineates certain places or objects as powerful in various ways and to varying degrees. Some places and objects are perceived as rejuvenating or healing, others as dangerous, and still others as nuanced mixtures of these and other qualities. Elders also described scenarios such as accidental anthropogenic wildfires, which might cause the land to fall into a state of imbalance or unhealthiness by offending the land and degrading its ecological function. Such states of health or balance diverge from Christian conceptions of good and evil and necessitate the active participation of Nuwuvi practitioners to perform particular ceremonies or practices to bring the land back into a state of environmental healthiness 
and spiritual balance. Despite disparate epistemological foundations and historical origins, elements of Christianity were detectable in the statements of many Nuwuvi practitioners of "traditional spirituality". A Kaibab Paiute elder described how the Christian construct of good and evil has influenced Nuwuvi taboos and behaviors:

Well nowadays, with the coming of the Mormons, they tell you not to shout [in caves] because the evil spirits are going to talk back to you....That's part of [the] differentiation between evil and good.

His statement reveals how older, "traditional" Nuwuvi prescribed and proscribed behaviors (see Chapter 6), such as respectful, quiet conduct in caves, were still followed, despite evidence of Christian influences in the explanation of why one should follow such practices. The primary theological conflict reported by practicing Nuwuvi Christians of all faiths, especially LDS members, was the Christian doctrine of a single true God. Nuwuvi beliefs in multiple gods, spiritual entities, and a sentient landscape were seen to directly conflict with the monotheistic Christian view, despite points of disagreement among individual Christian denominations about whether saints, angels, demons, and spirits of the deceased also challenge this tenet. Since older strands of Nuwuvi ecological knowledge and practice are indelibly tied to its foundational spiritual worldview, several changes may be expected from religious conversion. Adherence to taboos for instance, especially those enforced by threat of spiritual sanctions by non-Christian spiritual beings, would be expected to decline. Erasure of these regulatory mechanisms that limit and control resource use and habitat entrance could result in a plethora of negative conservation outcomes including local species extirpations, biodiversity loss, and increased negative environmental disturbances (see Chapter 6). Although much of the literature assumes that Christianity is inimical to conservation because of its espoused 
ideals of human dominion over nature (White 1967), local sites of hybridization may result in novel religio-spiritual forms that reshape ecological knowledge and practices in unpredictable ways (Jacka 2010). Despite a seeming disparity in the construction of the human/nature relationship among variants of "traditional Nuwuvi spirituality" and Christianity, many of my consultants effortlessly negotiated, translated, and syncretized multiple worldviews without any apparent contradictions, all the while maintaining a strong conservation ethic.

\section{From Beaded Cell-Phone Holders to Microwaves: Adaptation of Practice}

Despite over two centuries of radical changes, some Nuwuvi practices remain largely as they have for millennia. For instance, supple branches of alder or willow are still used to whip pinecones from piñon trees and green pinecones are still roasted in campfires to open their closed, indehiscent scales and steam the pine nuts within. ${ }^{15}$ Subtle detectable modifications have even occurred with these practices however as new materials and technologies have become available. Green pinecones are now cooked in microwaves by some Nuwuvi as a Las Vegas Paiute elder explained:

Somebody was telling me that you can throw them in the microwave and I was like, what? You mean I don't have to make my little hole in the fire and all that? And they go, just put them in the microwave and make sure you have a little bit of water in the back [of a plastic bag] and it kind of steams it and they open too!

Once pruned with pieces of edge-modified obsidian, plants are now cut with pruners, loppers, and saws. A change in pine nut collection containers over time from burden

15 Dehiscence refers to the opening of protective cone scales when pine nuts are ripe (Harris and Harris 2001:35). This process occurs automatically once piñon cones are mature and turn brown. Nuwuvi also harvest immature green cones, which require additional processing to access pine nuts. 
Figure 3.1 The Preferred Pine Nut Container for Many Nuwuvi, Sheep Range, Nevada, October 2012 (Image: B. J. Lefler)

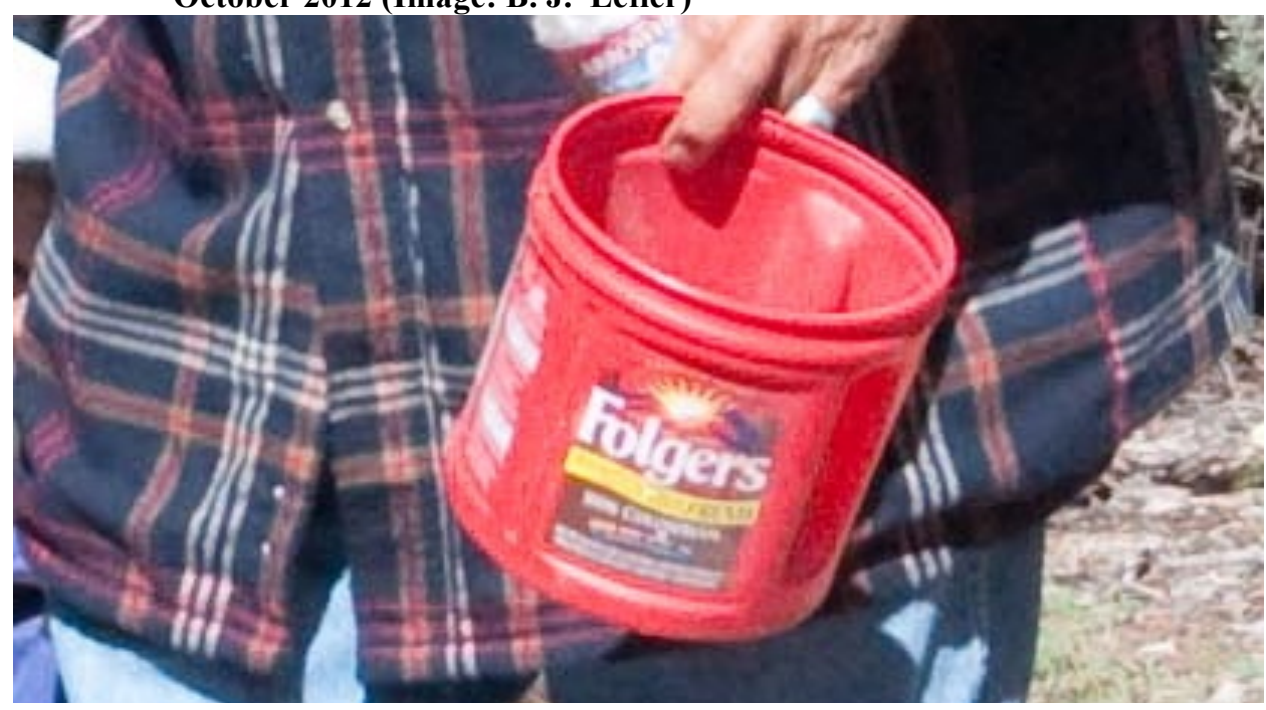

baskets, to burlap gunnysacks, to red metal- and most recently plastic Folgers ${ }^{\mathrm{TM}}$ coffee cans, demonstrates a continuum of adaptation that has kept pace with the dominant U.S. culture. Consultants variously described all of these containers as "traditional". Beading, while still appearing in dance regalia and other traditional contexts, also adorns cell phone holders carried by some of my consultants. Further, despite binary representations of cowboys and Native Americans appearing in old western films, one knowledge holder described the current western style of dress worn by many older Nuwuvi men, jovially stating that Indians had become the cowboys. These adaptations, incorporations, and hybridizations of Nuwuvi and external cultural elements into novel forms and combinations represent the contemporary realities experienced by indigenous peoples worldwide, where tradition, modernity, and a diversity of practices, views, and beliefs are constantly being negotiated.

In this chapter I have discussed the ways by which Nuwuvi developed, transmitted, and adapted NEK to various drivers of change. I argued that some 
knowledge arose incrementally from long-term observations as well as learning from resource depletions. From my critical political ecology framing (Forsyth 2003), which avoids privileging Western science-based interpretations, I also described Nuwuvi explanations for knowledge generation including messages transmitted by a variety of spiritual entities. I used my political ecology lens to explain how various drivers of change have influenced Nuwuvi knowledge and its transmission (Biersack 2006, Escobar 1996), including the differential distribution of power across the landscape, environmental shifts, relocation programs, separation of families, boarding schools, English language hegemony, market integration, and Christianity. These events and forces effectively fragmented Nuwuvi knowledge from its more coherent, yet still localized precontact forms. NEK at the time of study was heterogeneous and syncretic in character, manifesting as adaptive, locally contingent knowledge assemblages. The adaptive capacity of Nuwuvi ecological knowledge directly informed and translated into a series of disturbance-based management practices such as pruning, prescribed fires, and hydrological management, which I highlight in the following chapter. 


\section{Chapter 4 \\ Causing Disturbance to Balance the Land: Nuwuvi Adaptive Management and Non-Equilibrium Ecology}

They [plants] love to be manhandled, shaken around, bent here and bent there, but you know, not destroyed.... So they'll know that you've been around I guess.

-Chemehuevi (CRIT) Elder

\section{Introduction}

Nuwuvi have an engaged role in ecological systems. From a Nuwuvi perspective, the Creator charged them with stewardship of their ancestral homeland. Stewardship entails spiritually balancing the land, supporting its health, ensuring abundant resources, and maintaining their relationship with the sentient landscape through conversation, prayer, ritual, and offerings. ${ }^{16}$ In this chapter, I discuss NEK as it pertains to the management of select flora and hydrological features in piñon-juniper woodlands at the species, population, habitat, and landscape scales. I suggest that Nuwuvi management adapts as a result of ecological learning and induces low to intermediate levels of disturbance to shape the land towards Nuwuvi perspectives of environmental and spiritual health and balance. These practices mimic non-anthropogenic natural disturbances and operate within a framework of non-equilibrium ecology, engendering ecological rejuvenation and supporting high levels of biodiversity and biocomplexity (Connell 1978; Forsyth 2003; Van Vlack 2007; Wallington et al. 2005). ${ }^{17}$ Nuwuvi techniques included selective harvesting of plant material, pruning, transplanting, leaf

\footnotetext{
${ }^{16}$ Rappaport (1968) was among the first to examine the impacts of spiritual beliefs and practices in the physical, material realm.

${ }^{17}$ A natural disturbance is "any relatively discrete event in time that disrupts ecosystem, community, or population structure and changes resources, substrate availability, or the physical environment" (White and Pickett 1985:7). These disturbances include fire, scouring and silt deposition from floods, animal burrowing, rockslides, or wind-toppled trees, and may be required by some co-evolved plants for population establishment or life cycle completion (Anderson 2005:17).
} 
litter removal, prescribed burning, cleaning silt from springs, and additional spiritual methods of balancing the land. Indeed, millennia of Nuwuvi disturbance-based management of piñon-juniper woodlands likely affected the distribution and ecological structure of these partially anthropogenic forests. Further, a reduction in Nuwuvi management over the last two and a half centuries may be somewhat responsible for shifting ecological dynamics and linked management challenges from denser tree spacing and increased landscape flammability. Nuwuvi stewardship practices have adapted to both episodic and erratic environmental changes and offer a corollary to adaptive management as practiced in Western land management. This commonality provides a point of entry for developing collaborative resource stewardship partnerships between federal agencies and indigenous peoples on public lands.

\section{The Semantics of "Management"}

Management is a contentious and slippery word, eliciting a host of meanings and connotations. The form of management currently employed at both the SMNRA and DNWR is adaptive management, an iterative process by which decision-making, monitoring, and learning inform subsequent decisions in the face of constant uncertainty (Holling 1978). Adaptive management facilitates the co-evolution of people and ecosystems by monitoring the feedback between management policy and resource health and altering decisions accordingly (Berkes and Folke 1998:10) In one sense, management refers to the active manipulation of resources for various (ecological, recreation, production, etc.) goals. Some management decisions made by Nuwuvi and federal land managers necessitate inaction, such as leaving a plant population fallow to recover from 
harvesting without human intervention for one to several years. Under the rubric of adaptive management, such actions are termed passive management. ${ }^{18}$ Further, although many of the management techniques described here involve physical manipulations of plants and landscape features, some management actions are more appropriately described as healing or balancing the land by Nuwuvi consultants. From a Nuwuvi perspective, this form of management involves communication with the land, biota, landscape features, and resident spiritual beings. Prayer, offerings, songs, and rituals may be used to perform this form of management (see also Spoon et al. 2011; Spoon and Arnold 2012).

Many Nuwuvi consultants associated the term management with Western sciencebased approaches to manipulating resources towards certain goals and using particular techniques and technologies. When referencing their own human-environment interactions and balancing exercises, consultants used words and phrases including: steward, take care of, balance, and tidy up to describe this process. For them, these words evoked a more familiar, kin-based, and spiritual relationship with the land than that intimated by the term management. Interestingly, several knowledge-holders did not view any Nuwuvi harvesting activities or environmental interactions as a form of management. In a Kaibab Paiute elder's words: “Managing plants, how would I describe that? I don’t know. All I know is we harvest it [laughing]!” Alcorn (1993:425) similarly notes that indigenous people typically find the separation of Western conservation from normal respectful environmental conduct as inordinately odd and unnecessary.

\footnotetext{
${ }^{18}$ See Coles-Ritchie $(2013: 4,27)$ for a description of proposed active and passive spring management activities in the SMNRA.
} 
The land and all of its elements are enveloped within the Nuwuvi kinship system, which is constituted as a relationship of reciprocal care (Salmón 2000). Nuwuvi believe that as long as they hunt and gather in a respectful manner and fulfill their charge to heal and steward the land, the plants and animals will continue to thrive and provide vital resources, as ordained in the Nuwuvi creation story (Spoon et al. 2011; Spoon and Arnold 2012:486). Here a Pahrump Paiute elder described this duty:

Indian people were charged with that responsibility. At creation and with the Creator, deities and things, we were charged with certain tasks to make sure that the land would be good and be healthy and our world would be good and be happy. You know, a lot of the animals that are there, certain ones that were the teachers, they gave us that information.

Finally, the term management plays out on a political level as well, carrying the connotation of decision-making authority. Despite an increase in Native involvement and idea exchange in collaborative management projects, actual power sharing between Native Nations and federal agencies has yet to occur. Describing projects as collaborative stewardship as opposed to management avoids challenging federal authority and also appeals to Nuwuvi self-descriptions as caretakers or stewards of the land, while still providing opportunities for meaningful collaborative engagements (see Spoon et al. 2013). Collaborative resource stewardship moves beyond management by offering a venue for sharing different worldviews, integrating natural and cultural resource management, building relationships, and working towards positive outcomes for indigenous collaborators, federal agencies, the land, and the public. The Nuwuvi Knowledge to Action Project (NKTA) provided one example of this approach (see Spoon et al. 2013 for more information). Despite the highly politicized and potentially ambiguous meanings of management, I use the word here to describe the various 
decision-making processes, active and physical practices, moratoria of practices, and spiritual balancing practices used to achieve desired spiritual and material outcomes.

\section{Nuwuvi Adaptive Management and Non-Equilibrium Ecology}

Two primary paradigms compete to frame and explain ecological systems. The first, stable state equilibrium ecology is marked by a routine set of linear, successional steps towards a predictable and idealized climax state of an ecosystem in the absence of humans (Botkin 1990; Pickett et al. 1992; Wallington et al. 2005). Equilibrium ecology suggests concepts of harmony, balance, and homeostatic self-regulation in which any human-induced disturbance is interpreted as degradation to the system (Forsyth 2003; Spoon 2013). This paradigm was foundational to the creation of the Wilderness Act of 1964 (and protected areas in general), which defined wilderness in such terms as "untrammeled" and predominantly affected and maintained by the forces of nature, a philosophy that continues to hold sway in the discourse of some environmental campaigns.

The equilibrium ecology paradigm and the conservation approaches that draw from it define human disturbance as degradation that must be eliminated for ecological health to resume. This outlook explains in part the long history of indigenous expulsions from protected areas worldwide as a way of maintaining purportedly "pristine" ecosystems by squelching indigenous management (Dowie 2011; Keller and Turek 1998; Spence 1999). From his critical political ecology framework, Forsyth (2003) discusses the sustained persistence of such simplistic and faulty ecological explanations by revealing their rootedness as social constructions. He suggests that politicians wield 
science - in the form of hegemonic natural laws and environmental orthodoxies - as a political tool to substantiate misguided or malicious policies, while silencing alternate interpretations and worldviews. My consultants spoke of such experiences, citing innumerable instances in which their objections to herbicide use, logging, flame retardants, and developments in ancestral piñon groves fell on the deaf ears of federal agency land managers who used science to undermine and invalidate Nuwuvi concerns. ${ }^{19}$ A PITU elder described his frustrations about chemical contamination on public lands:

Every once in a while I go out there looking for medicine....[But then] they use a lot of pesticides and you really don't want to use it. So you go way out there where they hardly ever use that stuff.

Despite lingering vestiges of equilibrium ecology in policy and some forms of environmentalism, the preponderance of evidence of stochastic, non-linear ecological processes is demanding a shift in current management approaches towards those that accept a non-equilibrium view of ecology.

The second paradigm, non-equilibrium ecology, developed out of observations that ecosystems are constantly in flux because of stochastic events, and that both external and internal factors drive change at a variety of temporal and spatial scales (Forsyth 2003). Further, the historical contingency of events is cumulative, and their chronological order and scale may matter, resulting in not one but many possible stable states that may last for various periods of time before changing yet again (Wallington et al. 2005). Within Western science, the non-equilibrium paradigm shift challenges not only linear,

\footnotetext{
19 Sloppy chainsaw pruning and the felling of productive old growth piñon pines were among the most offensive practices noted by consultants. Assessments of health risks to indigenous harvesters from fire retardants and herbicides applied on public lands range from negligible (Labat-Anderson 2003:22-23) to substantial (Anderson 2005:319-320; LeBeau 1998:39).
} 
equilibrium ecology but also the schools of conservationism, environmentalism, and resource management that draw from its discourse (Forsyth 2003). Berkes et al. (2000) suggest that conventional resource management frames management issues according to equilibrium ecology, viewing management and its goals in quantitative measures that seek to increase the predictability and control of ecological processes and commodified resources, resulting paradoxically in decreased resilience of the ecosystem. My research suggests that Nuwuvi management practices operate within a non-equilibrium model of environmental processes, mimicking, accentuating, and adapting to natural disturbances to encourage ecosystem recharge, stimulate vegetative growth, and maximize ecotones and biological diversity. ${ }^{20}$ Nuwuvi resource stewards engage in an ongoing cycle of change in which they introduce disturbances and bring the land back into environmental and spiritual balance following both anthropogenic and natural perturbations before change occurs again.

Nuwuvi undoubtedly witnessed various environmental changes during their long tenure in the Great Basin. Some of these changes were marked by periodic droughts or fluctuations between resource scarcity and abundance, exemplified by the rotating mast years of pine nut crops. ${ }^{21}$ Other environmental changes were episodic, swift, and unprecedented, such as those wrought by Euro-Americans, including mass timber extraction for the logging, railroad, and mining industries; vegetation shifts induced by

\footnotetext{
${ }^{20}$ Ecotones or ecological edges refer to transition zones, or areas of overlap between discrete ecosystems, exhibiting species from adjacent ecosystems, high levels of biodiversity, and increased ecological interactions (Turner et al. 2003).

${ }^{21}$ Mast refers to the botanical fruits such as chestnuts and acorns produced by trees in the Fagaceae (Beech Family) (Smith 1929), in addition to pine nuts. Mast years are those during which a tree produces an abnormally large bumper crop, occurring every two or three years for single-leaf piñons (Zouhar 2001) and every three to seven years for Colorado piñons (Anderson 2002).
} 
grazing; altered hydrology from water developments; and more recent nuclear testing, urban development, and accelerated climate change (Hulse 2009; Knack 2001; Lanner and Frazier 2011; Spoon and Arnold 2012).

Nuwuvi management and balancing of the land adapted to these drivers of change and sought to assist the land in recovery from such large-scale disturbances. Spiritual forms of balancing complemented physical practices, and consisted of maintaining personal relationships with the land, explaining human-induced environmental impacts to spiritual beings, in addition to offerings, songs, and prayers in the Nuwuvi language that fed the land (Spoon and Arnold 2012:490). Nuwuvi indicators of balance and health in piñon-juniper woodlands include abundant pine nut crops, clean flowing springs, adequate snow pack, unobstructed cultural viewsheds (e.g., songscapes and storyscapes free of development), non-epidemic proportions of insects and mistletoe parasitism, the presence of animals on the land, a tidy landscape aesthetic, and the absence of catastrophic fires and those caused by negligence or arson.

Nuwuvi Piñon-Juniper Management and the Intermediate Disturbance Hypothesis

Certain human disturbances can prove beneficial and stimulating to ecological processes in a non-equilibrium view of ecology (Botkin 1990; Mistry et al 2005). Indeed, many indigenous groups and small-scale agrarian societies utilize disturbances to nurture ecological renewal and create landscape heterogeneity (Alcorn 1993; Anderson 2005; Berkes et al 2000; Deur and Turner 2005; Trusler and Johnson 2008). However, this does not imply that all human disturbances that have occurred in the Nuwuvi homeland are beneficial, such as dam construction, grazing, mining, and deforestation of piñon-juniper 
woodlands (Spoon and Arnold 2012:490). In contrast to these large-scale disturbances, Nuwuvi management practices generally operated at low and medium levels of disturbance, at both temporal and spatial scales (Van Vlack 2007:32). According to Connell's (1978) non-equilibrium Intermediate Disturbance Hypothesis (IDH), high disturbance levels reduce species diversity, in part by favoring certain taxa over others to the extent that some may be outcompeted and rendered extinct within the system. On the other end of the spectrum, absence or extremely low levels of disturbance will favor a different suite of species, resulting in a similar net loss of biodiversity. Intermediate disturbances, however, strike a balance between overly favoring either taxa adapted to instable environments or to predictable and stable environments. By allowing fluctuating yet persistent habitat for both types of organisms, maximum diversity is maintained. IDH is thus a useful explanatory tool for understanding Nuwuvi management effects on the environment. $^{22}$

According to many Nuwuvi knowledge holders, plants — as sentient beings_-liked to be harvested and would even go away if they were no longer taken care of and used. This view is remarkably similar to Connell's (1978) observations that extremely low levels of disturbance can actually result in reduced levels of biodiversity and biocomplexity. Here a Moapa Paiute elder shared her view of the importance of harvesting:

It's the same thing as taking care... we're doing the tree a service. They're there for us to eat. Creator gave it to us as a food. So when you pick them...the tree's thankful. The mountain's thankful, because they're

\footnotetext{
${ }^{22}$ Despite the focus of this hypothesis on tropical forests and coral reefs, and recent critiques against its accuracy (Fox 2013), ecologists widely continue to utilize the IDH (e.g., Hall et al. 2012; Roxburgh et al. 2004; Slik et al. 2008).
} 
seeing Indian people up there doing what they used to do. They're probably crying out for us.

Some conservation biologists adamantly object to indigenous resource management in protected areas (e.g., Redford and Sanderson 2000; Terborgh 2000), staunchly advocating the fortress conservation model, which seeks to expunge all human presence in and impact on ecological systems (Brockington 2002). Nuwuvi, however, viewed lack of interaction and use of natural resources as equally detrimental as over- and misuse of the environment. Indeed, the "benign neglect" (Fowler 2003) approach to management on many federal lands has created cluttered, unkempt forests that conflict with the Nuwuvi cultural landscape aesthetic. The close tree spacing that results from such policies increases susceptibility to catastrophic fires and result in smaller, scruffy trees that exhibit lower pine nut production because of heightened competition over resources.

Nuwuvi knowledge holders unanimously agreed that there was a disconcerting trend in reduced Nuwuvi interaction, harvesting, and spiritual balancing occurring in piñon-juniper woodlands at the time of research. Most consultants agreed about the importance of Nuwuvi stewardship and the current unbalanced state of the environment. Large-scale environmental impacts and a gradual reduction in Nuwuvi management and interaction with the land over the last 200 years were viewed as underlying causes. These concerns substantiate the need for collaborative stewardship and cultural revitalization projects such as those supported by the Nuwuvi Knowledge to Action Project (see Spoon et al. 2013), to ensure the continued health and resilience of piñon-juniper woodlands and Nuwuvi culture. 


\section{Nuwuvi Intermediate Disturbance-Based Management Practices}

\section{To Prune By Any Other Name: Harvest, Whip, Coppice, Trample, Scar}

According to consultants, select harvesting of plants was one of the most basic ways Nuwuvi caused environmental disturbances. Pruning occurred both intentionally and unintentionally as a by-product of some of these harvesting activities. I use the word pruning to refer to the removal of material from plants that are generally woody perennial taxa of shrubs and trees. In the prehistoric and protohistoric periods, Nuwuvi pruned live material from plants using edge-modified pieces of obsidian, although knives or pruning secateurs were more typical at the time of study. Nuwuvi removed dead branches from trees to improve access to crops such as pine nuts, but also to achieve a particular cultural aesthetic of cleanliness, openness, and health. In the case of the piñon pine, accessible branches were snapped by hand, while out-of reach branches were whipped with long, flexible branches of tree taxa such as alder (Alnus spp. Mill.), willow (Salix spp. L.), or oak (Quercus spp. L.). Whipping broke off dead branches, needles, growth tips and old pinecones from the tree, exfoliating the tree and reportedly stimulating new growth and increased pinecone production. Whipping poles were often propped against piñon pines and left to cure for a season to reduce water weight. Poles found today in favored groves may be several generations old. Sometimes the ends of these poles were tied off as they dried, creating an effective hook for dislodging stubborn pinecones. A Pahrump Paiute elder recalled her father's process for making a hook:

Yeah, my dad used to...put it through [the] wagon spokes, cut it down [and] make it curve like a cane. And he'd try to tie it up there so it will stay when it dries. 
Figure 4.1 Uncured Pine Nut Whipping Poles of Freshly Cut Alder (Alnus incana (L.) Moench), Lander County, Nevada, 2011 (Image: B. J. Lefler)

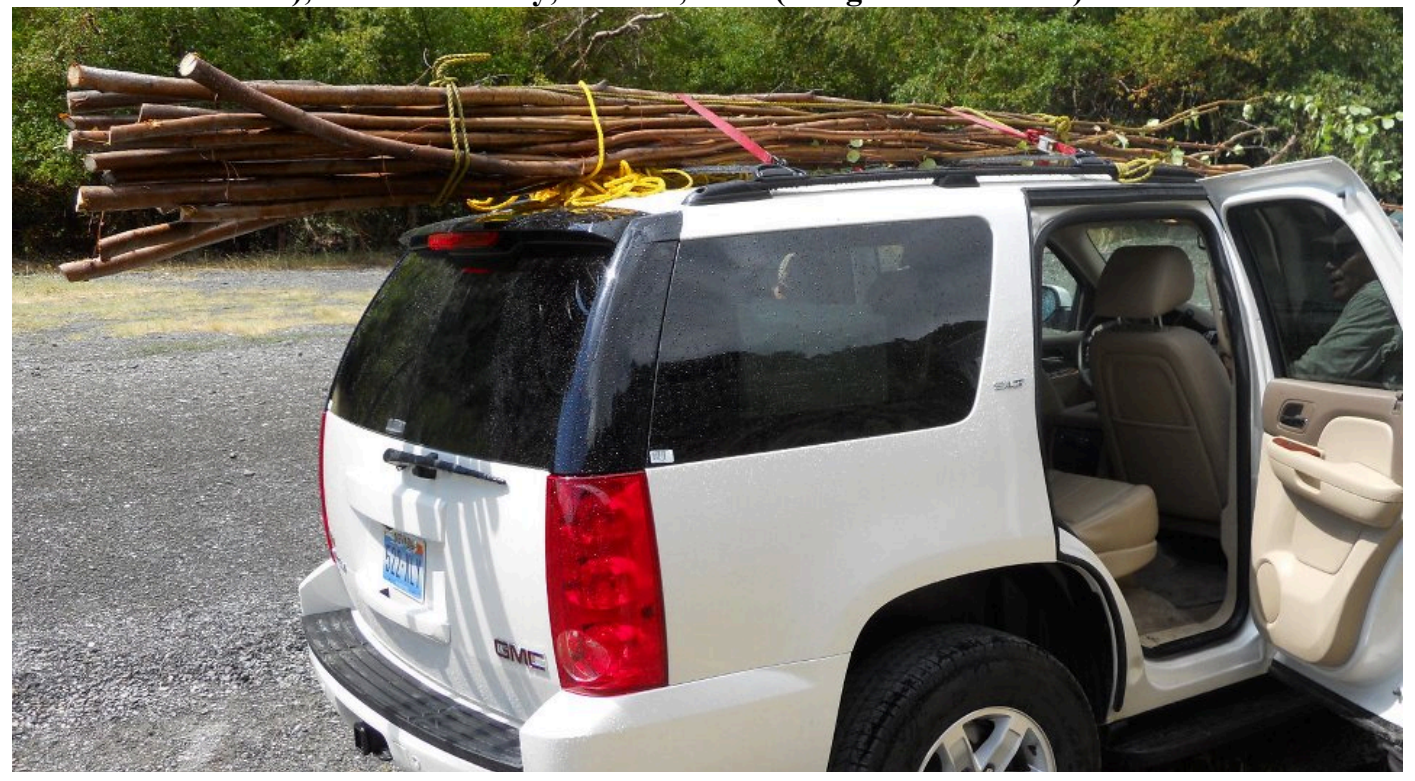

Consultants, including this Las Vegas Paiute elder, shared childhood memories of climbing piñon trees to dislodge pine nuts, often becoming coated in pitch in the process:

Oh yeah, we'd climb up [the tree] and shake it. And then all the pine nuts would just fall to the ground, and oooh that's so good!

Knowledge holders reported that other vegetation or bushes impeding mobility or access to the base of piñon pines might also be weeded or pruned back. Foot traffic beneath and around trees also broke down litter on the ground into smaller pieces of mulch, speeding the process of nutrient cycling.

Certain taxa of small trees and shrubs responded vigorously to intensive pruning, called coppicing (Anderson 2005). Coppiced plants were cut or burned all the way to the root crown, leaving behind a stool. Once old and diseased branches were removed, fresh branches emerged from the stool, exhibiting growth habits with less branching, and instead appearing long and slender with unbroken lengths of bark (Anderson 2005:139). Among willow species, these slender whips provided superior and highly sought-after 
branches used for cradleboards and bark, foundational for traditional Nuwuvi basketry. Nuwuvi harvested Indian tea (Ephedra nevadensis S. Watson and E. viridis Coville) by hand-snapping stems or snipping them with pruning shears, reporting a similar stimulating growth response from the plant.

Although unmentioned by my Nuwuvi consultants, the literature reveals that Nuwuvi scarred and managed juniper trees to produce the most preferred bow staves in the Great Basin (Wilke 1993). Bowyers would first arrest tissue growth by severing the future bow stave's vascular connection to the tree using stone chisels. The stave would then be seasoned in situ on the tree for several years before the bowyer returned to pry it out. Presumably an entire landscape of cultural modified trees (CMTs) existed at various stages of succession. Trees with the infrequent characteristic of straight wood grain were likely repeatedly managed, as the previous scar produced an ideal template for continued stave production (Wilke 1993:271-272) that required regularly monitoring and management. Both the infrequent occurrence of straight-grained wood within juniper populations and the incentives of keeping such individuals alive and healthy - in some cases for centuries (Wilke 1993:273) and across generations - most likely necessitated sustainable and conservative approaches to managing juniper CMTs.

Despite these various forms of Nuwuvi pruning, including intensive methods such as coppicing and scarring, the majority of knowledge holders expressed dismay regarding USFS chainsaw limbing practices on the SMNRA, that consist of removing lower branches or "fire ladders" of piñon pines to prevent beneficial low-intensity ground fires from transforming into dangerous crown fires. For many Nuwuvi, this disrupted the cultural landscape aesthetic and was believed to increase susceptibility to insect and 
Figure 4.2 Oozing Chainsaw Scars Resulting From Fuel Reduction Treatments. Lee Canyon, SMNRA, Nye County, Nevada. 2011 (Image: B. J. Lefler)

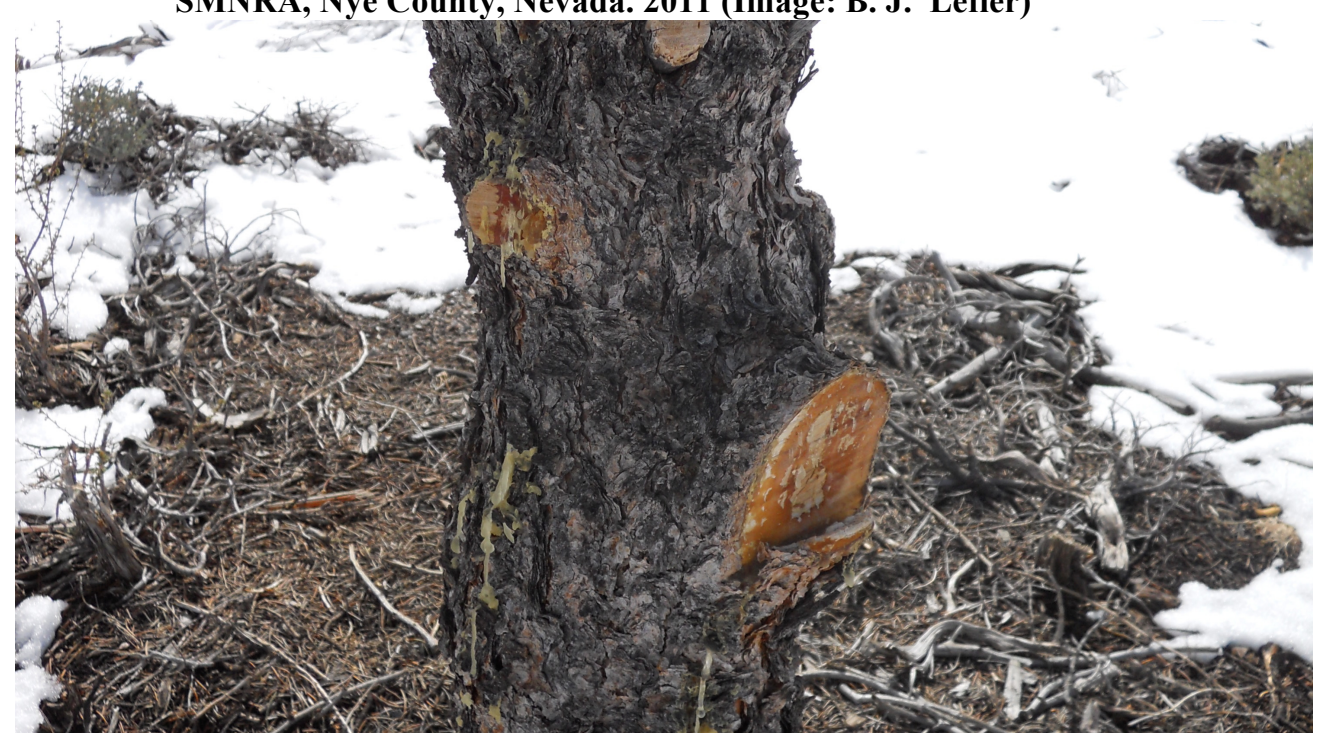

fungal attacks. The dripping sap emanating from these pruning scars - reminiscent of blood—proved emotionally disturbing for multiple individuals. Still, several elderly consultants enjoyed the improved access to the base of trees, while reporting that such heavily pruned trees also produced larger more abundant pine nuts in upper branches. As a Las Vegas Paiute consultant explained:

When you cut [the] bottom branches of pine trees, you make the pine nuts bigger up on top.

\section{To Tidy, Clean, Bulldoze, or Burn?: A Disturbance Continuum}

In the following section I turn my attention to Nuwuvi environmental perturbations that result in soil disturbance while also in many cases imparting stimulating effects to plants. An example of intermediate disturbance entailed the gathering and removal of downed limbs and other detritus, described by many consultants as cleaning or tidying up. From a Nuwuvi perspective, tidying served as a testament to Nuwuvi stewardship and care for the land, resulting in a spiritually balanced 
and healthy environment. In the material realm these practices consisted of removing, raking, mounding, and sometimes pile burning downed limbs, pinecones, pine needles, and material from other trees and shrubs. Areas were tidied when dead material formed an obstruction to movement and access or resulted in a cluttered, unhealthy aesthetic. Various forms of pruning contributed to this effort. During tidying, mistletoes (Arceuthobium divericatum Engelm. and Phoradendron juniperinum Engelm. ex A. Gray) were knocked from piñon pines and junipers respectively. Removal and burning of these hemiparasites was thought to slow their spread and keep population numbers below epidemic proportions. Similarly, removal and burning of downed material was thought to decrease insect habitat, control their populations, and limit tree morbidity and mortality. Some consultants warned against removing detritus from under shrubs such as Indian tea, explaining that removal of this natural mulch would lead to soil desiccation while reducing habitat for smaller animals and insects to live. Others believed that removing this litter stimulated the plant and improved soil permeability. As a Pahrump Paiute elder explained:

They'll thrive more too when you start clearing some of that stuff away. So even for rainfall, when it comes, that even though it acts as a mulch I guess it is...you're creating ways for the water to get down into the soil, to the roots...And it's harder to penetrate just laying on top. And eventually all those dead things...soak up the water too. And by the time it gets to the bottom of that you don't get much, just cool dampness.

In addition to the previous forms of tidying, which appeal to static caricatures of indigenous peoples as inherently conservationist or ecologically benign, several consultants reported more aggressive methods that shatter such essentialist notions. A Kaibab Paiute elder described one such approach: 
My uncle and them used to knock the cedar [juniper] trees down over here that weren't any good. They just didn't want them to grow too close to one another, like a whole big bunch all together. And so they used to knock those trees down....bulldozing them.

Despite the use of modern, even aggressive, technology, this method of tidying still shaped the land towards Nuwuvi aesthetics and perceptions of ecological and spiritual health and balance. Bloch (1995) described a similar account among the Zafimaniry of Madagascar, who clear-cut forests to fulfill a cultural value for expansive views and clarity. During another interview in Cedar City, Utah, a PITU tribal elder described the progression of land clearing methods used by her family. With a horse in the $19^{\text {th }}$ and early $20^{\text {th }}$ centuries and with automobiles as they became available, her relatives dragged logs, and later tire irons or metal pipes around in a spiral formation to clear out weedy shrubs and create open spaces around dwellings and ceremonial structures. Though this practice was clearly utilitarian in purpose and most likely decreased biodiversity in the area, many consultants did not appear to harbor misgivings about creating environmental perturbations for what were apparently conflicting goals. These and other practices, modified and adjusted over time to changing conditions and new technologies, offer testaments to the adaptive capacity of Nuwuvi ecological knowledge while revealing the challenging negotiations Nuwuvi resource stewards must make to respect and honor their cultural traditions while living in the modern world.

Nuwuvi extended the concept of landscape tidying to cleaning and maintaining the hydrological function of springs. Consultants cited multiple reasons for hydrological maintenance including preventing water contamination, improving access for humans and animals, increasing the volume of available water, and continuing Nuwuvi relationships 
with the land. Contaminated water supplies were detrimental for humans and animals and served as indicators of ecological imbalance. Many of these practices had been discontinued among contemporary Nuwuvi, however, the NKTA project and subsequent resource stewardship events aim to reintroduce some of these practices within the framework of collaborative stewardship in both the DNWR and the SMNRA (see Spoon et al. 2013). In the past, when water sources meant the difference between life and death in the arid desert terrain, Nuwuvi frequently walked the waterways and removed any dead animals fouling the water. Algae blooms were pushed to the side of the basin or scooped out to allow access to clean water. Sometimes roses (Rosa woodsii var. ultramontane (S. Watson) Jeps.), gooseberries and currants (Ribes spp. L.), and other plants with thorns or prickles were removed or cut back to allow easier access to the springs. This may have induced a secondary result of increased vigor and fruit production in these plant taxa (Anderson 2005:278). Silt and rocks occasionally fell into springs, impeding water flow or causing pools to become shallower while reducing accessible water volume. Consultants indicated that their ancestors regularly scooped out rocks and silt to ensure continued flow. A Las Vegas Paiute elder described this cleaning process:

They might have a big rain come down and the boulders would get down in that water. They automatically cleaned it out, because that's where they got their water.

And a Moapa Paiute elder continued:

They kind of clear around the springs just to make sure its flowing right, you know. Because we share it with the animals, the deer, the mountain lion... 
Prior to cleaning a spring, however, specific prayers and rituals were vital to transmit the practitioner's intent and to ensure that the next location in one's travels also had water available. Here a Kaibab Paiute elder explained:

Talking to the water, talking to the spring, talking to the minerals there, and talking to everything in the air, talking to the Creator asking the Creator to bless that spring so that it'll produce water again. And make an offering there.... and then clean that water out, get all that muck out of there....so that water will flow again and be clean and nice and the animals can drink from it.

Nuwuvi cautioned against aggressive spring management, however, because seriously altering the hydrology or offending a resident water spirit could make a spring reduce its flow or even disappear. For this reason major excavations and alterations of the stream course were generally avoided. ${ }^{23}$ Here, a Chemehuevi elder discussed the consequences of overly aggressive spring management:

The cattlemen....bring all their cattle in and then water them off the springs. And eventually they figure the springs aren't putting out enough water or not fast enough. So they want to help it along and they'll dynamite them. They dynamite where it's coming from to see if more water would come out. So consequently, when that happens, the spring goes dry [laughing]. And there are a lot of springs that were tampered with like that, that are dry today. There's nothing there.

A Kaibab Paiute elder reported a more recent experience he witnessed with the aggressive treatment of a nearby spring:

It started out good until the BIA [Bureau of Indian Affairs] official decided to increase the flow of water and dynamited it and it shut off! Lack of maintenance and relationship with springs can afflict similar tolls as another Kaibab Paiute elder described:

\footnotetext{
${ }^{23}$ Exceptions to this rule occurred along the Santa Clara River, Utah, and other locations, where ditches diverted stream courses to irrigate horticultural crops (Fowler 1995; Knack 2001; Von Till Warren 2007).
} 
They used to clean the springs out....so the water will keep flowing and so it doesn't get all filled up. And you know, you got to talk to that spring and give your offering there and take care of that water there....That's what they always said, you got to take care of the springs. If you don't do that they'll go away and that is true. Up here...there's a large spring that the family used there and they took care of it and the water flowed all the time. They were able to... fill the water troughs for their cattle from the springs. And it wasn't that big of a spring, but further up a little ways in the canyon there was another little spring there, and they took care of that, but they didn't take care of it as well as the other spring and eventually it got covered over. And so that spring was lost.

Methods of spiritual balancing work in tandem with and guided physical practices.

Consultants spoke of nurturing relationships with springs as with sentient creatures with feelings. A Pahrump Paiute elder explained this protocol:

Springs are always respected. So it's like with the noise and stuff. You're not supposed to be noisy around those. You're not supposed to be disrespectful. You're not supposed to throw things at it...It has feelings. You have to approach it very quietly and you have to almost coddle it. And you're trying to awaken it, let it know it's you that's there.

Spring management is indeed multifaceted and required various physical and spiritual practices to ensure the continued presence and health of one of the most vital desert

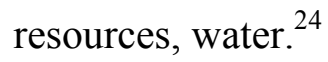

Fire was yet another disturbance-based tool Nuwuvi used in to achieve ecological health in piñon-juniper woodlands. Nuwuvi likely learned of the regenerative qualities of fire from protracted observation of the ecological recovery following lighting-ignited wildfires, a common occurrence throughout the Great Basin. As previously alluded to, Nuwuvi cleared downed material out of piñon groves, burning it in piles or using it in cooking fires. Prior to the interruption of Nuwuvi fire management practices and the advent of fire suppression policies, the collective effect of pile burning, prescribed patch

\footnotetext{
${ }^{24}$ See Fowler (2002) and Wendel (2014) for further information about Nuwuvi relationships with springs.
} 
burning, and uncontrolled lightning-ignited fires very likely caused a net reduction in landscape flammability and incidence of catastrophic burns. By removing lower tree limbs during the tidying process and burning them in controlled contexts, Nuwuvi likely created fuel breaks, preventing beneficial, low-intensity ground fires from transforming into destructive crown fires. Indeed, Nuwuvi learning through crises, long-term ecological observation, and personal experiences, had instilled a cautious use of fire in my consultants. Here a Chemehuevi elder described his personal experience with catastrophic wildfire:

I've seen fires in the mountains up there- that scared me, just looking at the fire. The mountain was burning.... When I came back...over the road... everything was black. That was scary, I've never seen something like that!

Nuwuvi also described recent intentional landscape-level and patch-level burns they had witnessed in their own lifetimes. Many of these fires served the purpose of stimulating the germination of tobacco and other seed crops, or vigorous regrowth of a particular stand of plants. As one Kaibab Paiute elder related:

They used to have gardens there. The men used to ... do their traditional burns [when]...the ground [was] damp. And that way they controlled it. And then there was man on each side like that .... [and if it got out of control] they'd just move it. They knew how much fire to make.

Women typically managed controlled burns in willow thickets, using fire as a tool to clear out old growth, open up access to the patch, and stimulate the production of fresh, un-branched whips that are harvested for basketry material. One consultant's family had matrilineally managed a willow copse for multiple generations. These burns occurred during damp conditions under strict management regimes to ensure the flames didn't get 
out of hand. Participants would sing songs of celebration to the land to communicate their intent of ecological renewal and spiritual balancing.

Most consultants did not believe that fire was used as a management tool on a large landscape-level scale, although one Kaibab elder mentioned large traditional burns from early historic times used to control bark beetle populations and to stimulate new plant growth. Stewart (2002) discussed previous ethnographic accounts from Drucker (1941), Steward (1941), and Stewart (1942), mentioning Nuwuvi use of fire during antelope, rabbit, and deer hunting drives, which would have occurred at a relatively large scale. Fowler (1995:109, citing Kelly 1932-1934:LVI:114, 121; M:59) also noted the use of brush fires to drive jackrabbits and cottontails, while desert woodrat (Neotoma lepida Taylor) nests were ignited as a hunting practice. Other studies substantiate that indigenous anthropogenic fire regimes, including small-scale patch burning, increase the diversity of habitats and percent cover of ecotones, while maximizing un-even aged tree stands (Anderson 2005; Boyd 1999; Turner et al. 2003). Rotating patch burning over time and space creates a mosaic of species, age classes, and habitats. Indeed, indigenous people have not only been drawn to the increased productivity and species richness exhibited by ecological edges, but have also intentional maintained and produced them (Turner et al. 2003). Nuwuvi burning techniques have the power to stimulate germination of the long-dormant native plant seed bank while curbing the spread of fire-intolerant invasive species. Indeed, a shift from the long-term Nuwuvi patch burning and tidying practices reported in the literature and among my consultants to an era of fire suppression, has led to long intervals between fires, resulting in fuel accumulation, 
canopy closure, seed bank depletion, and lowered resilience of piñon-juniper woodlands to fire (Allen et al. 2008; Miller et al. 2008)

In sum, these various methods of tidying the land, including duff removal, spring maintenance, and patch burning, introduced disturbance to serve multiple intentional and potentially unintentional functions. Tidying increased access for efficient pine nut picking and general mobility through an area, ensured consistent spring flow, reduced landscape flammability, stimulated seed germination (discussed below), controlled insect epidemics, and fostered Nuwuvi relationships with the land, fulfilling their charge as caretakers.

Plants on the Move: Anthropogenic Assistance of Plant Propagules

Plants evolved to contain multiple mechanisms for expanding populations, dispersing genetic material, and allowing species continuation. Nuwuvi variously aided many culturally significant plants in this process by transplanting, broadcast seeding, stimulating germination, and planting. As throughout this manuscript, I focus here on species occurring in piñon-juniper woodlands, although Nuwuvi likely aided plant dispersal in other ecosystems in addition to riparian and spring-fed horticultural gardens (Fowler 1995; Knack 2001).

Nuwuvi consultants recalled their elders describing the former practice of sowing the disturbance-linked annual plant coyote tobacco (Nicotiana attenuata Torr. Ex. Watson) in open disturbed sites, at times utilizing patch burning to stimulate its 
germination. ${ }^{25}$ A Kaibab Paiute elder described the origin of a patch of coyote tobacco in her garden that consistently reseeded every year:

[I] took a plant that was ready to drop its seeds....[and] I took the plant,...cut it down...[and] brought it home. And I was drying the leaves out. And then a whole bunch of the seeds came out and I didn't want to just throw them away so I threw them in my garden and they came up.

Blazing star (Mentzelia spp. L.) is another plant explicitly linked to disturbance regimes caused by fire and other pronounced forms of soil disturbance. In the past, patch burning prepared areas for such annual and fire-adapted plants, either activating an already present seed bank or clearing and fertilizing the ground for broadcast seeding. For certain seed and nut crops such as pine nuts, Great Basin wild rye (Leymus cinereus (Scribn. \& Merr.) Á. Löve), and Indian rice grass (Achnatherum hymenoides (Roem. and Schult.) Barkworth), seeds were seasonally scattered and dispersed somewhat unintentionally as a byproduct of harvesting. Many of these seeds and nuts fell into inadvertently prepared seedbeds of soil disturbed through intentional tidying and may have been unintentionally planted by the repeated pressure of foot traffic. Several consultants remarked, however, that harvesters realized the importance of leaving sufficient seed behind to ensure continued germination and establishment of new plants, and the literature suggests that Nuwuvi intentionally dispersed and increased the range of piñon pines (Waring 2011:98; Zouhar 2001).

\footnotetext{
${ }^{25}$ Interestingly, Baldwin et al. 1994 found that germination of $N$. attenuata responds to chemical cues in wood smoke but not wood ash. This means that wood ash alone does not stimulate these responses and that fire or smoke extract are required to trigger these responses. These findings support Nuwuvi patch burning practices as an effect management strategy for this plant.
} 
Underground portions of plants, such as roots, bulbs, tubers, and corms, offered Nuwuvi another way to move plants across the landscape. Nuwuvi harvested these vegetative storage organs with digging sticks and, more recently, with shovels. Elders spoke of practices that limited soil disturbance and erosion by targeting compromised plants growing in eroded washes or hillsides. They viewed such harvesting as a process of selective weeding or thinning that worked with the disturbance already in place and improved the overall health and vigor of the population. Nuwuvi sought the Utah agave plant (Agave utahensis Engelm.) for its succulent hearts, while the root was left in place to allow the plant to continue growth and reproduction. Rotational harvesting systems allowed at least four or five years for individual plants to regenerate. Utah agaves produce genetically-identical clonal pups (ramets) on the outside of the parent plant (Gentry 2004:257), which Nuwuvi left to mature after harvesting the central "mother" plant. This practice ensured continued future production while simultaneously freeing up space and resources for the remaining ramets and potentially increasing their survivorship. Two varieties of Utah agave (A. utahensis var. nevadensis and A. utahensis var. eborispina) distributed in southern Nevada are special conservation status plants (see Appendix J) and may have benefited from these Nuwuvi harvesting techniques.

Digging up and moving individual plants or small vegetative portions to different locations across the landscape, termed transplanting (see Appendix $\mathrm{H}$ for more information about select transplanted taxa), aided their propagation and spread and stimulated growth in both the mother plant and the propagule. Moving species across the landscape likely changed ecosystem dynamics, and may have increased local biodiversity while altering ecological processes to varying degrees. Transplanting various species of 
edible, medicinal, and utilitarian plants across the landscape may have effectively secured diverse resources at known points, stored in individuals' minds as cognitive landscape maps. Such resource sites were linked by trail systems and included springs as other important nodes.

Several consultants cited instances where relatives had transplanted wild plants into their home gardens, such as this account from a PITU elder:

Ethnographer: Are there any other plants she [your mother] dug up and moved around?

Consultant: Oh what do you call that? They used to make pie ... currants, is it currants? It's in the mountain. It's a big old ... it's like a big bush and it stands up really high too, but it has little berries about that big on it.

Ethnographer: Oh currants, yeah, like gooseberry or currant?

Consultant: Yeah, they had that for making pie and stuff.

Ethnographer: She moved a bush somewhere else?

Consultant: Yeah, to the house....Mine is...on the corner of the house.

Although Nuwuvi managed many of these plants with fire in non-domestic locations, they occasionally pruned back those growing near homes and fertilized them with wood ashes to simulate the stimulating, cleansing, and nutritive effects of fire. Plants mentioned in this context included brambles, shrubs, and small trees, such as mountain mahogany (Cercocarpus ledifolius S. Watson), currants/gooseberries, Woods' rose, skunkbush sumac (Rhus trilobata Nutt.), and willow. Consultants had transplanted many of these plants to provide easy access to their seasonal fruits, beauty and fragrance, or basketry materials. Willow responds especially well to transplanting because of a rooting hormone it manufactures, easily re-sprouting from small sections of stem. Consultants suggested that several currently utilized willow patches might have been created or expanded this way. 
Figure 4.3 Vegetative Phenophase of Water Cress (Nasturtium officinale) in Slack Water of Stream, Beatty, Nevada 2011 (Image: B. J. Lefler)

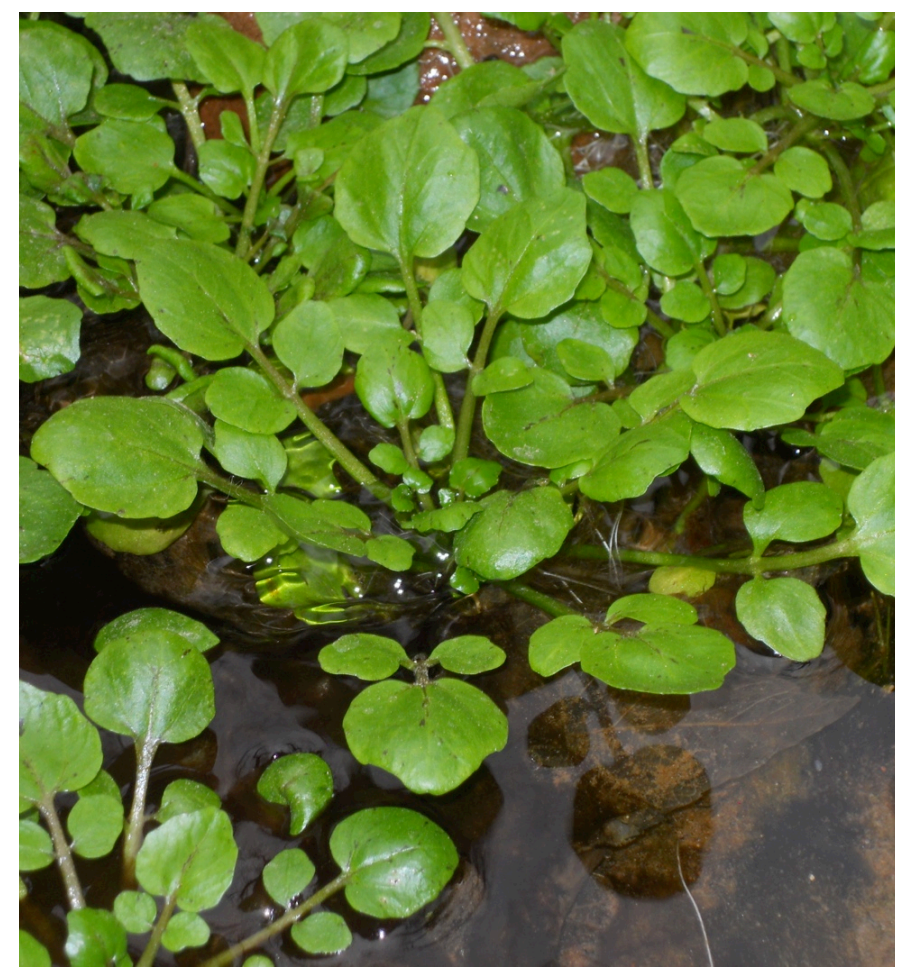

In addition to the aforementioned terrestrial species, Nuwuvi transplanted at least one aquatic species in piñon-juniper woodlands. Watercress (Nasturtium officinale W.T. Aiton), though of Eurasian and African origin (Howard and Lyon 1952), has been present in Great Basin waterways for multiple generations according to Nuwuvi accounts, and was readily incorporated into their foodways. ${ }^{26}$ Many Nuwuvi consider it to be a heritage food. Nuwuvi enjoy this spicy green fresh in salad or cooked it as a potherb to subdue its peppery flavor. Several consultants related stories from their grandparents describing how they gathered and transported clumps of watercress with well-established adventitious root systems in buckets to other aquatic environments, such as springs or the

\footnotetext{
${ }^{26}$ Watercress was noted in New England as early as 1620 and had reached the Pacific coast by the close of the $19^{\text {th }}$ century (Les and Mehrhoff 1999).
} 
slack water of a river margin. To prevent desiccation and wilting during transport and to increase the likelihood of survival, transplanting occurred under cool conditions, either on an overcast day or in the morning or evening. A Chemehuevi elder (CRIT) described the process:

They used it with their food,....So lots of them would pick it and carry it off to their own water supply, stream or whatever, and plant it there. And...it would grow there.

The establishment of watercress populations correlates with stream disturbance (WIDNR 2009), and once established, creates the potential for the alteration of stream flow and other ecological change (Lockwood et al. 2007). Watercress generally poses little threat to native plant communities, however (WIDNR 2009).

Nuwuvi assisted plant dispersal in piñon-juniper in multiple ways, moving roots and clonal pups, seeds, stems, and individual plants in both terrestrial and aquatic environments. Collectively, these various Nuwuvi practices effectively altered biotic communities by introducing disturbance, stimulating vegetative growth, thinning populations, expanding species' ranges, and introducing new species into ecological systems.

\section{Conclusion}

In this chapter I argued that Nuwuvi management practices - marked by low to intermediate levels of spatially and temporally limited levels of disturbance- operate within a non-equilibrium ecology paradigm and are tempered by resource and habitat taboos (see Chapter 6). These disturbance-based management practices include selective harvesting of plant material, pruning, litter removal, patch burning, hydrological 
maintenance, transplanting, and associated spiritual balancing that work in concert with these physical practices. The result of these cumulative practices in piñon-juniper woodlands over the course of innumerable Nuwuvi generations was a cultural landscape, managed at multiple scales. This cultural landscape persists to some degree despite marked environmental changes induced since Euro-American settlement and a reported reduction in Nuwuvi stewardship. Indeed, consultants viewed many "wild" patches of culturally significant plants as the artifacts and signatures of their ancestors and a constant reminder of their continued presence. Despite the continuation of these anthropogenic forests, some even bearing the cultural modifications of their forbears, a reduction in Nuwuvi management over the last two and a half centuries has resulted in an overgrown landscape in need of attention and care.

In the chapters that follow, I discuss two case studies, considering NEK at multiple spatial scales. I begin in Chapter 5 at the individual species level, considering the piñon pine — one of the most tended and significant of all Nuwuvi plants — as a cultural keystone species. I follow in Chapter 6 with a discussion of resource and habitat taboos regulating human-environment interactions variously at the species, population, habitat, and landscape scale. I utilize these case studies to operationalize NEK, rendering it conducive to collaborative stewardship initiatives. 


\section{Chapter 5 \\ Nuwuvi Cultural Keystone Species: The Case for the Great Basin Piñon Pines}

They wouldn't break the [piñon pine] limbs like they do nowadays... where they cut the trees down to get pine nuts and they break the limbs off to get the pine nuts. That was against the rules. Because the only limbs they could use are the ones that was already dried up and everything.

- Shivwits Paiute (PITU) Elder

\section{Introduction}

The Great Basin piñon pines (Pinus monophylla and P. edulis) are a cornerstone of Nuwuvi culture. Despite two and a half centuries of radical lifestyle changes, they continue to serve as a critical nexus for the transmission of Nuwuvi didactic cultural stories and ecological knowledge of piñon-juniper woodlands. Drawing from my research of NEK of piñon-juniper woodlands as a case study, I suggest the Great Basin piñon pines as Nuwuvi cultural keystone species (CKS) — particularly charismatic species that reflect place-based identity. I argue this point by providing evidence of the piñon pine's role and significance among Nuwuvi, which I evaluate against criteria developed by Cristancho and Vining (2004) and Garibaldi and Turner (2004). These include number of uses, role in story, use in ritual, and persistent importance despite reported trends in the decline of certain forms of ecological knowledge and practice. I close my discussion by suggesting the utility of the CKS concept in the context of collaborative stewardship and cultural revitalization projects in piñon-juniper ecosystems. 


\section{From Ecological to Cultural Keystone Species - Conceptual Development}

The CKS concept developed as a metaphorical extension of the ecological keystone species, which arose out of observations that certain species play critical ecological roles necessary for the continued resilience and persistence of biological diversity, and higher levels of complexity in a given ecosystem (Paine 1969). These ecological keystone species play critical roles at various trophic levels, and consist of predators, prey, habitat modifiers, and even abiotic ecosystem elements (Bond 1994; Daily et at. 1993; Knapp et al. 1999; Miller et al. 2000; Willson and Halupka 1995). Some scholars distinguish foundational species - abundant and dominant species that provide key ecological structure, function, and stability for other community members (Garibaldi and Turner 2004), from keystone species - which exhibit a disproportionately large impact relative to their abundance (Power et al. 1996). By this distinction, piñon pines constitute foundational species (McLain and Frazier 2008; Sthultz 2007) along with their co-dominant juniper; they appear in such abundance and provide such a vital role that the ecosystem itself - piñon-juniper woodland—-bears their names.

The metaphorical extension of this biological concept to the cultural realm can be traced back to multiple sources. Turner (1988) noted that many ethnobotanical studies over the last century have focused on particularly salient plant species and proposed an index of cultural significance (ICS) as a way to meaningfully evaluate and compare such species. Stoffle et al. (1999) later used this index to specifically assess the cultural significance of Nuwuvi plant taxa. Although this assessment was not limited to plants occurring in piñon-juniper woodlands, the single-leaf piñon ranked highly among important Nuwuvi cultural plants found in all utilized ecosystems (1999:422). The first 
explicit use of the term cultural keystone species comes from Nabhan and Carr's (1994) discussion of ironwood (Olneya tesota A. Gray) as both an ecological and cultural keystone species of the Sonoran Desert. Theoretical development of the concept was later to arise, following Ellen's (2001; 2006) discussion of ethnobiological keystone species, Cristancho (2001) and Cristancho and Vining's (2004) culturally defined keystone species, and Garibaldi and Turner's (2004) cultural keystone species. I employ Garibaldi and Turner's (2004:4) definition of CKS as "culturally salient species that shape in a major way the cultural identity of a people, as reflected in the fundamental roles these species have in diet, materials, medicine, and/or spiritual practices."

Some authors caution against the overenthusiastic application of the CKS concept and fail to find any difference between CKS and those known to be culturally salient to a culture group (Davic 2004; Platten and Henfrey 2009). Certain restoration ecologists have expressed concerns that exotic and invasive CKS may hinder restoration and conservation efforts (Nuñez and Simberloff 2005). Other researchers found the CKS concept useful, but failed to identify a single species that would drastically alter local cultures if it disappeared (The Snow Leopard Conservancy 2007). Some critics argue that the CKS concept assumes subsistence-based, bounded economic systems (Platten and Henfrey 2009:495), although proponents suggest the possibility of identifying CKS within agricultural and industrial societies (Cristancho and Vining 2004:162). Despite these identified stumbling blocks, the CKS concept holds promise as a vehicle for interdisciplinary discussion and engagement of conservation issues (Platten and Henfrey 2009:498), by serving as a focal point amidst the complex issues of contemporary land 
management to allow meaningful collaboration between indigenous land stewards and federal agencies.

\section{Evaluating Cultural Keystone Species}

In the following sections I evaluate the Great Basin piñon pines as Nuwuvi CKS, engaging NEK at the species scale to operationalize its use in the context of collaborative resource stewardship. Piñon pines are represented by two species in the Nuwuvi ancestral territory. In this analysis, I consider both the single-leaf piñon pine and the Colorado piñon pine collectively, because of their similarities in ecology, use, cultural significance, and because of difficulties in differentiating between individual species in consultant responses. Frequently plants and plant parts were simply referenced as "piñons" or "pine nuts" during interviews, with no reference to a specific species. Although in some cases I was able to ascertain the specific species referent based on geographic distribution and other contextual clues, I found it more appropriate, accurate, and beneficial to perform my analysis at the genus rather than the species level. It should also be noted that only single-leaf piñon occurs within the SMNRA and the DNWR.

To assess whether a given species qualifies as a cultural keystone species, Garibaldi and Turner (2004) suggest analyzing a species according to several criteria: (1) frequency and quantity used; (2) number and variety of uses; (3) presence of specialized vocabulary related to the species; (4) role in stories, songs and similar cultural elements; (5) resilience of cultural importance in spite of culture change; (6) uniqueness and difficulty of finding an analog to replace its cultural function; (7) and its use as a trade item. Cristancho and Vining (2004) suggest a similar model to assess prospective CKS, 
evaluating a species': (1) role in cultural stories; (2) role in knowledge transmission; (3) role in ritual; (4) utilitarian function; (5) spiritual significance; (6) distribution with the culture group's ancestral territory; (7) and stated significance by members of the culture group themselves. In the following section, I synthesize both of these frameworks to evaluate the Great Basin piñon pines as Nuwuvi CKS. I draw upon data collected from my ethnoecological interviews with Nuwuvi expert knowledge holders and from other ethnographic scholarship on Nuwuvi ecological knowledge and management practices.

\section{A Grocery Store and Pharmacy: One Tree, Many Uses}

The utilitarian function of piñon pines is unquestionable. Pine nuts prehistorically served as the most important plant food and continue to play significant cultural and culinary roles for contemporary Nuwuvi. In addition to food, living trees provided yearround shade, while dead wood served as fuel wood and building materials (Rhode 2002). Pine pitch also had many uses, serving as an adhesive, gum, waterproofing sealant, and as a purifying smudge (Spoon et al. 2013).

In prehistoric times and at the time of study Nuwuvi harvested pine nuts in much larger quantities relative to other botanical resources in the region, with the notable exception of mesquite pods, which some consultants also still harvested in large quantities at the time of research. Pine nut harvests occurred generally in late September through October, the timing varying according to latitude, elevation, species, annual fluctuations, and other environmental factors effecting each grove location. Some families preferred to gather piñon cones when they were immature and green while others waited until the cones matured. Green cone harvests occurred in the months preceding the 
brown cone harvest and necessitated cooking the cones to remove pitch, concurrently steaming the pine nuts and opening the dehiscent scales. As with virtually every plant gathering practice, the scale of pine nut harvesting has been greatly reduced since precontact times, although some consultants consistently gather pine nuts every year without fail. Numic peoples previously maintained networks of spatially distributed pine nut caches across portions of the Great Basin (Eerkens et al. 2002-2004; Holt 2006:31; Jackson 1996). Consultants reported gathering pine nuts in small quantities in recent times that serve as seasonal treats rather than a dietary staple. Despite the obvious decline in the quantity of pine nuts gathered since pre-contact times, pine nuts remain one of the most gathered wild foods in both quantity and frequency among contemporary Nuwuvi.

Piñon on the Move: Biological Distribution, Sharing, and Trading of an Edible Nut In prehistoric and early historic times, Nuwuvi traded pine nuts and other various goods via a network of trail systems linking the Great Basin to coastal California, the Mojave Desert, and the Southwest (Fowler 2004; Laird 1976; Musser-Lopez and Miller 2010). Certain difficulties constrain interpretations of trade items in archaeological deposits, however, because not all non-local materials are necessarily sourced via trade. Individuals may have also obtained these items through direct access or from scavenging (Heizer 1944; Hughes and Bennyhoff 1987:238). Further, most trade commodities from prehistory up until the time of European contact were perishable; it was only later that trade shifted to non-perishable items (Hughes and Bennyhoff 1987:240). Because of the persistence of non-perishables in archaeological sites and a relative dearth of perishable remains, understandings of pre-historic trade of perishable items remain tentative. Pine 
nuts were recorded as a historic trade item (Hughes and Bennyhoff 1987:240-241), although their mention is relatively scant. This may be because of their relatively ubiquitous distribution across many of the Great Basin ranges and surrounding regions, enabling most groups to access pine nuts directly rather than necessitating trade.

Sharing was another way in which Nuwuvi obtained pine nuts. This gesture was often eventually followed by customary reciprocation. In addition to the pine nuts themselves, sharing also entailed granting access to family-tended piñon groves when neighboring groups experienced lean years. Most of the Nuwuvi aboriginal territory lies within the natural range of piñon pines, although their distribution diminishes in the southern, Chemehuevi-occupied areas along the Colorado River in California and Arizona. It is possible that the value of pine nuts as a trade good may have increased in these areas outside of their natural biological range. While many Chemehuevi consultants reported less interaction with piñon-juniper woodlands than more northerly Nuwuvi, elders still held vivid childhood memories of pine nut picking and of pine nuts gifted by their northerly relatives. A Chemehuevi elder (CRIT) recalled such sharing, while noting its decline:

Well, every year we used to have these people come down from Utah.... They called him Joe...[and he] used to bring down a whole gunnysack full of piñons, and boy we ate piñons for a while [laughing]. There was piñons all over the place and he used to do that. They did that every year. He'd come down and stay with us about a month and then go back. It's not like that no more, the Indians really don't visit one another or do this or do that... we are almost like loners.

Many elders joyfully recalled similar stories of sharing and socialization connected to pine nuts, although all expressed a detectable hint of sadness and longing as well. Such sentiments speak to both the timeliness, urgency, and need to develop joint collaborative 
resource stewardship and cultural revitalization events while the waning population of contemporary expert knowledge holders is still available to share their ecological knowledge of this culturally and ecologically important ecosystem to Nuwuvi youth and agency partners.

In the archaeological record, pine nuts appear less important compared to other, mostly nonperishable trade items. Difficulties with linking any remains with trade routes further complicate reconstructions of a possible prehistoric pine nut trade (Hughes and Bennyhoff 1987). Nonetheless, the appearance of pine nuts as a trade item in the historic record and the reported practice of sharing pine nuts and access to productive piñon groves in living memory, substantiate the importance of piñon pines to Nuwuvi.

\section{$\underline{\text { Role in Ritual, Story, and Song }}$}

Nuwuvi consultants spoke of a world not strictly dichotomized into the sacred and the secular, but one in which all things were sacrosanct to some degree. As part of the sentient, living landscape, plants had individual spirits, as this Kaibab elder related:

And if you're very fortunate, you can see the life of that...tree. You can see it shake itself. It's very awesome to see that and not very many people get to see that....And it just makes you think, geez, how can people say... that trees and plants aren't...living beings or they don't have spirits in them, 'cause they do and they show you sometimes.

Piñon pines were seen in such a way, with personal connections developing in some cases among certain trees or groves and individual Nuwuvi over years of sustained relationships and careful tending. A taboo against harvesting green wood from piñon pines further substantiates their spiritual significance (see Chapter 6). Consultants also noted the key role piñon pine pitch had served as the traditional Nuwuvi smudge prior to 
the introduction of sagebrush and white sage, playing an important function in the ritual purification of both people and spaces. Among some Numic groups, round dances oriented and circled around piñon pines (Hultkranz 1986:634). Although multiple plants served a variety of spiritual and ritual functions for Nuwuvi, the piñon pine was undeniably one such plant, supporting its role as a Nuwuvi CKS.

Pine nuts appear in several Nuwuvi stories including several explanatory accounts for the origin of pine nuts in the region. Here, a Chemehuevi elder from CRIT recounted a tale that explains why pine nuts are different sizes in Arizona and Nevada:

[Coyote] had the responsibility to be with the Wolf and go back in there and plant the pine nuts in this area. But he went and got mischievouschasing girls. And he told Wolf, you know, that I'm going to go over here for a while, I'll catch up with you later. And Wolf went ahead and he planted all the pine nuts in the Nevada area and Coyote got sidetracked. So when he found out that all the other plants had been planted, instead of going where he was supposed to go he planted them here in Arizona. So they say that's why the pine nut is small here in Arizona, 'cause the Creator punished Coyote for being mischievous.

Interestingly, this legend-encoded differentiation between big Nevada pine nuts and small Arizona pine nuts matches the east-west species transition from the smaller pine nuts of the Colorado piñon to the larger pine nut-bearing single-leaf piñon. Thus, cultural stories such as this act as mnemonic repositories of LEK, encoding spatial and ecological information and moral lessons in an entertaining form. Several consultants also confirmed the previous existence of certain dances, songs, and prayers associated with pine nut gathering, although no one was able to demonstrate or describe them at the time of study. Despite the reported reduction in this type of knowledge, my data revealed no other piñon-juniper woodland botanical taxa with a greater appearance in songs or stories. 
Figure 5.1 Pine Nuts (Pinus monophylla) in Cone, Sheep Range, Nevada 2012 (Image: B. J. Lefler)

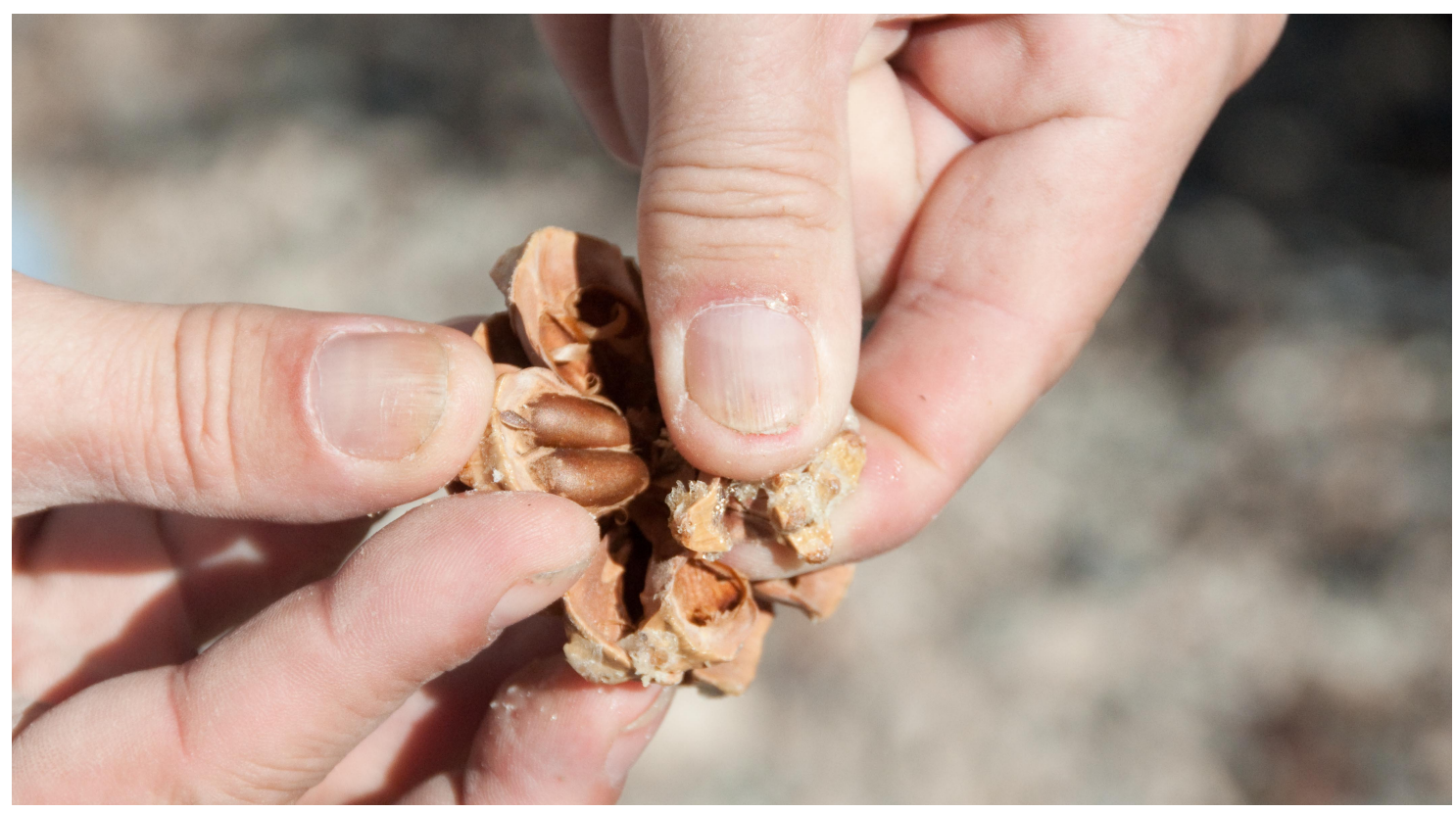

\section{Continued Use, Continued Importance}

Pine nut harvests also provide some of the most intensive contexts for knowledge transmission on a variety of topics for contemporary Nuwuvi. During these harvests, elders relate stories to younger generations, including legends and personal histories, while providing hands-on instruction concerning spiritual practices, offerings, resource management, ecological awareness, and harvesting. Despite larger trends among Nuwuvi towards reduced interaction and botanical knowledge, pine nut harvesting and linked intergenerational knowledge transmission persisted at the time of study. Indian rice grass was also extremely significant to Nuwuvi in the prehistoric and early historic periods. According to Steward (1938:104), the tiny seeds produced by this grass were second only to pine nuts as a dietary staple for Nuwuvi. And with a ripening period in April or May (Knack 2001:17), the Indian rice grass harvest was conveniently offset from the fall 
piñon harvest. Despite its previous importance, my research revealed scant ecological knowledge and little to no use or management of this species among my consultants and their families. Widespread destruction of Nuwuvi edible grass fields by livestock from late $19^{\text {th }}$ century onwards (Knack 2001:90), forced sedentism, and broader dietary shifts (see Eagan 2013) are among the explanatory factors for its waning cultural significance. My sample reported gathering only a handful of botanical species from piñonjuniper woodlands. It is important to note that certain plant specialists gathered a wider variety of plants than other Nuwuvi, and that some Nuwuvi gathered no plants at all. Among these frequently gathered species and plant products were pine nuts, willows for basketry and cradleboards, Indian tea as a beverage, and coyote tobacco for ritual use. Mesquite pods and Indian spinach (Stanleya pinnata (Pursh) Britton)—an important edible spring green, were also mentioned as important and frequently harvested plants resources from neighboring plant communities. ${ }^{27}$ Pine nuts were among the most frequently harvested and discussed of these plant foods.

Consultants from every Nuwuvi community visited noted the continued existence of community and family networks used to communicate the timing and locations of productive piñon groves each year. These predominantly verbal exchanges happened variously through chance encounters on the street, at community events and meetings, and over the telephone. A Kaibab Paiute elder explained these networks:

Ethnographer: Is there a communication network? Do people call each other on the phone, or see each other on the street and communicate about the location of pine nuts?

Consultant: Well you know what, I think there is something like that that goes on. 'Cause I know a few times when I've been

\footnotetext{
27 "Indian spinach" was the preferred common name of this plant among most of my consultants.
} 
out, I've run into one of my cousins from Shivwits [Utah] and he'd tell me, you know, I was out there picking pine nuts out there on Indian Peaks - a lot of pine nuts out there. So I think people do tell each other that....I think some of them still do tell those who they know are interested, who still like to go pick pine nuts.

A testament to the persistent significance of the Nuwuvi oral tradition, such information is only infrequently circulated in emails, newsletters, and other written media.

Family networks and childhood connections to particular pine nut groves also influenced use and discussions of pine nuts. Proximity of a given Nuwuvi reservation, community, or dwelling to a pine nut grove also appeared to correlate with higher levels of continued practice. Rather predictably, Nuwuvi living nearer to the Spring Mountains and those who formerly lived near Las Vegas had both childhood memories and strong continued practices of picking pine nuts in the Spring Mountains and surrounding areas. This group primarily included individuals from the Pahrump Paiute, Las Vegas Paiute, and Moapa Paiute Nations, but also individuals residing on reservations further afield in surrounding states. Chemehuevi members of the Chemehuevi Tribe and Colorado River Indian Tribes (CRIT) reported low levels of discussion about and collection of pine nuts. Situated south of the other Nuwuvi communities, these Chemehuevi groups inhabit the drier and hotter Mojave Desert and are consequently further away from productive piñon groves. The adjacent Providence Mountains were a notable exception, visited by two consultants and their families in their youth for pine nut procurement. Collectively, these active communication networks and ongoing pine nut harvests testify to the continued significance of pine nuts, especially to northern Nuwuvi groups. 


\section{Table 4.1: Evaluation of the Great Basin Piñon Pines as Cultural Keystone Species ${ }^{1}$}

\section{INDICATORS}

DATA $^{2}$

\begin{tabular}{|c|c|}
\hline $\begin{array}{l}\text { Linked to stories, ceremonies, symbols, } \\
\text { and songs? }\end{array}$ & $\begin{array}{ll}\text { - } & \text { Story of pine nuts arriving in the area } \\
\text { - } & \text { Previous existence of pine nut songs and ceremonies } \\
\text { - } & \text { Round dances oriented around piñon pines }\end{array}$ \\
\hline $\begin{array}{l}\text { Plays critical role in knowledge } \\
\text { transmission? }\end{array}$ & $\begin{array}{l}\text { - Pine nut harvesting events lasting days to weeks offer } \\
\text { opportunities for sharing stories and hands-on learning }\end{array}$ \\
\hline Species shared and traded? & $\begin{array}{l}\text { - } \quad \text { Some ethnographic evidence of pine nut trade } \\
\text { Access to productive groves was granted to neighboring } \\
\text { groups } \\
\text { - Pine nuts were shared within communities and families }\end{array}$ \\
\hline Has utilitarian function? & $\begin{array}{l}\text { - } \quad \text { Pine nuts: food } \\
\text { - } \quad \text { Pine pitch: adhesive, sealant, gum, ceremony } \\
\text { - } \quad \text { Dead branches: fuel, shelter }\end{array}$ \\
\hline Used frequently? & $\begin{array}{l}\text { - } \quad \text { Harvested in large quantities } \\
\text { - } \quad \text { Pine nut harvesting occurred over weekends or full }\end{array}$ \\
\hline Used in large quantities? & $\begin{array}{l}\text { - } \quad \text { Large storage caches known from archaeological record } \\
\text { - } \quad \text { Seasonal use of ecosystem (fall) occurring annually }\end{array}$ \\
\hline Has spiritual significance? & $\begin{array}{l}\text { - } \quad \text { All plants hold spiritual significance } \\
\text { - } \quad \text { Pine pitch smudge used for purification and ceremony }\end{array}$ \\
\hline Plays important role in rituals? & $\begin{array}{l}\text { - Taboo against live green wood collection } \\
\text { - Personal relationships with individual trees and groves }\end{array}$ \\
\hline Distribution lies in traditional territory? & $\begin{array}{l}\text { - All seven participant Nations are within a 1-2 hour } \\
\text { drive of productive piñon groves except for the } \\
\text { Chemehuevi Indian Tribe and CRIT }\end{array}$ \\
\hline $\begin{array}{l}\text { Considered important from an emic } \\
\text { perspective? }\end{array}$ & $\begin{array}{l}\text { - } \quad \text { Explained as one of most important food crops } \\
\text { Suggested focal species for collaborative stewardship } \\
\text { projects }\end{array}$ \\
\hline $\begin{array}{l}\text { Uniqueness/difficulty in replacing } \\
\text { species with other to fulfill same } \\
\text { function. }\end{array}$ & $\begin{array}{l}\text { - Only other potential analogs are mesquite and Indian } \\
\text { rice grass } \\
\text { - No other seed crop still gathered to the same extent } \\
\text { - No other species is the focus of such a large social } \\
\text { gathering }\end{array}$ \\
\hline $\begin{array}{l}\text { Still discussed and used in spite of } \\
\text { culture change? }\end{array}$ & $\begin{array}{l}\text { - Still important, especially compared to many other } \\
\text { botanical species } \\
\text { Pine nut ripeness discussed through well-developed, yet } \\
\text { informal communication networks }\end{array}$ \\
\hline
\end{tabular}

${ }^{1}$ Table adapted from criteria developed by Cristancho and Vining (2004); Garibaldi and Turner (2004)

${ }^{2}$ Data drawn from primary data, Heizer (1944), Hughes and Bennyhoff (1987), and Spoon et al. (2013) 


\section{Evaluation Results}

Upon close inspection, my evaluation revealed a variety of roles the Great Basin piñon pines played in Nuwuvi culture, both in the past and at the time of study. Piñons offer a variety of useful products for both utilitarian and spiritual functions, including what some consider to be the original Nuwuvi smudge, providing a purifying and protective smoke for ritual and ceremony. Piñon pines appear in Nuwuvi stories and dances, including a story detailing their arrival in the Great Basin. Pine nuts were previously traded and continue to be gathered, shared, and talked about despite larger trends in decreasing Nuwuvi consumption of heritage foods. This uniquely positioned species is irreplaceable in Nuwuvi culture and continues to serve a variety of vital roles associated with the perpetuation of NEK.

\section{Conclusion - Utility of the Cultural Keystone Species Concept}

In this chapter I argue the centrality of the Great Basin piñon pines to Nuwuvi culture and human-environment interactions by suggesting their role as cultural keystone species. While knowledge-holders explained that all biota, landscape features, elements, and spiritual beings are vital to the health the environment, my research substantiated the chief role of piñon pines, which I evaluated using two frameworks. I contend that the CKS concept holds promise as a vehicle for interdisciplinary discussion and engagement of conservation issues (Platten and Henfrey 2009:498) while forwarding meaningful collaboration between indigenous land stewards and federal agency land managers by serving as a focal point amidst the complex issues of contemporary land management. I suggest the identification of CKS as an important goal of ethnography, consultation, and 
collaboration on indigenous ancestral lands now managed by federal entities. The mismanagement or extirpation of these species would prove detrimental to the continued persistence of certain aspects of ecological knowledge, practice, identity, and culture. Indeed, CKS may even have heightened levels of cultural significance as symbols of indigenous identity and the historic experience of land dispossession and social marginalization (Spicer 1971). In cases where indigenous stewards continue to actively manage lands for ecological health and biodiversity, the loss of CKS and linked indigenous management regimes could result in further ecological unraveling and loss of resilience to environmental perturbations (Cristancho and Vining 2004:162).

Within the Nuwuvi ancestral territory, the piñon pine is especially relevant and conducive to collaborative stewardship because of its significance as both a Nuwuvi CKS and an ecological foundational species for piñon-juniper woodlands. The suitability of the piñon pine as a rallying point has already been validated by three consecutive annual pine nut harvest events in the SMNRA and the DNWR as part of the NKTA project. These Gathering for our Mountains events drew participation of multi-generational families from several Nuwuvi Nations. Consisting of piñon grove management activities, pine nut harvests, and demonstrations of traditional songs, dances, and skills, these events offered opportunities for knowledge transmission, cultural revitalization, and collaborative stewardship. ${ }^{28}$

\footnotetext{
${ }^{28}$ Higgs (2005) reported a similar ecological restoration and cultural revitalization project on Discovery Island, British Columbia, Canada. In 2000, a team of ethnobotanists and the Sounghees First Nation (Lekwungen) individuals performed the first harvest of camas lily (Camassia quamash), a cultural keystone species, in a hundred years in a particular meadow. Participants also performed management activities including prescribed fire, seed gathering, planting, and weeding.
} 


\section{Chapter 6 \\ Whistling at Night with Twisted Lips: The Conservation Value of Nuwuvi Local Social Institutions}

We don't whistle at night. We're not allowed to whistle no matter where you are because the spirits will come and twist your mouth sideways.

-Las Vegas Paiute Elder

\section{Introduction}

Sustainable resource use can be seen as a web of cause and effect, stemming from a series of decisions made by resource users and other actors at a variety of spatial and temporal scales. While long-term observation or learning from resource depletions informs some resource extraction decisions, certain local social institutions - such as taboos - also shape and influence these decisions. ${ }^{29}$ In the following chapter, I discuss Nuwuvi resource extraction and habitat taboos as a component of Nuwuvi ecological knowledge, and suggest several ways that they may regulate sustainable humanenvironment interactions in piñon-juniper woodlands. Some of these taboos limit resource use and habitat access according to demographic criteria, while others limit harvesting methods or restrict use of select taxa during certain time periods or vulnerable life stages. Still others afford partial to total protection of select species or types of cultural sites and azonal habitats ${ }^{30}$ within and adjacent to piñon-juniper woodlands. I speculate that many Nuwuvi resource and habitat taboos may have the capacity to regulate resource use at sustainable levels and support a variety of conservation functions by limiting ecological impacts in time and space, preventing local species extirpations,

\footnotetext{
${ }^{29}$ The word taboo is derived from the Polynesian word tapu, meaning proscribed behaviors (Tengö and Heland 2012:40).

${ }^{30}$ Azonal habitats are determined primarily by edaphic (soil) conditions, and include such places as springs, rocky outcrops, and cliffs. Zonal habitats are defined by dominant plant species (e.g., piñon-juniper woodlands) and are naturally segregated by elevation (Niles and Leary 2007:3).
} 
and ensuring population and habitat recovery and persistence of resources. These taboos might also protect threatened, endangered, and cultural and biological keystone species (Colding and Folke 2001:592). Although some consultants still observed many of these taboos at the time of study, some taboos existed solely as memories. I draw from my framework of political ecology to explain the change in knowledge and practice over time related to many of these taboos. Among the primary influences linked to reduced or changing observance of these taboos include shifting and hybridized worldviews and spiritual orientations (see Appendix F), impeded access to resources and habitats, English language hegemony, the persistent effects of the boarding school era, changes in the resources themselves (e.g., distribution, health, productivity), and reductions in intergenerational knowledge transfer. In addition to taboos, other influences also affect Nuwuvi resource extraction decisions, including changing food preferences, unprecedented resource contamination and diseases, and regulations that have criminalized land access and certain management practices. In addition to my primary ethnographic data, I occasionally draw from earlier ethnographic literature to provide supplementary material and to contrast beliefs and practices that may have changed over time.

This chapter builds upon my previous discussions of Nuwuvi ecological knowledge (Chapter 3), management practices (Chapter 4), and cultural keystone species (Chapter 5), to examine the role of taboos in mediating Nuwuvi interactions with piñonjuniper woodlands. It is my hope that this snapshot of Nuwuvi place-based relationships with piñon-juniper woodlands will serve as a foundation for developing collaborative stewardship projects that operationalize these various aspects of NEK while linking them 
to complementary corollaries in Western adaptive management approaches. In this chapter, I suggest building upon Nuwuvi resource and habitat taboos that overlap with agency policies (e.g., cave and cliff closures) as a way to increase Native participation in the management of their ancestral territory, honor indigenous knowledge and beliefs, and stimulate multi-faceted approaches to sustainable resource use and management of public lands.

\section{Anthropological Inquiry and Local Social Institutions}

Anthropology and allied disciplines have a long tradition of studying taboos (Douglas 1966; Durkheim et al. 2001; Frazer 1951; Freud 1952; Lévi-Strauss et al 1969; Malinowski 1961), although examinations of the linkages among belief systems, local social institutions, management practices and their ecological impacts emerged later (e.g., Rappaport 1968; Berkes 2008; Berkes et al. 2000; Colding and Folke 2001; Gadgil 1987; Gadgil et al. 1993; Johannes 1978; Ostrom 1990). Taboos are described variously in the literature as behavior regulated by a fear of retaliatory forces; feelings of repulsion and attraction; or behaviors and objects divergently seen as either sacred or profane, dirty or out of place; or in conflict with a culture's taxonomic or classificatory schemas (Douglas 1966; Fowles 2008:33-34; Freud 1952:18). Crawford and Ostrom (1995) suggest that taboos (proscriptions) exist within a framework of local social institutions composed of three components: (1) an agreed-upon, shared strategy within a group that defines the context (the who, what, where, and when) within which a rule applies; (2) a norm composed of permissions, prescriptions, and proscriptions; and (3) sanctions to enforce non-compliance with the above. 
My research revealed that Nuwuvi permissions and prescriptions were linked to an over-arching ethic of respect that pervades Nuwuvi interactions with people, places, particular biota, elemental forces, and spiritual beings. Although varying from person to person and Nation to Nation, Nuwuvi typically requested permission before approaching many types of landscape features, including springs, caves, and canyons. Nuwuvi petitioned resident spirits for safe passage through these locations or requested more specific guidance if seeking spiritual knowledge or harvesting resources. Prescriptions required offerings of food, water, soil, candy, tobacco, or sandwich portions to resident spirits. A Moapa Paiute elder described this protocol to me:

When you go through, to an area, you give an offering. You're saying, I'm... [name], I'm just passing this way....I say I, Creator, am a trespasser. I'm given to the Keeper of this Mountain....Here's some gum, here's some tobacco....I don't mean to disturb anything. I'm not coming here to harm anything, but get us safely through here.

Nuwuvi proscriptions, or prohibited behaviors, in piñon-juniper woodlands, receive the bulk of my attention in the pages that follow. I also discuss several overarching sanctions for violating proscriptions, permissions, and prescriptions (Table 5.2), with some mention of specific linkages between particular transgressions and punishments. Many punishments were reportedly spiritually inflicted, although self-enforcement and community social sanctions likely worked in concert to limit deviation from social norms.

In addition to taboos, land tenure and common and private property systems were other forms of local social institutions regulating resource use and management. My consultants agreed that concepts of private property were absent from pre-contact Nuwuvi. Several consultants did note, however, that their families formerly managed 
piñon groves at the extended family group level, the primary social unit noted by Steward (1938) and other early ethnographers. Inconsistent bumper crops of this staple food necessitated neighboring Nuwuvi and other Numic groups to occasionally request and grant access to each other's piñon groves during lean years. In most cases as long as permission was asked, access was granted. Core areas of the patch were generally kept for the primary family, while peripheral areas were opened up to the visitors (Spoon et al. 2013:35). Because of radical changes in land ownership within the Nuwuvi aboriginal territory, much of which is now under federal control, in addition to other changes discussed below, this system of land tenure has virtually disappeared. A Pahrump Paiute elder described an instance of shared grove access from her childhood:

Ethnographer: So they have to ask permission if they want to come over? Consultant: Yeah, uh huh. Ethnographer: But you let them if they ask?

Consultant: Yeah, the one time they did from Caliente [Nevada]. They went up to pick pine nuts and they stopped by and they [asked] if it's okay with ...us, tribes. Mama says yes, you can go up and get some pine nuts.

Other individual or group management institutions extended to springs, eagle aeries, mesquite groves, riparian and spring-fed gardens, and other patches of intentionally tended plant species. Kelly suggested that male and female individuals owned particular springs uninhabited by spirits, passing ownership to offspring or other kin (Fowler 2002; Kelly 1964). Cliff-top eagle aeries and the resident eagles were similarly noted by Kelly (1964:92-93) as owned, managed, and inherited by individuals.

Political ecology helps explain changes in these local social institutions by examining the impacts of the differential distribution of power across the landscape (Biersack 2006; Escobar 1996). Since the onslaught of Euro American contact, Nuwuvi 
have gradually lost access and control of many springs, eagle aeries, piñon groves, and other resource sites because of the initial forced evictions by settlers and government agencies during the historic period, the later reclassification of the land into a patchwork of public and private property, and their resettlement on spatially distant reservations. The state continued to exert power over this marginalized group by criminalizing eagle rearing practices, prescribed burning, and access to privatized water supplies, in addition to assimilation programs aimed at stripping Nuwuvi of their Nativeness and integrating them into the dominant society through compulsory boarding schools for children and wage labor jobs as laborers, hired hands, and household servants for adults (Knack 2001). These policies induced breaches in intergenerational knowledge transfer that are still felt and experienced by contemporary Nuwuvi. Although these forms of Nuwuvi local social institutions may also offer possible links to conservation-oriented land use and warrant further research, I focus on Nuwuvi taboos in the current treatment. Collectively, Nuwuvi local social institutions served as a moral fabric, guiding and regulating Nuwuvi choices, behaviors, and environmental impacts.

In the following section, I describe Nuwuvi resource extraction and habitat entrance taboos associated with piñon-juniper woodlands and suggest their potential role in regulating sustainable resource use and conservation. I frame my discussion of Nuwuvi taboos with Colding and Folke's (2001) delineation of six resource and habitat taboos observed among indigenous groups worldwide that facilitate conservation and sustainable resource use. These include segment taboos (based on demographic variables), temporal taboos (based on various periods of time), method taboos (certain tools or approaches), life history taboos (concerning vulnerable life-stages), specific-species taboos (affording 
partial to total protection for particular species), and habitat taboos (protecting discrete habitats).

Where Only Some May Go and Some May Do

Segment taboos restrict access to specific resources according to demographic factors such as sex, age, status, or social position. Many Nuwuvi segment taboos were food-related and proscribed groups such as pregnant and menstruating women, male hunters, and parents of newborns from ingesting certain species. Only a portion of these food-based restrictions involved direct links to resource extraction in piñon-juniper plant communities.

Certain segment taboos were explicitly tied to gender-specific places, some of which were associated with phases of the female reproductive cycle. Menstrual huts were one such place, which were taboo for men, children, and non-menstruating women to enter. Menstrual blood was generally viewed as contagiously dirty, necessitating a taboo prohibiting menstruating women from interacting with men's hunting implements and dancing regalia. Non-compliance would deleteriously affect a man's hunting ability, causing his rifle to shoot untrue. A Shivwits (PITU) elder jovially described a remedy for this dilemma:

[T] he only way you can get rid of it [the jinx] is if you find a little boy and lay your rifle down. Tell that little boy to pee on it. [laughing] He pees on your gun and it cleans it off. I don't know if that's a wives' tale or not. But it's what they used to say.

Restrictions prevented menstruating women from consuming meat. Some families extended this rule to women between the age of 16 and motherhood. Post-partum women and their husbands also avoided meat for up to a month after delivery, lest they cause 
Table 5.1 Nuwuvi Piñon-Juniper Resource and Habitat Taboos and their Hypothesized Conservation Functions

\begin{tabular}{|c|c|c|c|}
\hline $\begin{array}{c}\text { TABOO } \\
\text { CATEGORY }\end{array}$ & DESCRIPTION & $\begin{array}{c}\text { NUWUVI } \\
\text { PROSCRIPTIONS }\end{array}$ & $\begin{array}{l}\text { HYPOTHESIZED } \\
\text { CONSERVATION } \\
\text { FUNCTION } \\
\end{array}$ \\
\hline Segment & $\begin{array}{l}\text { Restricts access to } \\
\text { specific resources and } \\
\text { locations according to } \\
\text { demographic factors } \\
\text { such as sex, age, status, } \\
\text { or social position }\end{array}$ & $\begin{array}{l}\text { - Meat and hunting } \\
\text { taboos associated with } \\
\text { pregnancy, menses, } \\
\text { and puberty rites } \\
\text { - Restricted access to } \\
\text { caves, cliffs, hematite } \\
\text { quarries, and use of } \\
\text { certain species }\end{array}$ & $\begin{array}{l}\text { - Regulates and limits } \\
\text { hunting } \\
\text { - Regulates and limits } \\
\text { resource extraction and } \\
\text { access to sensitive } \\
\text { locations } \\
\text { - Increases impact } \\
\text { monitoring precision }\end{array}$ \\
\hline Temporal & $\begin{array}{l}\text { Restricts resource } \\
\text { access to delineated } \\
\text { periods of time such as } \\
\text { nighttime or } \\
\text { crepuscular moments; } \\
\text { or alternately may } \\
\text { occur sporadically, } \\
\text { weekly, seasonally, or } \\
\text { over multiple years }\end{array}$ & $\begin{array}{l}\text { - Hunting and gathering } \\
\text { moratoria and fallow } \\
\text { periods } \\
\text { - Avoidance of caves, } \\
\text { canyons, cliffs, and } \\
\text { water sources at night }\end{array}$ & $\begin{array}{l}\text { - Allows regeneration of } \\
\text { animal herds and plant } \\
\text { stands } \\
\text { - Prevents disturbance to } \\
\text { nocturnal feeding, } \\
\text { watering, and sleep cycles } \\
\text { - Prevents trampling of } \\
\text { plants and soil compaction } \\
\text { during low visibility }\end{array}$ \\
\hline Method & $\begin{array}{l}\text { Imposes limits on the } \\
\text { tools and approaches to } \\
\text { resource extraction }\end{array}$ & $\begin{array}{l}\text { - Take limits } \\
\text { - Rotational harvesting } \\
\text { - Strict medicinal plant } \\
\text { gathering protocols }\end{array}$ & $\begin{array}{l}\text { - Limits and diffuses impact } \\
\text { - Ensures animal fodder } \\
\text { - Ensures plant and animal } \\
\text { survival and reproduction }\end{array}$ \\
\hline Life-history & $\begin{array}{l}\text { Bans access to certain } \\
\text { resources during } \\
\text { sensitive periods in an } \\
\text { organism's life cycle } \\
\text { and may use criteria } \\
\text { based on sex, age, size, } \\
\text { or reproductive stage }\end{array}$ & $\begin{array}{l}\text { - Harvesting and } \\
\text { hunting moratoria } \\
\text { during certain juvenile } \\
\text { and reproductive life } \\
\text { stages }\end{array}$ & $\begin{array}{l}\text { - Allows continued } \\
\text { reproduction, population } \\
\text { stability, and organismal } \\
\text { health } \\
\text { - Ensures a sustained } \\
\text { resource }\end{array}$ \\
\hline $\begin{array}{l}\text { Species- } \\
\text { specific }\end{array}$ & $\begin{array}{l}\text { An organism is avoided } \\
\text { in all environments and } \\
\text { at all times }\end{array}$ & $\begin{array}{l}\text { Taboos on killing } \\
\text { and/or eating sacred, } \\
\text { dirty, poisonous, or } \\
\text { legally-protected } \\
\text { species }\end{array}$ & $\begin{array}{l}\text { - Species protection in time } \\
\text { and space to varying } \\
\text { degrees }\end{array}$ \\
\hline $\begin{array}{l}\text { Habitats and } \\
\text { Cultural Sites }\end{array}$ & $\begin{array}{l}\text { Access to certain places } \\
\text { or resources within } \\
\text { them is limited to } \\
\text { segments of the } \\
\text { population or } \\
\text { prohibited }\end{array}$ & $\begin{array}{l}\text { - Restricted access to } \\
\text { caves, canyon, cliffs, } \\
\text { water sources, rock } \\
\text { apertures, natural } \\
\text { bridges, cultural sites } \\
\text { - Restricted access of } \\
\text { crystal and hematite } \\
\text { deposits } \\
\text { - Protection of } \\
\text { archaeological sites }\end{array}$ & $\begin{array}{l}\text { - Restricts use of resources } \\
\text { and access to places } \\
\text { - Affords protection to } \\
\text { sensitive habitats and } \\
\text { species } \\
\text { - Limits access to cultural } \\
\text { sites; Leaves } \\
\text { archaeological deposits } \\
\text { intact } \\
\text { - Protects certain geological } \\
\text { formations (crystal } \\
\text { deposits, hematite) }\end{array}$ \\
\hline
\end{tabular}

${ }^{1}$ Adapted from Colding and Folke 2001:586 
offense to game animals or suffer increased hemorrhaging during subsequent pregnancies (Kelly 1964). Edward Sapir also noted that young boys were forbidden to eat game they had hunted themselves and would become weak and lazy if they broke this taboo (Bright 1992:554). Instead, they distributed meat to elders in the community, or traded it amongst other boys to side step this taboo. A linked Nuwuvi cultural story details Eagle's attempt to break this taboo as a sign that he has come of age (Bright 1992:824). Collectively, these proscriptions may have created temporary nonmeat-eating subpopulations, presumably resulting in intervals of reduced hunting pressure on animal populations. Depending on the relationship between these taboo periods and vulnerable animal lifeand reproductive cycles, these alterations in the temporal and spatial patterning of hunting pressure may very well have reduced impacts to game species, affording intervals of respite for population regeneration and maturation of juveniles.

Consultants additionally spoke of men's ritual sites that were taboo to women and children. A male Chemehuevi (CRIT) elder described a punishment for non-compliance:

Well one specific place I know...they don't allow women up there because they have some monster up there that likes women I guess. And he'll chase them around. Or if they're up there after sundown he gets them....and only men could go into that area and do whatever has to be done.

Only certain men, often elders, or individuals of any gender who were called to become traditional doctors entered powerful caves. These caves beckoned initiates through dreamtime messages to engage in rituals. Certain remote rocky outcroppings also represented places of power that were only visited by shamans. Red hematite clay quarries were similarly powerful, and the exclusive province of men. Nuwuvi harvested this clay from naturally occurring deposits in caves and other locations to create a sacred 
Indian Paint, or ompi, sometimes adding animal fat to achieve a paint-like consistency. ${ }^{31}$ Use of ompi was, however, open to any individual for protection against malevolent forces. Elders warned children of the perils of not only caves, but also water sources and the night in general. Segment taboos associated with children exhibited concomitant temporal and habitat dimensions as well, and are discussed in greater detail in the following subsections detailing temporal and habitat proscriptions.

Consultants noted several specific male-only plants. One such plant was an undisclosed mountain herb harvested by men who joined the United States Armed Forces. Prior to deployment into warzones, a little piece of this herb was harvested by the soldier and kept on his person. It reputedly protected the bearer from bullets and other bodily harm. Other plants, known to be poisonous or to possess power or high-level medicinal properties were only approached and gathered by traditional doctors, usually men. The only plant specifically mentioned in relation to this taboo was sacred datura (Datura wrightii Regel). No further discussion of this subject is offered here, however, because of cultural sensitivities about medicinal plant knowledge and fears of knowledge appropriation and biopiracy. Another male-only plant was reported to have the most complex gender-related resource harvesting taboo identified in this study. According to one consultant, only a naked man born in the month of June should harvest Utah agave. Bunte and Franklin (1987:29) note similarly that only a man born during the summer was allowed to tend agave roasting pits. Because of the apparent difficulty of performing this task naked, while enduring heat from both the sun and the steam of the roasting pit, this may have served as a hazing ritual for an initiation. Regardless of the potential social

\footnotetext{
${ }^{31}$ Indian Paint was the term preferred by several consultants.
} 
function it served, such a taboo, if widespread, would likely limit harvesting impacts on this species, or perhaps encourage a select few individuals to perform bulk harvesting for the larger population. Restricted use of these plants by a select few individuals may have allowed a higher level of precision in plant population monitoring and management than if multiple harvesters were harvesting plants in various intervals. Family-group piñon groves may have served a similar conservation function, with each group becoming familiar with a particular grove, enabling acute monitoring and adaptive management to avoid negative harvesting impacts. Incremental learning resulting from observations of the diachronic effects, whether positive or deleterious, of particular management and harvesting regimes, likely led to a continued refinement of practices aimed at achieving the optimal health and output of a particular species or plant community.

The locations of many gender-specific places, such as men's ritual sites and women's menstrual huts, have fallen into varying levels of obscurity. Reasons for this include changes and disruptions in intergenerational NEK transfer and resource access induced by the differential distribution of power across the landscape (Biersack 2006). Knowledge-holders maintained that certain Nuwuvi, attuned to the land, continued to detect such places associated with their gender. A female Moapa Paiute elder related an experience:

When we were up here at the Mormon Mountains on both sides, even some of the guys expressed that ooh, this is a masculine place where only the men come here and do whatever they do....I imagine there are [male places] all over.... think only the male can tell you [where they are].

Despite this continued ability to identify gender-specific places, many Nuwuvi no longer observed access restrictions as this female Chemehuevi elder revealed: 
Ethnographer: Have you ever heard if there are places were only men or only women should go?

Consultant: No, I never heard about that, because that wouldn't work with me [laughing].

Ethnographer: You'd go anyway, or what?

Consultant: Uh huh.

Her response likely reflects her exposure to and acceptance of broader U.S. societal shifts towards gender equality and renegotiated gender roles. Although consultants reported decreased visitation of these places and changing attitudes towards the observance of gender-based taboos, it is highly likely that these practices had positive ecological ramifications in former times. Hunting moratoria and meat taboos associated with individual Nuwuvi age groups or reproductive stages may have created periods of reduced pressure on game species, allowing population recovery. Taboos restricting gathering of select botanical species to a particular demographic may have limited the number of individuals making resource management decisions, potentially enabling higher levels of precision in monitoring harvesting impacts. A net reduction in harvesters may have also resulted in a reduction in both the frequency and quantity of resource extraction that a biological community would have to sustain. Gendered places and sites of power that were limited to a select demographic likely further reduced negative disturbance to associated habitats and cultural and natural resources.

\section{A Stitch in Time Saves Species}

Temporal taboos restrict resource access during delineated periods of time such as nighttime or crepuscular moments. They may alternately occur sporadically, weekly, or seasonally. Contemporary PAs similarly impose closed periods to harvesting and hunting 
Table 5.2 Reported Sanctions for Non-Compliance with Taboos

\begin{tabular}{|c|c|c|}
\hline TABOO CATEGORY & NUWUVI SUBCATEGORIES & REPORTED SANCTIONS \\
\hline SEGMENT & $\begin{array}{ll}\text { - } & \text { Children } \\
\text { - } & \text { Young boys } \\
\text { - } & \text { Women (general) } \\
& \text { (parturient, menstruating) } \\
\text { - } & \text { Men (general) } \\
\text { - } & \text { Men (husbands of parturients) } \\
\text { - } & \text { Non-elders } \\
\text { Non-doctors }\end{array}$ & $\begin{array}{ll} & \text { Death } \\
\text { - } & \text { Sickness } \\
\text { - } & \text { Lost hunting ability } \\
\text { - } & \text { Become weak and lazy } \\
& \text { Cause offense to game animals }\end{array}$ \\
\hline TEMPORAL & $\begin{array}{ll}- & \text { Nighttime } \\
- & \text { Crepuscular moments (twilight) } \\
\text { - } & \text { Seasonally } \\
- & \text { Multi-year }\end{array}$ & $\begin{array}{ll}\text { - } & \text { Death } \\
\text { - } & \text { Sickness } \\
\text { - } & \text { Twisted lips } \\
\text { - } & \text { Experiencing a stroke } \\
\text { - } & \text { Drowning } \\
\text { - } & \text { Being crazy } \\
\text { - } & \text { Snake, scorpion, or spider bites } \\
\text { - } & \text { Soul taken over by malevolent force }\end{array}$ \\
\hline METHOD & $\begin{array}{ll}\text { - } & \text { Live green piñon pine wood } \\
\text { - } & \text { Backing pickup into tree trunks } \\
\text { - } & \text { Unnecessary uprooting } \\
\text { - } & \text { Raiding animal caches } \\
\text { - } & \text { Medicinal plant associations } \\
\text { - } & \text { Cardinal directions } \\
\text { - } & \text { Quantity }\end{array}$ & $\begin{array}{ll}\text { - } & \text { Lightning strike } \\
\text { - } & \text { Choking } \\
\text { - } & \text { Low resource availability } \\
\text { - } & \text { Carm to loved ones }\end{array}$ \\
\hline LIFE-HISTORY & $\begin{array}{ll}\text { - } & \text { Juveniles } \\
\text { - } & \text { Pregnant Females } \\
\text { - } & \text { Flowering/sporulating plants } \\
\text { - } & \text { Clonal pups }\end{array}$ & - $\quad$ Sickness \\
\hline SPECIFIC SPECIES & $\begin{array}{ll}\text { - } & \text { Carrion feeders } \\
\text { - } & \text { Kertain predators } \\
\text { - } & \text { Changing food preferences } \\
\text { - } & \text { Poisonous plants } \\
\text { - } & \text { Powerful/sacred plants } \\
\text { - } & \text { Cultural Keystone Species } \\
& \text { (certain plant parts) } \\
\text { - } & \text { Legal protected status }\end{array}$ & $\begin{array}{l}\text { - Offense to animals and spiritual beings } \\
\text { - } \quad \text { Poisoning }\end{array}$ \\
\hline $\begin{array}{l}\text { HABITAT/ } \\
\text { CULTURAL SITE }\end{array}$ & $\begin{array}{ll}\text { - } & \text { Cliffs } \\
\text { - } & \text { Rocky outcroppings } \\
\text { - } & \text { Caves } \\
\text { - } & \text { Canyons } \\
\text { - } & \text { Springs } \\
\text { - } & \text { Rock apertures } \\
\text { - } & \text { Burial sites } \\
\text { - } & \text { Menstrual sites } \\
\text { - } & \text { Birthing sites } \\
\text { - } & \text { Ritual sites }\end{array}$ & $\begin{array}{ll}\text { - } & \text { Death } \\
\text { - } & \text { Sickness } \\
\text { - } & \text { Disappearance } \\
\text { - } & \text { Altered physical form } \\
\text { - } & \text { Being chased or captured } \\
\text { - } & \text { Being taken as a bird's lover }\end{array}$ \\
\hline
\end{tabular}

\footnotetext{
${ }^{\mathrm{T}}$ Bright (1992:554)

${ }^{2}$ Kelly (1964)
} 
of certain species at seasonal intervals, offering one possible inroad for aligning indigenous and nation state social institutions. Although a variety of Nuwuvi temporal taboos were revealed during my research, and even included phenological cues, many had no obvious link to resource extraction or habitat use. For instance, a taboo against telling creation stories outside of winter was backed by the belief that a snake, spider, or scorpion would bite the individual breaking this taboo. Ecological cues delineate winter as the time when animals are hibernating, the time between the winter solstice and the vernal equinox, or the time up until the first dove cry is heard in the spring.

Other taboos have more direct linkages to potential conservation outcomes. In former times Nuwuvi organized group pronghorn antelope drives in a variety of ecosystems including piñon-juniper, where up to three hundred animals were killed en masse, at times nearly decimating a herd (Thomas 1973:161). Antelope populations could not sustain such drives every year, necessitating the observance of hunting moratoria of up to twelve years in a particular area to allow herd recovery (Steward 1938:35). Some seasonal observances are more easily explained by incremental learning than taboo compliance. For instance, prescribed willow burns avoided detrimental and uncontrolled conflagrations by burning under ideal moisture conditions.

Taboos based on time of day were the most prevalent temporal taboo category, with many dealing with crepuscular moments and nighttime specifically. The liminal twilight time between night and day was described as a particularly active time for spirits. Proscribed behaviors included running around, making noise, whistling, gazing out into the night, approaching water, entering canyons or caves, or being alone in the mountains. Disrespectful, noisy behavior was seen to attract unwanted, malicious spirits. Multiple 
consultants remarked that those whistling at night would have their lips twisted by ghosts, which one individual interpreted as stroke-induced facial paralysis. Spirits would trip individuals running around in the night resulting in injury, sickness, or death. Elders particularly instilled children with proscriptions involving the night and water, as powerful and mischievous water baby spirits were known to drown children by enticing them into the water with their long hair. Only certain powerful people could reportedly withstand the negative impacts associated with nighttime travel in the mountains. Despite this abundance of negative connotations, one Las Vegas Paiute consultant was raised to believe the night was her friend.

Some of the aforementioned temporal proscriptions have obvious potential conservation linkages. A moratorium on antelope hunting for up to twelve years would most likely assist with herd recovery by allowing maximum reproduction to occur with no anthropogenic mortality. Others, such as seasonal story-telling periods, critically regulated the timing of knowledge transmission, but may not have served any direct conservation function. Although speculative, prohibitions on nighttime travel may have prevented disturbance to nocturnal animal watering and feeding patterns, disruption of diurnal cave-dwelling animal sleep cycles, and trampling and compaction of sensitive wetland plants and soil during low visibility.

\section{"You Don't Ever Just Yank a...Plant Out By its Roots"}

Method taboos impose limits on tools for and approaches to resource extraction. For Nuwuvi, these taboos regulated such factors as plant portion selection, harvesting implement, technique, and the spatial distribution of harvesting impacts. Interestingly, 
consultants noted no detailed proscriptions limiting the specific quantity of a resource that could be taken. Instead, their elders had instructed them to "leave enough" of the resource for the animals and other harvesters and to sense - through direct communication with the plants - when they had harvested enough. Sometimes a plant sought for a spiritual or medicinal purpose was not only a specific species of plant, but also a particular individual within a species - at once both a spiritual and physical entity. Through open communication with plants and receptivity to their messages, the competent practitioner knew which plant he or she was intended to pick. If the harvester failed to receive such a message, or received a strong message against picking the plant, harvesting was proscribed regardless of its level of abundance. Failure to comply with these protocols could cause the medicine to backfire, worsening an ailment or even bringing about death to the gatherer or patient. Certain medicinal plants had to be growing alongside other particular species in order to function properly. Consultants considered this specialized knowledge highly sensitive, and thus it was not shared freely. Some consultants asserted that plants had to be spoken to in the Nuwuvi language, although many consultants did not speak their native language and believed that spiritual beings understood one's intentions regardless of the language spoken. Such particular rules governing harvesting practices severally limited the extent and locations where harvesting occurred.

Additional rules dictated which portions of a given plant could be harvested. These rules covered not only the type of plant tissue gathered - whether roots, leaves, stems, etc. - but also the aspect in relation to the cardinal directions. Consultants reported that the east, or sun-side, represented life and growth. Certain plants, such as cedar 
(juniper) sprigs used as a purifying smudge were harvested from the east because of this association. As a Kaibab Paiute elder relates:

[It] has to do with spirituality, you know, pick it [cedar] on the side of the rising sun. And the sun is what causes everything to grow. It helps create life and so it's kind of a spiritual side.

For Nuwuvi, no particular tool was explicitly mentioned as taboo, yet many activities or resource extraction methods of recent advent were seen as disrespectful and thus proscribed. These included cutting live green wood from piñon pines and the damaging practices reportedly used by some commercial pine nut pickers, such as backing pickup trucks into trees to dislodge pine nuts, or cutting off whole branches with pruning saws or chainsaws in order to access pine cones. Proscriptions against these practices explicitly avoided bark and root damage and creating vectors for fungal and insect morbidity and mortality. While it is difficult to demonstrate whether or not the effect was intentional, limitations on woodcutting likely ensured adequate downed logs and snags as habitat for the Spring Mountains endemic Palmer's chipmunk (Neotamias palmeri Merr.), and roosting and perching sites for northern goshawks (Accipiter gentilis L.) and other avian and bat taxa (USFS et al. 1998:26).

Other taboos forbid causing unnecessary damage to plants. This was especially true in regards to uprooting entire plants. Whenever possible, plants harvested for their roots were gathered from eroded washes where they are already compromised, which simultaneously reduced work and limited disturbance, while selectively thinning the population. Rotational harvesting spatially diffused impacts and allowed stand regeneration during interim periods. Elders considered excessive harvesting to be stealing, inviting a range of sanctions from severe car crashes to feelings of guilt for the 
difficulty animals have in overwintering. Several consultants noted a taboo against raiding bird and rodent pine nut caches, although this was likely of recent advent, as cache raiding was previously a normal part of Nuwuvi subsistence (Steward 1938:33). Nuwuvi harvesting activities currently play a significant symbolic role but do not contribute substantially to subsistence in most cases. Several generations of disconnect from what may have previously been a necessary subsistence practice may help explain the advent of this relatively new cache raiding taboo.

Several potential conservation values emerge from these method taboos. Harvesting quotas, live green wood taboos, limits to wood removal, and cache-raiding taboos might act to ensure sufficient habitat, fodder, survival, and reproductive success for both plants and animals, while rotational harvests, strict medicinal plant harvesting protocols and prohibited practices may have mediated, diffused, and limited ecological impacts.

\section{"Not...[the] Baby One! Not [the] Fawn With Spots on the Back!"}

Life-history taboos ban access to certain resources during sensitive periods in an organism's life cycle and may use criteria based on sex, age, size, or reproductive stage. Life history taboos are also imposed by many state and federal regulatory agencies on hunting and fishing. As previously noted, such areas of obvious overlap between nation state and Nuwuvi social institutions are ideal launching points for collaborative resource stewardship engagements. Taboos on particular animal life stages were scant, both in my interviews and the literature, possibly due to relatively low levels of faunal density in the Great Basin (Fowler 1972:20), which may have necessitated Nuwuvi use of most animal 
species and most life stages and precluded the development of multiple life-stage taboos. However, most consultants concurred that taboos protect pregnant does and juvenile deer from hunting. A pregnant doe taboo may have ensured continued and unrestrained reproduction and replenishment of this previously vital food source. Prohibitions on juvenile deer may have stalled hunting until later life stages, when hunters presumably obtained greater and more efficient returns of meat per individual deer. Delayed hunting likely also benefited herd genetics, by allowing opportunities for individuals to mate before they were hunted.

Juvenile and reproductive life stages of select plant species also experienced harvesting moratoria, however none of these were directly linked to spiritual beliefs or sanctions. Rather, incremental learning about the negative impacts of disturbing certain key life phases and experiences with resource scarcity likely stimulated their development. For instance, consultants noted the care they took to avoid damaging nascent pine cones, which appear well in advance of a mature crop and necessitate up to two and a half years to develop viable seeds (Chambers et al 1999:2). Clonal pups from Utah agave were similarly left in situ until fully grown. A reproductive-stage taboo was noted for Indian tea, proscribing the harvest of cone-bearing branches. ${ }^{32} \mathrm{~A}$ few respondents hypothesized that the phytochemical composition of Indian tea detrimentally changed during this stage. Many elders simply followed protocols laid out to them as children, including a moratorium on gathering flowering branches. When I probed further, seeking a cause and effect explanation for such proscriptions, the common

\footnotetext{
${ }^{32}$ Colloquially this phenophase was termed "flowering" by my consultants, however botanically speaking Indian tea belongs to an ancient group of non-flowering plants that reproduce via spore-bearing cones.
} 
response was "I don't know, that's just how they did it." Although Nuwuvi continually adapt to changing conditions, they also maintain a strong tendency to continue practices as they were instructed, as a way of respecting and deferring to the knowledge and wisdom of their elders. Consultants reported that reproductive structures were generally left alone to ensure the proliferation of new plants and resources into the future.

Obviously with species such as the piñon pine, the fruit itself is harvested, imparting a direct impact to its reproductive success. Despite this reduction in individual propagules, consultants believed that because of a large number of pine nuts inaccessible to humans, that enough pine nuts always remained to provide sufficient animal fodder and ensure germination of new trees. In sum, Nuwuvi life-history taboos protected certain juvenile and reproductive stages of plants and animals and may have supported continued reproductive success and sustained resource availability over time.

"They Never Ate Lizards....They Just Let Those Be."

Colding and Folke (2001) define specific-species taboos as avoidance and protection of a species in all environments and at all times. I use a broader definition, discussing additional species that were only protected in certain contexts. Knowledge holders listed several animal and plant species that were taboo to kill or eat for various reasons. Carrion feeders such as crows (Corvus brachyrhynchos Brehm) were taboo to eat because of their perceived dirtiness, but may not have received full hunting protection. Plants such as death camas (Zigadenus spp. Michx.) and sacred datura were cautiously avoided because of their respective poisonous and powerful natures. Still other species were afforded protection because of their sacred status or importance as cultural 
keystone species. For instance, both the piñon pine and mesquite tree were almost unanimously afforded taboos against live, green wood collection and tree destruction, although other plant products from these species were utilized and one Chemehuevi elder admitted to harvesting piñon pines for use as Christmas trees. Still other species, such as deer, rabbits, and cactus pads (Opuntia spp. Mill.), have only recently become avoided, because of concerns about environmental toxicity. Flora and fauna exposed to nuclear radiation near the Nevada National Security Site (formerly the Nevada Test Site) or pesticides and fire retardants, and disease-ridden game fall into this category. An elder from the Paiute Indian Tribes of Utah described his fears of contamination:

So they tell us when we kill a deer to cut his head off and bring his full head in so they can check his eyes and his brain, they kind of cut it out and look at it. It has some kind of tumor thing going on with the deers down here....It's scary to you, but this is what we eat, and I don't know, it's like they say [with] the mercury in fish....

Some taxa were mentioned as taboo by consultants, yet are well represented as food items in the ethnographic literature. The chuckwalla lizard (Sauromalus ater Baird) is one example of this phenomenon. Consider one Kaibab elder's opinion on the matter:

And as for animals...it was mostly just rabbit and deer that they used to eat. They never ate lizards or anything else. They just let those be.

This statement contrasted with an account from a Chemehuevi (CRIT) elder who had eaten a variety of traditional foods including desert wood rat, desert tortoise and chuckwalla in his youth. In his own words:

Yeah, I'd eat it and I know people say, oh gross... How could you do such a thing? Hey, I ate it just like you ate a Whopper [hamburger]! (laughing) And he [my dad] loved chuckwalla lizards.

In fact, chuckwalla lizards were previously of such import that Moapa Paiutes celebrated a boy's first game ceremony after he had successfully hunted this lizard (Fowler 
1995:109, citing Kelly 1932-1934:M:53). Rather than representing a taboo per se, such culinary aversions may indicate a divergence of contemporary food preferences from heritage foods because of a combination of factors including breaches in knowledge transmission, the imposition and reliance on BIA subsidy food programs, and partial to complete adoption of the contemporary American diet. ${ }^{33}$ This difference in food preference may also be linked to the differential presence and availability of chuckwallas between these particular Nuwuvi Nations. Chemehuevis live in the lower, hotter latitudes of the Mojave Desert, which likely supports higher population numbers of chuckwallas than the higher, colder elevations of the Kaibab Plateau where the Kaibab Paiute reside. Previous ethnographic evidence supports a Chemehuevi aversion to fish (Fowler 1995:10; Laird 1976), despite their proximity to the fish-bearing Colorado River, although my consultants did not note this.

Elders mentioned several mammals as taboo, including several predator species such as wolves (Canis lupus L.) and coyotes (Canis latrans Say). Mountain lions (Puma concolor L.) were also mentioned, although Fowler (1986) cited them as a component of the Nuwuvi diet, as were bobcats (Lynx rufus Schreber) (Fowler 1995:110). Wolf and Coyote are venerated characters in Nuwuvi cultural stories, including the creation story and a recounting of the origin of pine nuts. Their role as key characters in cultural stories helps to explain their protection. Taboos protecting these predators allowed them to play their critical ecological role of preventing overpopulation of prey species. By culling weak and diseased prey, predators prevent a strain on the carrying capacity of the land while positively influencing herd health and genetics. Furthermore, wolf kills provide

${ }^{33}$ See Eagan 2013 for more information on Nuwuvi foodways. 
vital scavenge to a variety of other species, including bald eagles (Haliaeetus

leucocephalus L.), golden eagles (Aquila chrysaetos L.), ravens (Corvus corax L.), foxes (Vulpes vulpes), and coyotes (Wilmers et al. 2003). While Nuwuvi predator taboos may not have been intended to support such critical ecological functions, they likely did.

Eagles also played an important role as guardians and protectors of Nuwuvi and help carry prayers to the Creator (Spoon et al. 2011:47). According to my consultants their cliff-top aeries were especially safe-guarded, while Franklin (1994:250) adds that aeries were directly linked to the well-being of local Nuwuvi communities. Interestingly this information conflicts with ethnographic data gathered by Kelly (1964:92-93), who described aeries and the eagles within as owned and inherited, their primary use being utilitarian as a feather source for arrow fletching. Once eaglets properly fledged, their tender reportedly plucked them live and either released them or unceremoniously dispatched them. These conflicting accounts illustrate the potential for either regionally divergent practices or adaptation and change over time. Although taboos are commonly seen to exist on a unilinear track from existence to dissolution, this example demonstrates the possibility of new taboos arising as adaptations to changing worldviews and lived experiences. The potentially recent advent of a Nuwuvi eagle taboo ${ }^{34}$ is particularly interesting in light of its symbolism and importance within United States patriotism. Indeed, the majority of male consultants had served in the U.S. military and were proud of their service, often displaying conspicuous symbols of patriotism. This taboo may also be linked to the eagle's federally protected status. Although bald eagles were delisted

\footnotetext{
${ }^{34}$ Unfortunately, species distinctions between bald and golden eagle were neither clarified in the ethnographic record nor in my primary data.
} 
from the Endangered Species Act (ESA) in 2007 after recovering from DDT-induced dieoffs in the 1950s and 1960s, they are still protected under the Bald and Golden Eagle Protection Act, the Migratory Bird Treaty Act, and the Lacey Act (USFWS 2013). These protective measures effectively criminalized certain aspects of eagle rearing and live feather harvesting and may have created rifts in the transmission of eagle related knowledge, belief, and practice. As a federally unrecognized tribe, the Pahrump Paiute may have been differentially impacted by these regulations, as they are ineligible for special religious use permits. ${ }^{35}$

Not surprisingly, Nuwuvi species-specific taboos engendered some of the most tenable links to conservation. For species experiencing full protection, individual growth and reproduction of a given species were presumably allowed to progress unchecked by anthropogenic mortality. Other species, while not eaten, may have been hunted for utilitarian use. Still other species may no longer be harvested because of local extirpation or general lack of availability, changing food preferences, federal or state protection of species, criminalization of practices, or changing symbolism and importance.

\section{Avoided Places, Protected Spaces}

The final taboo category involves habitat taboos, which limit or prohibit access to certain places or resources within them and may help ensure localized perpetuation of ecosystem services and biodiversity. While Colding and Folke (2001) limit their analysis

\footnotetext{
${ }^{35}$ The Bald and Golden Eagle Protection Act of 1940 prohibits taking, possessing, or transporting bald or golden eagles, or their nests or eggs. Special permits issued under the Code of the Federal Register: 50 $\$ 22.22$, allow individuals belonging to federally recognized Indian tribes to take and use eagles, nests, and eggs for "bona fide tribal religious ceremonies", but not for utilitarian purposes (U.S. NARA 1999).
} 
of culturally sanctioned protected places to those aligning with ecological habitats or plant communities, I include a discussion of culturally significant protected areas that do not necessarily align with ecological or physiographic delineations, and may exist from the scale of a single burial plot to that of an entire mountain range. For Nuwuvi, the various forms of locally protected places include locations where events in cultural stories occurred (such as the site of the Nuwuvi creation story in the Spring Mountains), locations where significant events in recent history occurred, places where protected animal species reside, places linked to specific ancestors, places where spiritual beings reside (such as in caves, springs, or high points on the landscape), places where significant resources are found (e.g., crystals or red hematite), or rock writing locations.

Although some of the literature lumps such sites together as sacred sites (Mallarach 2008), King (2003:6-10) points out the slipperiness of the term and its connotations, recommending the broader term spiritual places instead. For instance, many places — such as gathering sites — may be important socially or economically to people without necessarily being sacred, and may represent an important part of their identity and heritage. Such culturally significant places are extremely variable in appearance, meaning, and degree of protection afforded to them. Despite this confusion in the typology of significant sites, there is ample evidence of habitats protected at the local level by local social institutions worldwide (Mallarach 2008). Sacred groves and valleys are prevalent in India, Nepal, and Madagascar (Gadgil 1987; Spoon 2011; and Tengö et al. 2007 respectively), and support high levels of biodiversity, old growth, and species endemism (Salick et al. 2007). Nuwuvi taboo locations in piñon-juniper woodlands include various geologic landscape features and bodies of water. To Nuwuvi, 
the arid and rocky desert mountain landscape is itself alive and replete with sentient spiritual beings connected to specific places and landscape elements. Entrance into many of these places warranted requests for permission and prescribed behaviors of respect, while several of them were only visited by certain population segments. Some places even warned interlopers when their presence was not welcomed.

Piñon-juniper woodland terrain varies from gently rolling hills to steep slopes and cliffs, rocky ridgelines and outcroppings, and deeply incised canyons (Bradley and Deacon 1967). Nuwuvi avoided many of these exposed rocky locations because of dangerous protector spirits that lived there. A guardian snake lived in one such location in Utah, using its tail to flip interlopers off the mountainside if they climbed too high. Spiritual beings also inhabited canyons, causing those breaching protocol to become lost, or inflicting sickness or even death. A Kaibab Paiute elder described proper protocol for entering such a site:

Part of the ritual is the journey itself. In canyons and other mountain areas, you have to take four days to get there and stop four times in order to arrive at the ritual location in a purified state.

Nuwuvi viewed openings in the earth, such as caves, as entrances to the spirit world. While some caves were avoided for this reason, others were not approached because of habitation by bears or mountain lions. Some consultants especially avoided caves containing powerful polychrome rock writing. ${ }^{36}$ A few Nuwuvi entered caves but abided by strict cultural protocols as a Chemehuevi elder (CRIT) explained:

Every time you go to a cave, introduce yourself, you know, who you are.... And then you're supposed to.... Have some kind of token that you could give it as a gift so that cave won't hurt you.....They have a fine line

\footnotetext{
${ }^{36}$ Some Nuwuvi believe little people rather than their ancestors created rock writing.
} 
in front of it like that, kind of like a shield. So if you go past that shield without your introduction....you're going to be in trouble.

Sometimes ompi (Indian Paint) was applied on the top of the head and bottoms of the feet to protect those entering the cave. Consultants reported several spiritual sanctions for failing to ask permission or honor prescribed or proscribed behaviors. Interlopers might suddenly be overwhelmed by a physical presence forcing them to the ground, or might emerge from the cave as a different gender or as an animal. Spiritual beings called little people played tricks or brought harm to visitors. Stories abounded of the plight of trespassers, including those who were led deep into caves, never finding their way out again. A male Pahrump Paiute elder described the dangers of a particular cave in the Spring Mountains:

There's a cave up here... by Wheeler Springs....[There's] a bird that's got the ability to change into a human being and particularly if you're up there by yourself they will ...turn into a female and try to entice you in. And you'll disappear and pretty soon somebody will find you, you'll just be sitting there on top of the mountain with a bird as a lover (laughing).

Nuwuvi similarly viewed rock apertures, arches, and natural bridges as portals to the spirit realm, and thus avoided them. One consultant, however, regularly visited a special rock aperture regarded for its healing properties and had no fear of passing through the opening as long as he followed prescribed behaviors.

Taboos regulating access to cliffs, canyons, caves, apertures, and other geologic formations likely limited negative impacts to the sensitive biological communities that evolved to these habitats. For instance, desert bighorn sheep occupy steep slopes and canyons in piñon-juniper woodlands, and are easily disturbed by human presence and noise (Ostoja 2013:103). Cliffs and steep slopes in piñon-juniper woodlands in the 
SMNRA provide foraging and nesting sites for peregrine falcons (Falco peregrinus anatum Bonaparte) (CCDCP and DRI 2008:54), as well as habitat for other birds of prey, bats, and plants, including one Spring Mountains endemic and 11 species of concern (USFS et al. 1998:12). Stemming from their respect of these habitats, consultants voiced concerns regarding the damaging practices of some rock climbers in both PAs, especially regarding permanent bolt installation and rock writing defacement. Rock climbing can also disturb nests and roosting sites of bats and raptors. Additionally, numerous studies indicate that "gardening",37 and other impacts of technical rock climbing reduce both the number and diversity of sensitive cliff-side botanical species (Rusterholz et al. 2004; McMillan and Larson, 2002; Camp and Knight 1998). Two taxa of greasebush (Glossopetalon pungens var. glabra and G. pungens var. pungens) occurring on cliffs in piñon-juniper woodlands of the SMNRA are particularly vulnerable (USFS et al. 1998:22). Both of these taxa are conservation species of concern, and the latter is a southern Nevada endemic (see Appendix J.).

Caves are particularly sensitive refugia, exhibiting unique archeological, biological, hydrological, and geological features. Limited cave access likely minimized perturbations to sensitive nursery and maternity roosts and hibernacula of several vulnerable bat species, where bats spend at least half of their lives (USFS et al. 1998:16). ${ }^{38}$ Some bat species, including the Townsend big-eared bat (Corynorhinus townsendii pallescens Miller) — the bat species of greatest concern at the SMNRA-

\footnotetext{
${ }^{37}$ Gardening refers to the intentional removal of vegetation along climbing routes (USDA 2013:20).

${ }^{38}$ Bats found in the SMNRA include: the long-eared myotis, fringed myotis, long-legged myotis, western small-footed myotis, spotted bat, Townsend's big-eared bat, silver haired bat, Allen's big-eared bat (USDA 2013:28) (see Appendix I).
} 
readily abandons roosts following minimal disturbances (USFS et al. 1998:22, citing Ramsey 1997), and spends as much as seven months of the year in hibernation (NDW 2012). Cave taboos likely protected other cave dwelling taxa in addition to sensitive geologic formations and cultural sites.

The SMNRA hosts approximately 200 springs and riparian areas over a wide elevational range, from 1,220 to 3,100 meters, occurring within piñon-juniper woodlands and other ecosystems (USFS et al. 1998:11), while the DNWR has 34 currently mapped seeps and springs, 22 of which occur in the Sheep Range (Bair and Tiehm 2003:6).

Consultants viewed hydrological features, including lakes and both hot and cold springs, as residences of spiritual beings. These places were regarded with respect and generally avoided unless necessary to obtain water, resources, or to perform spring maintenance. This was especially true at night when spirits were particularly active. As previously mentioned, these water babies were known to entice children to a watery death. Here a Kaibab Paiute elder explained the phenomenon:

Springs are occupied by spirits....it lures small kids with his hair. His wavy hair gets in there....the hair of that spirit will entice the child to get further into the water, and then it will grab it and eat it.... They say it has a really eerie sound, like a baby crying....They say it's something like a loon.

Nuwuvi taboos prescribed behaviors for the careful, respectful treatment of springs may have minimized negative habitat impacts to a variety of bird, invertebrate, and mammal species, including 29 species of concern in the SMNRA, 15 of which are endemic to the Spring Mountains (USFS et al. 1998:11). These endemic species of concern include butterflies, the Spring Mountain springsnail (Pyrgulopsis deacon), and the southeast Nevada springsnail (P. turbatrix). Inhabiting artesian springs with mineralized, 
oxygenated, and unpolluted water, springsnails are currently threatened by impacts from ungulates and water diversions, the latter of which has the most detrimental effect on spring biota of all such impacts (USFS et al. 1998). Nuwuvi spring taboos also may have limited trampling of vegetation and invertebrates, which has been shown to alter vegetation communities, affect mollusk abundance, and increase erosion, water temperature, turbidity, and nutrient loading (Fleischner 1994; Kauffman and Krueger 1984; Sada 2001; USFS et al. 1998).

Many of the protected geological and hydrological features and habitat discussed above also contain sensitive cultural resources. For instance, rock writing, crystal outcroppings, and archaeological deposits frequently occur in caves, canyons, and areas adjacent to waterways. Because of a cultural ethic of respect for ancestral Nuwuvi, and beliefs about lingering energy and power held in objects and places, Nuwuvi generally left these and other cultural sites including burial grounds, menstrual sites, and ritual sites intact and protected. Indeed, cultural site proscriptions most likely limited impacts to sensitive and non-renewable archaeological sites and other of cultural resources.

\section{Conclusion}

In this chapter I discussed Nuwuvi local social institutions associated with piñonjuniper woodlands, including land tenure systems, taboos, and sanctions for noncompliance with social protocols. I suggested that many of these social institutions existed solely as memories at the time of study, although many consultants still followed certain protocols of respect when visiting this plant community. Using my political ecology lens, I explained the reduction in the observance of these social institutions, 
because of changes in resource access and control (Biersack 2006; Escobar 1996) from land privatization and the criminalization of Nuwuvi cultural practices, in addition to reductions in intergenerational knowledge transfer and other socio-economic impediments.

I highlighted Nuwuvi resource extraction and habitat taboos related to piñonjuniper woodlands, linking proscriptions to sustainable resource use and potential conservation outcomes. I examined six taboo categories identified by Colding and Folke (2001), including segment, temporal, method, life history, specific-species, and habitat taboos. I also expanded this biologically oriented analysis, considering taboos related to cultural sites as well. Nuwuvi taboos may have served multiple conservation functions: limiting resource extraction and impacts to sensitive habitats and cultural sites; avoiding disruptions to animal breeding, watering, feeding, roosting, and hibernating cycles; and observing fallow periods and hunting moratoria to allow population recovery. Nuwuvi even afforded some species total protection in time and space. Many taboos worked in concert to provide multi-layered protection to certain habitats and species. Caves and associated botanical and faunal taxa offer one such example - protected concurrently by overlapping segment, temporal, and habitat taboos. Certain taboos show evidence of change over time, while some appear to be recent creations. These changes reflect shifting cultural values among Nuwuvi related to gender, symbolism, and dietary preferences.

In contrast to formal institutions that govern behavior via legal, judicial, and punitive systems, taboos are informal systems that regulate human actions by imposing social norms (Colding and Folke 2001). Although the predominant conservation 
approach at SMNRA, DNWR, and internationally employs formal institutionsexemplified by bounded and policed protected areas with strict rules-informal institutions may offer several advantages in local contexts by building upon already existent belief systems that protect sacred and often biodiverse sites. In some cases, formal and informal institutions may even work in tandem, achieving similar conservation outcomes. For instance, both Nuwuvi and the USFS have rules limiting cave access in the SMNRA. According to the Mt. Charleston Wilderness Management Plan (USDA 2013:13), “Caves may be closed (permanently or seasonally) to access when necessary for human health and safety or to prevent degradation to wildlife, plants, cultural resources, or recreational opportunities," and the spread of White Nose Syndrome, an epidemic that threatens bats in western states. The plan places further restrictions on rock climbing to protect peregrine falcons nesting and roosting sites, while limiting natural resource extraction and access to sensitive sites to preserve cultural and biological values. Many of such policies clearly align with Nuwuvi proscriptions.

Despite evidence of decreased knowledge transfer and observance of Nuwuvi taboos, I agree with Middleton, that "taboos are far from static proscriptions - rather, as a kind of cultural practice, they will change, mutate and be re-invented as people redefine their identities and their perceptions of the past" (1997:391). Such a view of the adaptive, responsive, and ever-changing reality of culture, mirrors the state of Nuwuvi ecological knowledge and practice at the time of study. Whether intentionally designed to provide conservation functions or not, Nuwuvi taboos provide points of entry for collaborative natural and cultural resource conservation between Nuwuvi and agency land managers by offering areas of potential agreement on priority species, habitats, and cultural resources. 


\section{Chapter 7 \\ Conclusion}

When [the federal agencies] start messing with the forest, they've got ideas they're going to try...they're gonna try this and they're gonna try that. And they'll say oh, that sounds good, let's do it. They don't ask us what we know about the mountains, how to take care of the mountains. They need to get with us and find out something about it!

-Las Vegas Paiute Elder

To many Nuwuvi, the SMNRA and DNWR are not only "natural grocery stores" that provides vital sources of medicine, fiber, and sustenance, but sentient and animate landscapes teeming with spiritual beings that communicate wisdom and proper behavior to humans. In stark contrast to fortress conservation supporters, who advocate the removal of resident indigenous peoples and the cessation of their management activities in protected areas (Redford and Sanderson 2000; Terborgh 2000), Nuwuvi explain the vital importance of human interaction, care, and use of resources for the ecological and spiritual health of the land. Indeed, the Creator charged them at the beginning of time with the duty to steward the land and to continually bring it back into ecological health and balance. From a Nuwuvi perspective the flora, fauna, and the land itself are intimately linked to Nuwuvi communities by an expansive kinship system.

I began this monograph with an overview of the research project, including my research questions; my theoretical frameworks of political ecology, ethnobiology, and local ecological knowledge; a description of my research sites; my methodological approach to sample selection, data collection and data analysis; and several ethical considerations. I continued in Chapter 2, introducing the Nuwuvi homeland, describing the ecological foundations of piñon-juniper woodlands in the Great Basin, and presenting 
several current management concerns. Using my lens of critical political ecology (Forsyth 2003) I discussed the differential causal explanations for piñon-juniper encroachment into surrounding sagebrush steppe plant communities and revealed the use of science by various interest groups to substantiate their divergent political agendas. Then I summarized the previous ethnographic work in the region, revealing a difficult Nuwuvi history following Euro American contact, marked by forcible evictions and blocked access to critical resources, massive population reductions from disease, federal and Mormon cultural assimilation initiatives, and more. I closed the chapter with a discussion of indigenous peoples and their relationships with protected areas. Through my lens of political ecology I showed how unequal distributions of power have differentially influenced indigenous relationships with ancestral lands and resources within protected areas (Biersack 2006) by limiting access, criminalizing and regulating practices, and ethnically spacing Native American communities on spatially distant reservations (Biolsi 2007), among other ways.

In Chapter 3 I discussed the ways in which ecological knowledge is generated and transmitted, notably through incremental learning from protracted observation and learning through resource crises. In order to avoid privileging Western science-based explanations (Forsyth 2003), I also discussed several Nuwuvi interpretations of knowledge production including messages received from spiritual entities. Using my framework of political ecology that considers the influences of spatial, historical, environmental, social, political, and economic forces (Biersack 2006:28), I described several drivers of Nuwuvi knowledge change, including Christianity, relocation, forced sedentism, market economy integration, shifting ecologies, and more. Collectively, these 
factors help to explain knowledge fragmentation over time and the heterogeneous character of Nuwuvi knowledge assemblages at the time of study. Despite an overall reduction in knowledge transmission and an increase in impediments to accessing longtended groves of piñon pines and other piñon-juniper woodland resources, my consultants - ranging in age from 52 to 85 - still carried a great reservoir of detailed ecological knowledge of this culturally significant ecosystem.

I then discussed Nuwuvi management practices in piñon-juniper woodlands. Using the lens of critical political ecology (Forsyth 2003), I analyzed two dominant and competing paradigms for explaining ecological processes. The first, equilibrium ecology, interprets ecological succession as a linear progression towards a terminal, stable state. Within this paradigm Nuwuvi are considered separate from nature. Thus, all anthropogenic disturbances are by definition viewed as detrimental to healthy ecological function. This thinking continues to influence many protected area policies that restrict access and use of resources by indigenous peoples and is evidence of the political nature and powerful impact that orthodox Western science-based "natural laws" have on indigenous lifeways and identities. I followed with a description of the competing nonequilibrium ecology paradigm, which views ecosystems as constantly in flux and influenced by external and internal factors at a variety of temporal and spatial scales (Forsyth 2003). Non-equilibrium ecology includes human disturbances as a component of ecological processes, which can be either positive or negative depending on frequency, scale, and degree. I argued that select Nuwuvi management practices operate within this paradigm by introducing low to moderate levels of environmental disturbances. These practices mimic "natural", non-anthropogenic disturbances, and engender multiple 
ecological and utilitarian functions, including increased plant productivity, landscape heterogeneity, reduced catastrophic wildfire risk, and continued water availability in springs. Spiritual practices work in tandem with physical techniques to achieve Nuwuvi conceptions of balance. These states of balance are only temporary achievements and necessitate a continuous relationship between Nuwuvi and the land, where Nuwuvi balancing follows the punctuated and stochastic disturbances described by a nonequilibrium paradigm of ecology (Forsyth 2003).

I followed this chapter with two case studies that operationalized NEK at individual, species, population, habitat, and landscape scales, highlighting its relevance and compatibility with Western resource management under the umbrella of collaborative stewardship. The first case study involved an evaluation of the Great Basin piñon pines as Nuwuvi cultural keystone species, especially salient species of significance to Nuwuvi culture. I advocated operationalizing the CKS concept by using the Great Basin piñon pines as a rallying point for collaborative stewardship projects and as a vehicle for ameliorating Nuwuvi relationships with piñon-juniper woodlands after over 200 years of alienation from portions of their ancestral territory due to various historic, political, economic, environmental, and social influences (Biersack 2006:28). I described this use of the Great Basin piñon pines during three annual collaborative, multigenerational piñon-juniper stewardship and cultural revitalization events as part of the NKTA project on the SMNRA and the DNWR between 2011 and 2013.

In the second case study I analyzed Nuwuvi local social institutions that mediate human-environment interactions in piñon-juniper woodlands. Many of the land tenure systems and taboos revealed during my interviews with consultants were no longer 
practiced at the time of study, existing solely as vestigial memories. I explained these changes using my political ecology framework, examining the influences of the differential distribution of power across the landscape, including access and control of resources (Biersack 2006; Escobar 1996). I explained how previous land tenure systems for springs, eagle aeries and piñon groves ceased because of forced evictions by settlers and government agencies, the reclassification of the land into a patchwork of public and private property, Nuwuvi resettlement on spatially distant reservations, criminalization of certain practices, and reductions in intergenerational knowledge transfer. I also discussed changes in taboos, noting how some individuals no longer observe gender-specific taboos due to reductions in sharp gender role divisions and larger U.S. societal shifts towards gender equality. I also discussed the recent genesis of an eagle species taboo and pointed to possible causative factors including the criminalization of previous eagle-rearing practices, Nuwuvi removal from ancestral lands, breaches in knowledge transfer, and changing symbolism of the eagle influenced by U.S. patriotism. Despite these and other changes evident in Nuwuvi local social institutions, many Nuwuvi continue to adhere to resource and habitat taboos in piñon-juniper ecosystems. I speculated that many of these taboos, both remembered and still practiced, conferred positive conservation benefits, regulating human-environment relations towards sustainable resource use and habitat protection. I provided examples of overlap between Nuwuvi taboos and protected area policies, suggesting these areas of agreement as starting points for effective collaboration on the conservation of species, habitats, and landscapes.

In this manuscript, I have sought to illuminate a portion of the rich yet nuanced ecological knowledge, belief, and practice held and remembered by select Nuwuvi 
knowledge holders, relating to piñon-juniper woodlands in general and two southern Nevada montane protected areas in particular. I suggest that Nuwuvi ecological knowledge and practice is relevant to contemporary land management, offering a reservoir of strategies and innovations generated over their long tenure in the Great Basin. Over millennia, Nuwuvi experienced and adapted to climactic fluctuations and periods of resource scarcity by drawing upon their extensive corpus of ecological knowledge and modifying management practices accordingly. This body of knowledge and practice remains directly relevant to current land management in this era of rapidly increasing global climate change, offering novel, yet time-tested empirical knowledge and adaptive approaches to resource management. For example, NEK stored as oral history can provide information about previous environmental fluctuations and climatic events that have occurred over multiple human generations. Nuwuvi adaptive management regimes operate variously at individual, species, population, and landscape scales and can offer new approaches to resource management at a variety of spatial scales. Nuwuvi informal social institutions that limit and regulate resource use, such as resource and habitat taboos, are enforced socially, either by the individual or the community, and thus offer a significant advantage to the costly and logistically difficult task of enforcement by agents in state and federal protected areas (Berkes et al. 2000:1259; Colding and Folke 2001:585).

Perhaps most-importantly, the holism of the Nuwuvi worldview holds the promise of engendering a paradigm shift in protected area management. As PA management involves managing both people and resources, successful management must be grounded in a comprehensive understanding of the social and ecological forces at play. Further, 
Nuwuvi view the distinction between cultural and natural resource management to be unnecessary and even detrimental to effective resource management, as they consider all resources to be interconnected and culturally significant. Such an epistemological shift within agencies would encourage greater collaboration between cultural and natural resource managers, who frequently manage resources independently of one another and without interdisciplinary crossover. As a further step towards a paradigmatic shift in protected area management, I have included a summary of management recommendations oriented towards protected area managers in Appendix K.

This research is grounded in mountainous piñon-juniper ecosystems in two southern Nevada protected areas. Its relevance extends, however, to protected area management in other montane forests and arid lands, and indeed, to protected areas worldwide to which indigenous and local peoples attach continuing cultural significance. As land management challenges escalate in the face of global climate change, so too does the need for socially just treatment of indigenous and other historically marginalized peoples. Collaborative stewardship offers an opportune venue for joining these dual ventures by validating and operationalizing indigenous knowledge to address complex management concerns, reconnecting indigenous peoples with their ancestral lands, and healing historic rifts by recasting indigenous peoples and state and federal governments as allies and partners rather than adversaries. Ultimately, I advocate a paradigmatic shift away from the failed attempts of fortress conservation — with its policies of indigenousexclusion - to a biocultural approach of protected area management that emphasizes the simultaneous and linked conservation of both cultural and biological diversity through collaborative partnerships that highlight the shared goals of healthy, productive, and 
biodiverse landscapes. It is my hope that Nuwuvi, federal, and academic partnerships continue to proliferate and flourish, creating innovative projects that benefit all stakeholders, providing opportunities for Nuwuvi to reconnect with their ancestral lands, and developing strategies for sustainable resource use and conservation amidst unprecedented change. 


\section{Bibliography}

Abele, S. L.

2011 Nevada Springs Conservation Plan. Springs Conservation Plan Working Group. The Nature Conservancy. Reno, NV.

Ackerman, Thomas L.

2003 A Flora of the Desert National Wildlife Range. Mentzelia 7:1-16.

Adams, William M. and Jon Hutton

2007 People, Parks and Poverty: Political Ecology and Biodiversity

Conservation. Conservation and Society 5(2):147-183.

Agrawal, Arun

1995 Dismantling the Divide Between Indigenous and Scientific Knowledge. Development and Change 26(3):413-439.

Alcorn, Janice B.

1981 Huastec Noncrop Resource Management: Implications for Prehistoric Rainforest Management. Human Ecology 9(4):395-417.

1993 Indigenous Peoples and Conservation. Conservation Biology 7(2):424426.

Allen, E. A., J.C. Chambers, and R.S. Nowak

2008 Effects of a Spring Prescribed Burn on the Soil Seed Bank in Sagebrush Steppe Exhibiting Pinyon-Juniper Expansion. Western North American Naturalist. 68:265-277.

Anderson, Michelle D.

2002 Pinus edulis. In Fire effects information system U.S. Department of Agriculture, Forest Service, Rocky Mountain Research Station, Fire Sciences Laboratory. Electronic document, http://www.fs.fed.us/database/feis/, accessed June 2, 2014.

Anderson, M. Kat

2005 Tending the Wild: Native American Knowledge and the Management of California's Natural Resources. Berkeley: University of California Press.

Armitage, Derek

2005 Adaptive Capacity and Community-Based Natural Resource Management. Environmental Management 35(6):703-715.

Asch, Michael, Colin Samson, Dieter Heinen, Justin Kenrick, Jerome Lewis, Sidsel Saugestad, and Terry Turner

2004 On the Return of the Native. Current Anthropology 45(2):261-265. 
Baldwin, Ian. T., Lynn Staszak-Kozinski, and Robert Davidson

1994 Up in Smoke: I. Smoke-Derived Germination Cues for Postfire Annual, Nicotiana attenuata Torr. Ex. Watson. Journal of Chemical Ecology, 20( 9):2345-71.

Bair, Janet and Arnold Tiehm

2003 Introduction to A Flora of the Desert National Wildlife Range. Mentzelia $7: 1-16$

Bauer, John M. and Peter J. Weisberg

2009 Fire History of a Central Nevada Piñon -Juniper Woodland. Canadian Journal of Forest Research 39:1589-1599.

Begossi, Alpina

1998 Resilience and Neotraditional Populations: The Caic aras of the Atlantic Forest and Caboclos of the Amazon (Brazil). In Linking Social and Ecological Systems: Management Practices and Social Mechanisms for Building Resilience. F. Berkes and C. Folke, eds. Pp. 129-157. Cambridge University Press, Cambridge, UK.

Berkes, Fikret

1998 Indigenous Knowledge and Resource Management Systems in the Canadian Subarctic. In Fikret Berkes and Carl Folke, eds. Pp.98-128. Cambridge: Cambridge University Press.

2008 Sacred Ecology: Traditional Ecological Knowledge and Resource Management. $2^{\text {nd }}$ Edition. New York: Routledge.

Berkes, Fikret and Carl Folke

1998 Linking Social and Ecological Systems for Resilience and Sustainability. In Linking Social and Ecological Systems: Management Practices for Building Resilience. Fikret Berkes and Carl Folke, eds. Pp.1-26. Cambridge: Cambridge University Press.

Berkes, Fikret and Nancy J. Turner

2006 Knowledge, Learning, and the Evolution of Conservation Practice for Social-Ecological System Resilience. Human Ecology 34(4):479-494.

Berkes, Fikret, Johan Colding, and Carl Folke

2000 Rediscovery of Traditional Ecological Knowledge as Adaptive Management. Ecological 10(5):1251-1262.

2003 Introduction. In Navigating Social-Ecological Systems: Building Resilience for Complexity and Change. F. Berkes, J. Colding, and C. Folke eds. Pp. 1-29. Cambridge, UK: Cambridge University Press. 
Berlin, Brent

1992 Ethnobiological Classification: Principles of Categorization of Plants and Animals in Traditional Societies. Princeton, New Jersey: Princeton University Press,

Bernard, H. Russell

2006 Research Methods in Anthropology: Qualitative and Quantitative Methods. $4^{\text {th }}$ edition. Walnut Creek, CA: AltaMira Press.

Biersack, Aletta

2006 Reimagining Political Ecology: Culture/Power/History/Nature. In Reimagining Political Ecology. Aletta Biersack and James B. Greenberg, eds. Pp.1-40. Durham, N.C.: Duke University Press.

Biolsi, Thomas

2007 Race Technologies. In A Companion to the Anthropology of Politics. David Nugent and Joan Vincent, eds. Pp.400-417. Oxford: Blackwell Publishing.

Bloch, Maurice

1995 People into Places: Zafiminiry Concepts of Clarity. In The Anthropology of Landscape. Eric Hirsch and Michael OHanlon, eds. Pp. 63-77.

Clarendon Press: Oxford University Press.

Bond, William J.

1994 Keystone Species. In Biodiversity and Ecosystem Function. E. D. Shultze and H. A. Mooney, eds. Pp. 237-253. Berlin:Springer.

Botkin, D.

1990 Discordant Harmonies: A New Ecology for the Twenty-First

Century. Oxford University Press, New York.

Boyd, Richard (ed.)

1999 Indians, Fire and the Land in the Pacific Northwest. Corvallis: Oregon State University Press,

Bradley, W. Glen, and James E. Deacon

1967 The Biotic Communities of Southern Nevada. Nevada State Museum Anthropological Paper 13(4):201-295.

Bright, William (ed.)

1992 Southern Paiute and Ute Linguistics and Ethnography. Vol. 10. Walter de Gruyter. 
Brockington, Dan

2002 Fortress Conservation: The Preservation of the Mkomazi Game Reserve, Tanzania. Indiana University Press,

Bunte, Pamela A. and Robert J. Franklin

1987 From the Sands to the Mountain: Change and Persistence in a Southern Paiute Community. Lincoln: University of Nebraska Press.

Bureau of Indian Affairs (BIA)

2005 American Indian Population and Labor Force Report. Washington, DC: US Department of the Interior.

Camp, Richard J., and Richard L. Knight

1998 Effects of Rock Climbing on Cliff Plant Communities at Joshua Tree National Park, California. Conservation Biology. 12(6): 13021306.

Chambers, Jeanne C.

2001 Pinus monophylla Establishment in an Expanding Pinus - Juniperus Woodland: Environmental Conditions, Facilitation and Interacting Factors. Journal of Vegetation Science 12(1): 27-40.

Chambers, Jeanne C.; Matthew L. Brooks, Burton K. Pendleton; Carol B. Raish (eds.)

2013 The Southern Nevada Agency Partnership Science and Research Synthesis: Science to Support Land Management in Southern Nevada. Gen. Tech. Rep. RMRS-GTR-303. Fort Collins, CO: U.S. Department of Agriculture, Forest Service, Rocky Mountain Research Station.

Chambers, Jeanne C., Stephen B. Vander Wall, and Eugene W. Schupp.

1999 Seed and Seedling Ecology of Piñon and Juniper Species in the Pygmy Woodlands of Western North America. The Botanical Review 65(1):1-38.

Charlet, David A.

2008 Shah-Kan-Daw: Anthropogenic Simplification of Semi-Arid Vegetation Structure. In Kitchen, Stanley G.; Pendleton, Rosemary L.; Monaco, Thomas A.; Vernon, Jason, comps. Proceedings—Shrublands Under Fire: Disturbance and Recovery in a Changing World; 2006 June 6-8; Cedar City, UT. Proc. RMRS-P-52. Fort Collins, CO: U.S. Department of Agriculture, Forest Service, Rocky Mountain Research Station.

Chape, Stuart, Jeremy Harrison, Mark Spalding, and Igor Lysenko

2005 Measuring the Extent and Effectiveness of Protected Areas as an Indicator for Meeting Global Biodiversity Target. Philosophical Transactions of the Royal Society: Biological Sciences. 360:443-455. 
Chmara-Huff, Fletcher P.

2006 A Critical Cultural Landscape of the Pahrump Band of Southern Paiute. Master's thesis, Department of Geography, University of Arizona.

Clark County Desert Conservation Program and Desert Research Institute (CCDCP and DRI)

2008 Adaptive Management Report for the Clark County, Nevada, Multiple Species Habitat Conservation Plan. Department of Air Quality and Environmental Management Desert Conservation Program, Clark County, Nevada.

Clifford, James

2007 Varieties of Indigenous Experience: Diasporas, homelands, sovereignties. Indigenous Experience Today: 197-223.

Colding, Johan and Carl Folke

2001 Social Taboos: "Invisible" Systems of Local Resource Management and Biological Conservation. Ecological Applications 11(2):584-600.

Coles-Ritchie, Marc, Stephen J. Solem, Abraham E. Springer, and Burton Pendleton 2013 Framework for Springs Stewardship Program and Proposed Action Development: Spring Mountains National Recreation Area, HumboldtToiyabe National Forest.

Connell, Joseph H.

1978 Diversity in Tropical Rain Forests and Coral Reefs". Science: 199( 4335):1302-1310.

Connelly, John W., Steven T. Knick, Michael A. Schroeder, and San J. Stiver 2004 Conservation Assessment of Greater Sage-Grouse and Sagebrush Habitats. Cheyenne, WY: Western Association of Fish and Wildlife Agencies.

Crawford, Sue S., \& Ostrom, Elinor

1995 A Grammar of Institutions. American Political Science Review 89(3):582600 .

Cristancho, Sergio

2001 Letuama Psychological Representations of Nature and Human-Nature Interactions. Unpublished M.S. Thesis. Champaign, IL: University of Illinois.

Cristancho, Sergio, and Joanne Vining

2004 Culturally Defined Keystone Species. Human Ecology Review 11(2):153164. 
Cronquist, Arthur, Arthur H. Holmgren, Noel H. Holmgren, Patricia K. Holmgren, and James L. Reveal, Barneby, Rupert C.

1972 Intermountain Flora; Vascular Plants of the Intermountain West, U.S.A. New York: Hafner Publishing Company.

Cunningham, Anthony, ed.

2001 Applied Ethnobotany: People, Wild Plant Use and Conservation. New York: Earthscan.

Daily, Gretchen C., Paul R. Ehrlich, and Nick M. Haddad

1993 Double Keystone Bird in a Keystone Species Complex. Proceedings of the National Academy of Sciences of the United States of America 90(2):592594.

Davic, Robert D.

2004 Epistemology, Culture, and Keystone Species. Ecology and Society 9(3): r1.

Deur, Doug, and Nancy J. Turner

2005 Keeping it Living: Traditions of Plant Use and Cultivation on the Northwest Coast of North America. Seattle: University of Washington Press.

Diamond, Jared

2005 Collapse: How Societies Choose to Fail or Succeed. New York: Viking.

Dowie, Mark

2011 Conservation Refugees: the Hundred-Year Conflict Between Global Conservation and Native Peoples. Cambridge: MIT Press.

Douglas, Mary

1966 Purity and Danger: An Analysis of Concepts of Pollution and Taboo. New York: Praeger.

Drucker, Phillip

1941 Cultural Element Distributions: XVII, Yuman-Piman. University of California Anthropological Records 6(3).

Durkheim, Émile, Carol Cosman, and Mark Sydney Cladis 2001[1912] The Elementary Forms of Religious Life. Oxford: Oxford University Press. 
Eagan, April Hurst

2013 Heritage and Health: A Political-Economic Analysis of the Foodways of the Paiute Indian Tribe of Utah and the Bishop Paiute Tribe. Master's Thesis. Department of Anthropology, Portland State University, Portland, Oregon.

Eerkens, Jelmer W., Jerome King, and Eric Wohlgemuth

2002-2004 The Prehistoric Development of Intensive Green-Cone Piñon Processing in Eastern California. Journal of Field Archaeology 29(1/2):17-27.

Ellen, Roy F.

2001 Cultural Salience, Nomenclatural Polytypy and Ecology: Local

Knowledge and Management of Sago Palm Diversity in Maluku. Lecture Delivered at Yale University Council on Southeast Asia Area Studies, 28 November.

2006 Local Knowledge and Management of Sago Palm (Metroxylon sagu Rottboell) Diversity in South Central Seram, Maluku, Eastern Indonesia." Journal of Ethnobiology 26(2): 258-298.

Escobar, Arturo

1996 After Nature: Steps to an Antiessentialist Political Ecology. Current Anthropology 40(1):1-30.

1999 After Nature: Steps to an Antiessentialist Political Ecology. Current Anthropology 40(1): 1-30.

Fleischner, Thomas L.

1994 Ecological Costs of Livestock Grazing in Western North America. Conservation Biology 8:629-644.

Fontana, Andrea and James H. Frey

1994 Interviewing: The Art of Science. In The Handbook of Qualitative Research, eds. N. K. Denzin and Y. S. Lincoln, 361-376. Thousand Oaks, CA: Sage.

Forsyth, Tim

2003 Critical Political Ecology. New York: Routledge.

Fox, Jeremy W.

2013 The Intermediate Disturbance Hypothesis Should be Abandoned. Trends in Ecology \& Evolution 28 (2):86-92. 
Fowler, Catherine $\mathrm{S}$.

1972 Comparative Numic Ethnobiology. Ph.D. dissertation, Department of Anthropology, University of Pittsburgh

1986 Subsistence. In Handbook of North American Indians: Volume 11, Great Basin. William C. Sturtevant and Warren L. D’Azevedo, eds. Pp. 64-97. Washington: Smithsonian Institution.

1995 Some Notes on Ethnographic Subsistence Systems in Mojavean Environments in the Great Basin. Journal of Ethnobiology 15(1):99-117.

2002 What's in a Name? Some Southern Paiute Names for Mojave Desert Springs as Keys to Environmental Perception. Conference Proceedings. Spring-Fed Wetlands: Important Scientific and Cultural Resources of the Intermountain Regions.

2003 Caring for the Trees: Restoring Timbisha Shoshone Land Management Practices in Death Valley National Park. Ecological Restoration 21(4):302-306.

2004 Southern Paiute - Chemehuevi Trails Across the Mojave Desert: Isabel Kelly's Data,1932-33. Darling/Sneed Symposium, AAA.

Fowler, Don D. and Catherine S. Fowler

1971 Anthropology of the Numa; John Wesley Powell's Manuscripts on the Numic Peoples of Western North America, 1868-1889. Washington: Smithsonian Institution Press.

Fowles, Severin M.

2008 Steps toward an archaeology of taboo. In Religion, Archaeology, and the Material World, Lars Fogelin ed. Pp. 15-37. Center for Archaeological Investigations, Occasional Paper No. 36. Southern Illinois University Press, Carbondale.

Framework Convention on Climate Change (FCCC)

2001 Climate Change 2001. Working Group II: Impacts, Adaptation and Vulnerability.

Frazer, James G.

1951 The Golden Bough: A Study in Magic and Religion. New York: Macmillan.

Freud, Sigmund

1952 Totem and Taboo: Some Points of Agreement Between the Mental Lives of Savages and Neurotics. New York: Norton.

Garibaldi, Ann and Nancy Turner.

2004 Cultural Keystone Species: Implications for Ecological Conservation and Restoration. Ecology and Society 9(3):1[online] URL:

http://www.ecologyandsociety.org/vol9/iss3/art1. 
Gentry, Howard Scott

2004 Agaves of Continental North America. University of Arizona Press.

Glaser, Barney G. and Anselm Strauss

1967 The Discovery of Grounded Theory: Strategies for Qualitative Research. New York: Aldine.

Gillihan, Scott W.

2006 Sharing the Land with Pinyon-Juniper Birds. Partners in Flight Western Working Group. Salt Lake City, Utah.

Hall, Alex R., Adam D. Miller, Helen C. Leggett, Stephen H. Roxburgh, Angus Buckling, and Katriona Shea

2012 Diversity-disturbance relationships: frequency and intensity interact. Biological Letters 8:768-771.

Hames, Raymond

2007 The Ecologically Noble Savage Debate. Annual Revue of Anthropology 36:177-190.

Hardin, Garrett

1968 The Tragedy of the Commons. Science 162(3859):1243-1248.

Harris, James G. and Melinda Woolf Harris

2001 Plant Identification Terminology: An Illustrated Glossary. $2^{\text {nd }}$ Edition. Spring Lake, Utah: Spring Lake.

Heizer, Robert F.

1944 Artifact Transport by Migratory Animals and Other Means. American Antiquity 9(4):395-400.

Higgs, Eric

2005 The Two-Culture Problem: Ecological Restoration and the Integration of Knowledge. Restoration Ecology 12(1):159-164.

Holling Crawford S.

1978 Adaptive Environmental Assessment and Management. Laxenburg, Austria: International Institute for Applied Systems Analysis.

Holt, Ronald, L.

2006 Beneath These Red Cliffs: An Ethnohistory of the Utah Paiutes. Logan, Utah: Utah State University Press. 
Howard, H.W., and Lyon, A.G.

1952 Nasturtium officinale R. Br. (Rorippa Nasturtium-Aquaticum (L.) Hayek). Journal of Ecology 40:228-245.

Hughes, Richard, E. and James A. Bennyhoff

1987 Early Trade. In Handbook of North American Indians: Volume 11, Great Basin. William C. Sturtevant and Warren L. D'Azevedo, eds. Pp.238-255. Washington: Smithsonian Institution.

Hulse, James W.

2009 Nevada's Environmental Legacy: Progress or Plunder. Reno: University of Nevada Press.

Hultkrantz, Åke

1986 Mythology and Religious Concepts. In Handbook of North American Indians: Volume 11, Great Basin. William C. Sturtevant and Warren L. D’Azevedo, eds. Pp. 630-640. Washington: Smithsonian Institution.

Hunn, Eugene

1982 The Utilitarian Factor in Folk Biological Classification. American Anthropologist (84)4:830-847.

Hunter, David E., and Phillip Whitten (eds.)

1976 Encyclopedia of Anthropology. New York: Harper and Row.

Huntington, Henry P.

2000 Using Traditional Ecological Knowledge in Science: Methods and Applications. Ecological Applications 10(5):1270-1274.

Jacka, Jerry K.

2010 The Spirits of Conservation: Ecology, Christianity, and Resource Managmeent in Highlands Papua New Guinea. Journal for the Sutdy of Religion, Nature and Culture 4(1):24-47.

Jackson, Scott

1996 Testing for the Remains of Prehistoric Piñon Nut (Pinus monophylla) Use at Site 26-NY-8913, Central Nevada. Master's Thesis. Department of Anthropology, California State University, Bakersfield.

Johannes, Robert E.

1978 Traditional Marine Conservation Methods in Oceania and their Demise. Annual Reviews of Ecology and Systematics 9:349-364.

2002 Did Indigenous Conservation Ethics Exist? Traditional Marine Resource Management and Knowledge Information Bulletin 14:3-6. 
Kauffman, J. Boone, and William C. Krueger

1984 Livestock Impacts on Riparian Ecosystems and Streamside Management Implications. A Review. Journal of Range Management 37:430-437.

Keller, Robert H., and Michael F. Turek

1998 American Indians and National Parks. Tucson: The University of Arizona Press.

Kelly, Isabel T.

1932-1934 Southern Paiute Field Notes: Las Vegas Volume I (LVI); Moapa (M)

1934 Southern Paiute Bands. American Anthropologist 36(4):548-560.

1939 Southern Paiute Shamanism. Berkeley: University of California Press.

1964 Southern Paiute Ethnography. Glen Canyon Series 21. University of Utah Anthropological Papers 69. Salt Lake City: University of Utah.

Kelly, Isabel T. and Catherine S. Fowler

1986 Southern Paiute. In Handbook of North American Indians: Volume 11, Great Basin. William C. Sturtevant and Warren L. D'Azevedo, eds. Pp.368-397. Washington: Smithsonian Institution.

Knack, Martha

2001 Boundaries Between: The Southern Paiutes, 1775-1995. Lincoln, NB: University of Nebraska Press.

King, Tom

2003 Places that Count: Traditional Cultural Properties in Cultural Resource Management. Walnut Creek, CA: Altamira Press.

Knapp, Alan K., John M. Blair, John M. Briggs, Scott L. Collins, David C. Hartnett, Loretta C. Johnson, and E. Gene Towne

1999 The Keystone Role of Bison in North American Tallgrass Prairie. Bioscience 49(1):39-50.

Krech, Shepard III.

1999 The Ecological Indian: Myth and History, Norton, New York.

Kroeber, Alfred L.

1976 Handbook of the Indians of California. Smithsonian Institution, Bureau of American Ethnology Bulletin No. 78. Washington D.C.: USGPO, 1925. Reprint, New York: Dover Publications.

Kuper, Adam

2003 The Return of the Native. Current Anthropology 44(3):389-402. 
Labat-Anderson Incorporated

2003 Human Health Risk Assessment: Wildland Fire-Fighting Chemicals.

Report Prepared for: Missoula Technology and Development Center USDA Forest Service Missoula, Montana.

Laird, Carobeth, and George Laird.

1976 The Chemehuevis. Malki Museum Press.

Lanner, Ronald M.

1996 Made for Each Other: A Symbiosis of Birds and Pines. New York: Oxford University Press,

1981 The Piñon Pine, A Natural and Cultural History. University of Nevada Press, Reno.

Lanner, Ronald M., and Penny Frazier

2011 The Historical Stability of Nevada's Piñon-Juniper

Forest. Phytologia 93:360-387.

Lantz, Trevor C. and Nancy J. Turner

2003 Traditional Phenological Knowledge of Aboriginal Peoples in British

Columbia. Journal of Ethnobiology 23(2):263-286.

LeBeau, Michelle L.

1998 Federal Land Management Agencies and California Indians: A Proposal to Protect Native Plant Species. Environs 21(2):27-47.

Lélé, Sharachchandra, and Richard B. Norgaard

1996 Sustainability and the Scientist's Burden. Conservation Biology 10(2): 354-365.

Les, Donald H., and Leslie J. Mehrhoff

1999 Introduction of Nonindigenous Aquatic Vascular Plants in Southern New England: A Historical Perspective. Biological Invasions 1:281-300.

Lévi-Strauss, Claude, John Richard Von Sturmer, James Harle Bell, and Rodney Needham

1969 The Elementary Structures of Kinship. Boston: Beacon Press.

Little Jr, Elbert L.

1971 Atlas of United States trees. Volume 1. Conifers and Important Hardwoods. Miscellaneous Publication 1146. US Department of Agriculture, Forest Service, Washington, DC. 
Lockwood, Julia L., Martha F. Hoopes, Michael P. Marchetti

2007 Invasion Ecology. Blackwell Publishing. Malden, Massachusetts.

Malinowski, Bronislaw

1961 Argonauts of the Western Pacific: An Account of Native Enterprise and Adventure in the Archipelagoes of Melanesian New Guinea. New York: E.P. Dutton \& Co.

Mallarach, Josep-Maria, and Josep Maria Mallarach i Carrera (eds)

2008 Protected Landscapes and Cultural and Spiritual Values. Volume 2. Heidelberg: Kasparek Verlag.

Mancillas, Stella C.

2000 When the Rocks Came Down: A History of the Indians of Yosemite Valley, 1916-1953. Master's Thesis. Department of History, California State University, Sacramento.

McLain, Rebecca J.

2008 Constructing a Wild Mushroom Panopticon: The Extension of NationState Control Over the Forest Understory in Oregon, USA. Economic Botany 62(3): 343-355.

McLain, Rebecca J. and Penny Frazier

2008 Management Guidelines for Expanding Pinyon Nut Production in Colorado's Pinyon-Juniper Woodlands. Electronic document, http://www.ntfpinfo.us/about/academicscidocs.html, accessed May 14, 2014.

McMillan, Michele A., and Douglas W. Larson

2002 Effects of Rock Climbing on the Vegetation of the Niagara Escarpment in Southern Ontario, Canada. Conservation Biology. 16(2): 389- 398.

Middleton, Karen

1997 Circumcision, Death, and Strangers. Journal of Religion in Africa 27(4): 341-373.

Miller, B., R. Reading, J. Hoogland, T. Clark, G. Ceballos, R. List, S. Forrest, L. Hanebury, P. Manzano, J. Pacheco, and D. Uresk

2000 The Role of Prairie Dogs as a Keystone Species: Response to Stapp. Conservation Biology 14(1):318-321.

Miller, Richard F., and Robin J. Tausch

2000 The Role of Fire in Pinyon and Juniper Woodlands: A Descriptive Analysis." Proceedings of the Invasive Species Workshop: The Role of Fire in the Control and Spread of Invasive Species. Fire Conference. 
Miller, Richard F., Robin J. Tausch, E. Durant McArthur, Dustin D. Johnson, Stewart C. Sanderson

2008 Age Structure and Expansion of Piñon-Juniper Woodlands: A Regional Perspective in the Intermountain West. Research Paper. RMRS-RP-69. Fort Collins, CO: U.S. Department of Agriculture, Forest Service, Rocky Mountain Research Station.

Miller, Richard F. and Peter E. Wigand

1994 Holocene Changes in Semiarid Pinyon-Juniper Woodlands: Response to Climate, Fire and Human Activities in the US Great Basin. BioScience 44:465-474.

Mistry, Jayalaxshmi, Andrea Berardi, Valeria Andrade, Txicaprô Krahô, Phocrok Krahô, and Othon Leonardos

2005 Indigenous Fire Management in the Cerrado of Brazil: The Case of the Krahô of Tocantíns. Human Ecology 33(3): 365-386.

Musser-Lopez, Ruth Arlene, and Steve Miller

2010 Archaeological Trails and Ethnographic Trails: Can They Meet?

Proceedings of the Society for California Archaeology 24.

Nabhan, Gary Paul and John L. Carr

1994 Ironwood: An Ecological and Cultural Keystone of the Sonoran Desert. Washington, DC: Conservation International.

NatureServe

2014 NatureServe Explorer: An Online Encyclopedia of Life [Web Application]. Version 7.1. Arlington, Virginia: NatureServe. Electronic document, http://explorer.natureserve.org, accessed on May 7, 2014.

Nevada Department of Wildlife (NDW)

2012 Townsend's Big-Eared Bat. Electronic document, http://www.ndow.org/Species/Furbearer/Townsend \%E2\%80\%99s_Big-eared_Bat/, accessed March 14, 2014.

Niles, Wesley Everett, and Patrick J. Leary

2007 Annotated Checklist of the Vascular Plants of the Spring Mountains, Clark and Nye Counties, Nevada. Nevada Native Plant Society.

Nuñez, Martin A. and Daniel Simberloff

2005 Invasive Species and the Cultural Keystone Species Concept. Ecology and Society 10(1): r4. 
Morefield, James D. (ed.)

2001 Nevada Rare Plant Atlas. Nevada Natural Heritage Program. Nevada Natural Heritage Program Nevada Department of Conservation and Natural Resources. Carson City, Nevada, U.S.A. Report for the U.S. Fish and Wildlife Service for the U.S. Department of the Interior. http://heritage.nv.gov/atlas.

Ostoja, Steven M., Matthew L. Brooks, Jeanne C. Chambers, and Burton Pendleton 2013 Species of Conservation Concern and Environmental Stressors: Local, Regional, and Global Effects. In The Southern Nevada Agency Partnership Science and Research Synthesis: Science to Support Land Management in Southern Nevada. Gen. Tech. Rep. RMRS-GTR-303. Fort Collins, CO: U.S. Department of Agriculture, Forest Service, Rocky Mountain Research Station. Chambers, Jeanne C.; Matthew L. Brooks, Burton K. Pendleton; Carol B. Raish (eds.).

Ostrom, Elinor

1990 Governing the Commons: The Evolution of Institutions for Collective Action, Cambridge University Press, Cambridge, UK.

Paine, Robert T.

1969 A Note on Trophic Complexity and Community Stability. American Naturalist. 103(929): 91-93.

Pendleton, Burton K., Jeanne C. Chambers, Matthew L. Brooks, and Steven M. Otoja 2013 Chapter 2: Ecosystem Stressors in Southern Nevada. In The Southern Nevada Agency Partnership Science and Research Synthesis: Science to Support Land Management in Southern Nevada. General Technical Report RMRS-GTR-303. Pp. 97-124, Jeane C. Chambers, Matthew L. Brooks, Burton K. Pendleton, Carol B. Raish, eds. Fort Collins, CO: U.S. Department of Agriculture, Forest Service, Rocky Mountain Research Station.

Pickett, Steward TA, V. Thomas Parker, and Peggy L. Fiedler

1992 The New Paradigm in Ecology: Implications for Conservation Biology Above the Species Level." In Conservation Biology. Pp. 65-88. P.L. Fiedler and S.K. Jain, eds. Springer US.

Platten, Simon, and Thomas Henfrey

2009 The Cultural Keystone Concept: Insights from Ecological Anthropology. Human Ecology 37(4): 491-500.

Posey, Darrell A.

1985 Indigenous Management of Tropical Forest Ecosystems: The Case of the Kayapo Indians of the Brazilian Amazon. Agroforestry Systems 3:139158. 
Power, Mary E., David Tilman, James A. Estes, Bruce A. Menge, William J. Bond, L. Scott Mills, Gretchen Daily, Juan Carlos Castilla, Jane Lubchenco, and Robert T. Paine 1996 Challenges in the Quest for Keystones. Bioscience 46(8):609-620.

Ramsey, Marikay A.

1997 Final Report on the Maternity Roost Study and Status of Bat Species of Concern of the Spring Mountains, Nevada. Unpublished report on file with the U.S. Fish and Wildlife Service, Reno, Nevada.

Rappaport, Roy

1968 Pigs for the Ancestors: Ritual in the Ecology of a New Guinea People. New Haven: Yale University Press.

Redford, Kent H., and Steven E. Sanderson

2000 Extracting Humans from Nature. Conservation Biology. 14(5): 1362-1364.

Redman, Charles. L.

1999 Human Impact on Ancient Environments. University of Arizona, Tucson.

Rhode, David

2002 Native Plants of Southern Nevada: An Ethnobotany. Salt Lake City, Utah: The University of Utah Press.

Romme, William H., Craig D. Allen, John D. Bailey, William L. Baker, Brandon T. Bestelmeyer, Peter M. Brown, Karen S. Eisenhart, Lisa Floyd-Hanna, David W. Huffman, Brian F. Jacobs, Richard F. Miller, Esteban H. Muldavin, Thomas W. Swetnam, Robin J. Tausch, Peter J. Weisberg

2008 Historical and Modern Disturbance Regimes, Stand Structures, and Landscape Dynamics in Piñon-juniper Vegetation in the Western US. Fort Collins, CO, USA: Colorado Forest Restoration Institute.

Ross, Anne, Kathleen Pickering Sherman, Jeffrey G. Snodgrass, Henry D. Delcore, and Richard Sherman

2011 Indigenous Peoples and the Collaborative Stewardship of Nature: Knowledge Binds and Institutional Conflicts. Walnut Creek: Lost Coast Press.

Roxburgh, Stephen H., Katriona Shea, and J. Bastow Wilson 2004 The Intermediate Disturbance Hypothesis: Patch Dynamics and Mechanisms of Species Coexistence. Ecology 85:359-371.

Rusterholz, H., S. W. Muller, and B. Baur

2004 Effects of Rock Climbing on Plant Communities on Exposed Limestone Cliffs in the Swiss Jura Mountains. Applied Vegetation Science. 7(1): 3540 . 
Sada, Donald W.

2001 Demography and Habitat Use of the Badwater Snail (Assiminea infima), with Observations on its Conservation Status. Hydrobiologia 466:255-265.

Salick, Jan, Anthony Amend, Danica Anderson, Kurt Hoffmeister, Bee Gunn, and Fang Zhendong

2007 Tibetan Sacred Sites Conserve Old Growth Trees and Cover in the Eastern Himalayas. Biodiversity and Conservation 16:693-706.

Salmón, Enrique

2000 Kincentric Ecology: Indigenous perceptions of the Human-Nature Relationship. Ecological Application 10(5):1327-1332.

Sapir, Edward

1930 Southern Paiute, a Shoshonean language. In Proceedings of the American Academy of Arts and Sciences, pp. 1-296. American Academy of Arts and Sciences.

Sheehan, Glenn W and Richard Glenn

2000 "Hearing" the People of a Subsistence Culture: Traditional Knowledge and Environmental Impacts on Alaska's North Slope. Presentation to the The Bureau of Ocean Energy Management, Regulation and Enforcement. Electronic document: http://www.boemre.gov/itd/files/sheehan-glenn.pdf., accessed June 12, 2014.

Slik, Ferry J. W., Caroline S. Bernard, Floris C. Breman, Marloes Van Beek, Agus Salim, and Douglas Sheil

2008 Wood Density as a Conservation Tool: Quantification of Disturbance and Identification of Conservation- Priority Areas in Tropical Forests.

Conservation Biology 22:1299-1308.

Smith, Eric A. and Mark Wishnie

2000 Conservation and Subsistence in Small-Scale Societies. Annual Review of Anthropology 29: 493-524.

Smith, J. Russell

1929 Tree Crops: A Permanent Agriculture. Rayway, NJ: Quinn and Boden.

Smith, Stanley D., Therese N. Charlet, Lynn F. Fenstermaker, Beth A. Newingham 2009 Effects of Global Change on Mojave Desert Ecosystems. In The Mojave Desert R.H. Webb, L.F. Fenstermaker, J.S. Heaton, J.S., D.L. Hughson, E.V. McDonald, and D.M. Miller (eds.). Reno, NV: University of Nevada Press: 31-56. 
Spence, Mark David

1999 New Dispossessing the Wilderness: Indian Removal and the Making of National Parks. York: Oxford University Press.

Spicer, Edward H.

1971 Persistent Cultural Systems. Science 174:795-800.

Spoon, Jeremy

2008 Tourism in a Sacred Landscape: Political Economy and Sherpa Ecological Knowledge in Beyul Khumbu/Sagarmatha National Park, Nepal. PhD Dissertation, Department of Anthropology, University of Hawai'i at Manoa.

2011 Tourism, Persistence, and Change: Khumbu Spirituality in Sagarmatha (Mount Everest) National Park and Buffer Zone, Nepal. Journal of Ecological Anthropology 15(1):41-57

2013 Different Ways of Knowing, Shared Goals: Applied Sustainability projects in the Nepalese Himalaya and the Great Basin. In Social Sustainability: A Multilevel Approach to Social Inclusion. Veronica Dujon, Jesse Dillard, and Eileen M. Brennan, eds. Pp.211-232. London: Routledge.

Spoon, Jeremy and Richard Arnold

2012 Collaborative Research and Co-Learning: Integrating Nuwuvi (Southern Paiute) Ecological Knowledge and Spirituality to Revitalize a Fragmented Land. Journal for the Study of Religion, Nature and Culture 6(4):477-500.

Spoon, Jeremy, Richard Arnold, and the Nuwuvi (Southern Paiute) Working Group 2011 Nuwu Kanee, Nuwu Tooveenup (Our Home, Our Story): Nuwuvi (Southern Paiute) and the Spring Mountains. Portland: The Mountain Institute and Portland State University.

Spoon, Jeremy, Richard Arnold, Brian Lefler, Kendra Wendel, the Nuwuvi (Southern Paiute) Working Group, the U.S. Forest Service, and the U.S. Fish and Wildlife Service 2013 Collaborative Resource Stewardship Plan: Nuwuvi (Southern Paiute), the Spring Mountains National Recreation Area and the Desert National Wildlife Refuge Complex. Portland: The Mountain Institute and Portland State University.

Stein, Bruce .S.

2002 States of the Union: Ranking America's Biodiversity. Arlington, Virginia: NatureServe.

Stepp, John Richard

2005 Advances in Ethnobiological Field Methods. Field Methods 17(3): 211218. 
Steward, Julian

1938 Basin-Plateau Aboriginal Sociopolitical Groups. Washington: U.S. Government Printing Office.

1941 Cultural Element Distributions: XIII, Nevada Shoshoni. University of California Anthropological Records 4.

1955 Theory of Culture Change: The Methodology of Multilinear Evolution. Urbana: University of Illinois Press.

Stewart, Omer C.

1942 Cultural Element Distributions: XVIII, Ute-Southern Paiute. University of California Anthropological Records 6:231-360.

2002 Forgotten Fires: Native Americans and the Transient Wilderness. Norman: University of Oklahoma Press.

Stoffle, Richard W., Fletcher P. Chmara-Huff, Kathleen A. Van Vlack, Rebecca S. Toupal

2004 Puha Flows from It: The Cultural Landscape Study of the Spring Mountains. Tucson, Arizona: Bureau of Applied Research in Anthropology, University of Arizona.

Stoffle, Richard W., David B. Halmo, Michael J. Evans, and John E. Olmsted

1999 Calculating the Cultural Significance of American Indian Plants: Paiute and Shoshone Ethnobotany at Yucca Mountain, Nevada. American Anthropologist 92(2):416-432.

Stoffle, Richard W. and Henry F. Dobyns

1982 Puaxant Tuvip: Utah Indians Comment on the Intermountain Power Project, Utah Section Intermountain-Adelanto Bipole I Transmission Line Ethnographic (Native American) Resources.

Stoffle, Richard W. and Marina Nieves Zedeño

2001 Historical Memory and Ethnographic Perspectives on the Southern Paiute Homeland. Journal of California and Great Basin Anthropology 23(2):229-248

Stoffle, Richard W., Michael J. Evans, David B. Halmo, Wesley E. Niles, and Joan T. LFarrell

1989 Native American Plant Resources in the Yucca Mountain Area, Nevada. Report DOE/NV-10576-19. Las Vegas, Nevada: U.S. Department of Energy, Nevada Operations Office.

Strauss, Anselm, and Juliet Corbin

1990 Basics of Qualitative Research. Grounded Theory Procedures and Techniques. Thousand Oaks, California: Sage. 
Sthultz, Christopher M., Catherine A. Gehring, and Thomas G. Whitham

2007 Shifts from Competition to Facilitation between a Foundation Tree and a Pioneer Shrub across Spatial and Temporal Scales in a Semiarid Woodland. New Phytologist (173)1:135-145.

Tengö, Maria and Jacob Von Heland

2012 Adaptive Capacity of Local Indigenous Institutions: the Case of the Taboo Forests of Southern Madagascar. In Boyd, Emily, and Carl Folke. 2012. Adapting Institutions: Governance, Complexity, and SocialEcological Resilience. Cambridge: Cambridge University Press.

Tengö, Maria, Kristin Johansson, Fanambinantsoa Rakotondrasoa, Jakob Lundberg, JeanAimé Andriamaherilala, Jean-Aimé Rakotoarisoa and Thomas Elmqvist

2007 Taboos and Forest Governance: Informal Protection of Hot Spot Dry Forest in Southern Madagascar. Ambio, 36(8):683-691.

Terborgh, John

2000 The Fate of Tropical Forests: A Matter of Stewardship. Conservation Biology 14(5): 1358-1361.

The Snow Leopard Conservancy

2007 Mountain Cultures, Key-stone Species: Exploring the Role of Cultural Keystone Species in Central Asia. Final Report (Grant 2005-2019) submitted to The Christensen Fund by SLC/ Cat Action Treasury, Sonoma, California.

Thomas, David Hurst

1973 An Empirical Test for Steward's Model of Great Basin Settlement Patterns. American Antiquity 38(2):155-176.

Tiller, Veronica E. Velarde, (ed.)

2005 Tiller's Guide to Indian country: Economic Profiles of American Indian Reservations. Albuquerque: BowArrow Publishing.

Trusler, Scott, and Leslie Main Johnson

2008 "Berry Patch" As a Kind of Place — the Ethnoecology of Black Huckleberry in Northwestern Canada. Human Ecology 36(4): 553-568.

Tueller, Paul T., C. Dwight Beeson, Robin J. Tausch, Neil E. West, and Kenneth H. Rea 1979 Pinyon-juniper Woodlands of the Great Basin: Distribution, Flora, Vegetal Cover. USDA Forest Service Research Paper INT-229. Intermountain Forest and Range Experiment Station. Ogden, Utah. 
Turnbull, David

1997 Reframing Science and Other Local Knowledge Traditions. Futures 29(6):551-562.

Turner, Nancy J.

1988 "The Importance of a Rose": Evaluating the Cultural Significance of Plants in Thompson and Lillooet Interior Salish." American Anthropologist 90(2):272-290.

Turner, Nancy and Fikret Berkes

2006a Coming to Understanding: Developing Conservation through Incremental Learning in the Pacific Northwest. Human Ecology 34(4):495-513

Turner, Nancy J., Iain J. Davidson-Hunt, and Michael O'Flaherty

2003 Living on the Edge: Ecological and Cultural Edges as Sources of Diversity for Social—Ecological Resilience. Human Ecology 31(3): 439-461.

Tyler, Edward Burnett

1874 Primitive Culture: Researches into the Development of Mythology, Philosophy, Religion, Language, Art and Customs. Volume 1. New York: Holt and Company.

U.S. Census Bureau

2010 City Quickfacts: Las Vegas. Retrieved May 30, 2012 from http://quickfacts.census.gov.

U.S. Department of State (USDOS)

n.d. UN Declaration on the Rights of Indigenous Peoples Review. Electronic document, http://www.state.gov/s/tribalconsultation/declaration/, accessed May 30, 2014.

U.S. Fish and Wildlife Service (USFWS)

2009 Desert National Wildlife Refuge Complex: Ash Meadows, Desert, Moapa Valley, and Pahranagat National Wildlife Refuge: Final Comprehensive Conservation Plan and Environmental Impact Statement.

2013 Federal Laws that Protect Bald Eagles. Electronic document, http://www.fws.gov/midwest/eagle/protect/index.html, accessed February $2,2014$. 
U.S. Forest Service Intermountain Region, State of Nevada, Department of Conservation and Natural Resources, U.S. Fish and Wildlife, Pacific Region (USFS et al.)

1998 Conservation Agreement for the Spring Mountains National Recreation Area Clark and Nye Counties, Nevada. Electronic document http://www.clarkcountynv.gov/Depts/dcp/Documents/Library/other\%20re ports/collab/ConservationAgreementForTheSpringMountainsNRA_April_ 1998.pdf, accessed January 4, 2014

U.S. National Archives and Records Administration (U.S. NARA)

1999 Code of Federal Regulations. Electronic document, http://www.ecfr.gov

/cgi-bin/text-idx?SID=c2034329adbc313c818d532184496b42\&node

$=50: 9 \cdot 0 \cdot 1 \cdot 1 \cdot 5 \cdot 3 \cdot 1 \cdot 2 \&$ rgn $=\operatorname{div} 8$, accessed April 14, 2014.

Vayda, Andrew P., and Bradley B. Walters

1999 Against Political Ecology. Human Ecology 27(1):167-179.

Von Till Warren, Heidi

2007 Chapter 5: Southern Paiutes in Las Vegas History. In Coyote Named this Place "Pakonapanti". Electronic document, http://www.fws.gov/ desertcomplex/desertrange/corncreekhistory.htm, accessed on November $2,2013$.

Wallington, Tabatha J., Richard J. Hobbs, and Susan A. Moore

2005 Implications of Current Ecological Thinking for Biodiversity

Conservation: a Review of the Salient Issues. Ecology \& Society 10 (1).

Waring, Gwendolyn L.

2011 A Natural History of the Intermountain West: Its Ecological and Evolutionary Story. Salt Lake City: The University of Utah Press.

Watson, Annette and Orville Huntington

2008 They're Here-I Can Feel Them: The Epistemic Spaces of Indigenous and Western Knowledges. Social \& Cultural Geography 9(3):257-281.

Welsh, Stanley. L., N. Duane Atwood, Sherel Goodrich, and Larry C. Higgins 2003 A Utah Flora. $3^{\text {rd }}$ edition. ML Bean Life Science Museum.

Wendel, Kendra Lesley

2014 Lifeblood of the Earth: Nuwuvi (Southern Paiute) Hydrological

Knowledge and Perceptions of Restoration in Two Southern Nevada

Protected Areas. Master's Thesis. Department of Anthropology, Portland State University, Portland, Oregon. 
White Jr., Lynn

1967 The Historical Roots of our Ecologic Crisis. Science 155(3767):12031207.

White, Peter S., and Steward T. A. Pickett

1985 Natural Disturbance and Patch Dynamics: An Introduction. In The Ecology of Natural Disturbance and Patch Dynamics. Pp. 3-13. San Diego, CA: Academic Press.

Willow, Anna J.

2010 Cultivating Common Ground: Cultural Revitalization in Anishinaabe and Anthropological Discourse." The American Indian Quarterly (34)1: 33-60.

Wilmers, Christopher C., Robert L. Crabtree, Douglas W. Smith, Kerry M. Murphy, and Wayne M. Getz

2003 Trophic Facilitation by Introduced Top Predators: Grey Wolf Subsidies to Scavengers in Yellowstone National Park." Journal of Animal Ecology 72(6): 909-916.

Willson, Mary F., and Karl C. Halupka

1995 Anadromous Fish as Keystone Species in Vertebrate Communities. Conservation Biology 9(3):489-497.

Wisconsin Department of Natural Resources (WIDNR)

2009 Nasturtium officinale Invasive Species Classification. Electronic document, http://dnr.wi.gov/invasives/classification/pdfs/

LR_Nasturtium_officinale.pdf, accessed on February 16, 2014.

Zouhar, Kristin L.

2001 Pinus monophylla. In: Fire Effects Information System. Available online at: http://www.fs.fed.us/database/feis/plants/tree/pinmon/all.html.

Accessed May 14, 2014. U.S. Department of Agriculture, Forest Service, Rocky Mountain Research Station, Fire Sciences Laboratory. 


\section{Appendix A: Nuwuvi Consultant Informed Consent Script}

\section{Nuwuvi Knowledge-to-Action Project}

Greetings. My name is Brian Lefler. I am a graduate student from the Anthropology Department at Portland State University (PSU). I am conducting research that is part of the Nuwuvi Knowledge-toAction Project, directed by Jeremy Spoon and Richard Arnold, which partners with PSU, The Mountain Institute, seven Nuwuvi Nations, the Spring Mountains National Recreation Area (U.S. Forest Service), and the Desert National Wildlife Refuge (U.S. Fish and Wildlife Service). The project seeks to document Nuwuvi knowledge of plants, landscapes, and landscape features such as caves, springs, and mountains. I will also generate a proposed collaborative resource management plan for both areas. Additionally, individual interview transcripts and audio CDs will be given back to each consultant.

I am approaching you because you were recommended as a key individual with expert knowledge related to the project. If you are willing to participate, I would like to ask you some questions about your knowledge related to piñon-juniper habitats in the Spring and Sheep mountains. With your permission, I would like to record what you say by both taking notes and with this recorder (show them recorder). You may refuse to have it recorded or may ask me to turn it off at any time. The notes and recordings are intended for project use to help me accurately remember everything that you say. The recorded information that I obtain from interviews will be kept secure at all times either on my person or locked in my luggage. I also request that I am able to take your photo so that we can have a visual record of you with the important information that you provide us.

I understand that this interview may take you away from your work or domestic tasks. For your participation, you will receive a $\$ 150$ stipend. If any of the questions upset you, please tell me and we can pause the interview or move onto the next question. I feel this project is important because it will potentially help to improve consultation between Nuwuvi and the U.S. Government, to provide enhanced opportunities for collaborative management of the Spring, Sheep, and other mountain landscapes, as well as to perpetuate and revitalize the culture through multi-generational participation and knowledge transmission. I want you to be an active collaborator in the project, so please give us feedback and advice on all stages of the research and writing processes.

Your participation in this project is completely voluntary and you can withdraw your involvement or statements at any time during or after the interview, or refuse responses to any questions. If you have any questions or concerns at any time, please contact me, Brian Lefler, the researcher, or ${ }_{\perp}$ at the Human Subject Research Review Committee, Portland State University, using the provided contact information.

***Permission will be given or denied; the interview will also be conducted without recording or photos if necessary***

Researcher:

Human Subject Research Review Committee:

Brian Lefler

Department of Anthropology

Portland State University

P.O. Box 751

Portland, Oregon 97213

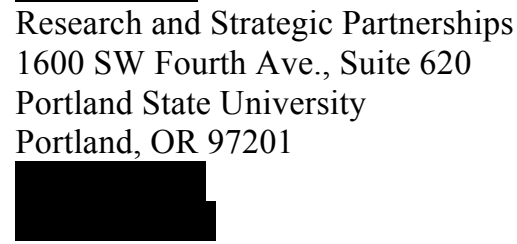




\section{Appendix B: Ethnoecological Interview Questions for Nuwuvi Consultants}

\section{Demographic Information}

1. What is your age?

2. What is the highest grade you completed in school?

3. What is you religion/spiritual affiliation(s)?

4. What Nation/ethnic group are you from?

5. Where did your family members come from and how far can you trace them back?

6. Have you always lived on the reservation/at your current location?

7. Did you attend boarding school or public school? Please explain.

8. Who taught you about the land, plants, and animals?

9. How did they teach you (stories, gathering plants, hunting, etc.)?

10. Have you read books on ethnobotany or Nuwuvi history/prehistory?

\section{Ethnobotanical Information}

1. How far/how long does it take for you to reach a grove of piñon- juniper?

2. How do you know when you're in piñon- juniper habitat, and how do you know when you've left it?

3. What plants do you consider the most significant in this ecosystem? How is this value determined in relation to other species?

4. For each plant:

a. Do you know this plant? What is its name?

b. What does the name mean?

c. Are there beliefs, stories, or songs about this plant?

d. Where is this plant found (geography, elevation, aspect, ecosystem, ecological associations)?

e. What time of year does each plant part emerge and for how long (shoot, leaves, flower, fruit, etc.)?

f. Does a particular life stage of this plant indicate anything (harvest, activity, etc.)?

g. Has the distribution and quantity of this plant changed, and how? What do you think caused this?

h. Does anything eat this plant?

i. Does this plant have a use? How did you learn about its use?

j. Is this plant still used, and how long does it take to procure?

\section{Landscape and Place-based Information}

1. Do you know this place/feature?

2. Do you know the name and/or meaning of the name for this place/feature?

3. Have you been to this place? When? What frequency? What time of year?

4. Are, or were there events that took place here? When did they stop, or how have they changed?

5. Are any plants, animals, songs, or stories associated with this place/feature?

6. Are there less (or more) of any mentioned plants at this place than before?

7. What time of year or day would each plant be present?

8. What other changes have happened at this place?

\section{Piñon-juniper Woodland Ecological and Management Information}

1. What does 'management' mean to you?

2. When does management need to occur, and why?

3. Are there any of the following types of restrictions (taboos) on these plants, water, features?
a. Segment - banning utilization during specific periods by a certain demographic
b. Temporal - banning access during certain time (sporadically, daily, seasonally, etc.)
c. Method - banning certain harvesting methods
d. Life history - banning use during certain life stages (age, size, sex, reproductive status)
e. Specific-species - permanent ban in time and space, self-enforcement
f. Habitat - regulating use and access to resources in certain habitats

4. Are there methods of growing (propagation, seed dispersal, or planting) the species we talked about? 
5. What is the preferred density of each species in this ecosystem? Is there more or less of any species than there should be?

6. Are there any other specific management techniques for any of the plants we talked about? For the ecosystem as a whole?

7. Are there currently problems occurring in this ecosystem? Is this ecosystem healthy?

8. What are the services that these plants and features offer wildlife, the ecosystem, and humans?

9. Why are the following trends occurring?:
a. Mistletoe
b. Piñon- juniper expansion into sagebrush steppe
c. Beetle infestation
d. Water scarcity
e. Increased catastrophic fires
f. Climate change
g. Other

10. How could each of these problems be addressed? Are there specific management actions that would help attain balance and ecosystem health? 
Appendix C: Select Focal Piñon-Juniper Woodland Botanical Species ${ }^{1}$

\begin{tabular}{|c|c|c|c|c|}
\hline GENUS & SPECIES & AUTHORITY & SSP., VAR. & COMMON NAME \\
\hline Pinus & monophylla & Torrey and Frémont & & Single-leaf piñon \\
\hline Pinus & edulis & Engelm. & & Colorado piñon \\
\hline Juniperus & osteosperma & Torrey (Little) & & Utah juniper \\
\hline Quercus & gambelii & Nutt. & & Gambel oak \\
\hline Quercus & turbinella & E. Greene & & Scrub oak \\
\hline Salix & spp. & $\mathrm{L}$. & & Willow \\
\hline Amelanchier & utahensis & Koehne & & Utah service berry \\
\hline Cercocarpus & ledifolius & Nutt. & var. intermontanus & Curl-leaf mountain mahogany \\
\hline Purshia & stansburiana & (Torrey) Henrickson & & Cliff rose \\
\hline Purshia & tridentata & (Pursh) DC. & & Bitter brush \\
\hline Ephedra & viridis & Coville & & Indian tea \\
\hline Ephedra & nevadensis & S. Watson & & Indian tea \\
\hline Rosa & woodsii & (S. Watson) Jepson & var. ultramontana & Woods' rose \\
\hline Rhus & trilobata & Nutt. & & Skunkbush (sumac) \\
\hline Artemisia & nova & A. Nelson & & Black sagebrush \\
\hline Artemisia & tridentata & Nutt. & ssp. tridentata & Big sagebrush \\
\hline Chysothamnus & spp. & Nutt. & & Rabbitbrush \\
\hline Ericameria & nauseosa & (Pall. Ex Pursh) G.L. Nesom \& Baird & & Rabbitbrush \\
\hline Nasturtium & officinale & W.T. Aiton & & Water cress \\
\hline Ribes & cereum & Douglas & var. cereum & Wax, Squaw currant \\
\hline Ribes & aureum & Pursh & var. aureum & Golden currant \\
\hline Eriogonum & inflatum & Torrey and Frémont & var. inflatum & Desert trumpet \\
\hline Nicotiana & attenuata & Torr. Ex S. Watson & & Coyote tobacco \\
\hline Arceuthobium & divaricatum & Engelm. & & Piñon dwarf mistletoe \\
\hline Phoradendron & juniperinum & Engelm. Ex A. Gray & & Juniper mistletoe \\
\hline Agave & utahensis & Engelm. & subsp. utahensis & Utah/pygmy agave \\
\hline Yисcа & baccata & Torrey & var. baccata & Banana yucca \\
\hline Achnatherum & hymenoides & (Roemer and J.A. Shultes) Barkworth & & Indian rice grass \\
\hline Leymus & cinereus & (Scribn. And Merr.) Á. Löve & & Great Basin wild rye \\
\hline
\end{tabular}

${ }^{\mathrm{I}}$ This plant list was generated by triangulating culturally and ecologically significant taxa occurring in piñon-juniper woodlands in both the SMNRA and the DNWR and through free listing exercises with an expert Nuwuvi knowledge holder and a conservation biologist. 


\section{Appendix D: Nuwuvi Demographic Information}

\begin{tabular}{ll}
\hline Constitution of Total Nuwuvi Sample $(\mathbf{N}=\mathbf{2 2})$ & \\
\hline Total Primary Interviewees $^{1}$ & 22 \\
\hline Female to Male Interviewee Ratio & $6: 5$ \\
\hline Age Range of Interviewees & $52-85$ \\
\hline Median Age of Interviewees & 67 \\
\hline Mean Age of Interviewees & 66 \\
\hline
\end{tabular}

${ }^{1}$ Some interviews included the impromptu participation of family members, not included here.

Constitution of Nuwuvi Sample by Nation $(\mathrm{N}=22)$

\begin{tabular}{lccccc}
\hline \multicolumn{1}{c}{ Nation } & $\begin{array}{c}\text { Number of } \\
\text { Consultants }\end{array}$ & $\begin{array}{c}\text { Gender } \\
\text { Ratio } \\
\text { F:M }\end{array}$ & Age & $\begin{array}{c}\text { Youngest/ } \\
\text { Oldest }\end{array}$ & $\begin{array}{c}\text { Median } \\
\text { Age }\end{array}$ \\
Chemehuevi & 3 & $1: 2$ & $64,69,72$ & 64,72 & 68 \\
Chemehuevi (CRIT) & 3 & $1: 2$ & $66,74,78$ & 66,78 & 73 \\
Kaibab & 3 & $2: 1$ & $57,61,63$ & 57,63 & 60 \\
Las Vegas & 4 & $3: 1$ & $52,53,70,72$ & 52,72 & 62 \\
Moapa & 3 & $2: 1$ & $56,68,72$ & 56,72 & 65 \\
Pahrump & 3 & $1: 2$ & $58,64,85$ & 58,85 & 69 \\
PITU & 3 & $2: 1$ & $63,68,74$ & 63,74 & 68 \\
\hline
\end{tabular}

Nuwuvi Demographic Information by $\operatorname{Nation}^{1}(\mathrm{~N}=22)$

\begin{tabular}{|c|c|c|c|c|c|c|c|}
\hline Nation & $\begin{array}{l}\text { Reservation } \\
\text { Acreage }\end{array}$ & Population & $\begin{array}{l}\text { Tribal } \\
\text { Enrollment }\end{array}$ & $\begin{array}{l}\text { High School } \\
\text { Diploma }\end{array}$ & $\begin{array}{l}\text { Bachelor's } \\
\text { Degree }\end{array}$ & $\begin{array}{l}\text { Unemployment } \\
\text { Rate }\end{array}$ & $\begin{array}{l}\text { Per Capita } \\
\text { Income }\end{array}$ \\
\hline Chemehuevi & 30,653 & 325 & 708 & $61.90 \%$ & $1.80 \%$ & $8.50 \%$ & $\$ 13,130$ \\
\hline $\mathrm{CRIT}^{2}$ & $269,920.52$ & 7,466 & 3,595 & $64 \%$ & $8.90 \%$ & $9.61 \%$ & No data \\
\hline Kaibab & $120,797.70$ & 196 & 270 & $83 \%$ & $7.10 \%$ & $9.17 \%$ & $\$ 7,951$ \\
\hline Las Vegas & $3,852.68$ & 108 & 56 & $77 \%$ & $0 \%$ & $3 \%$ & $\$ 48,529$ \\
\hline Moapa & $70,587.49$ & 295 & No data & $60.30 \%$ & $0.70 \%$ & $11.50 \%$ & $\$ 12,255$ \\
\hline Pahrump & No data & No data & No data & No data & No data & No data & No data \\
\hline PITU & $43,566.58$ & 270 & 799 & $51.20 \%$ & $4.70 \%$ & $12.7 \%$ & $\$ 5,666$ \\
\hline
\end{tabular}

${ }^{1}$ Sourced from BIA 2004; BIA Labor Report 2001; BIA Realty 2003, 2004; Tiller 2005; U.S. Census Bureau 2000

${ }^{2}$ Colorado River Indian Tribes (CRIT) includes Navajo, Mohave, and Hopi, in addition to Chemehuevi tribal members 
Appendix E: Nuwuvi Level of Western Education (N=22)

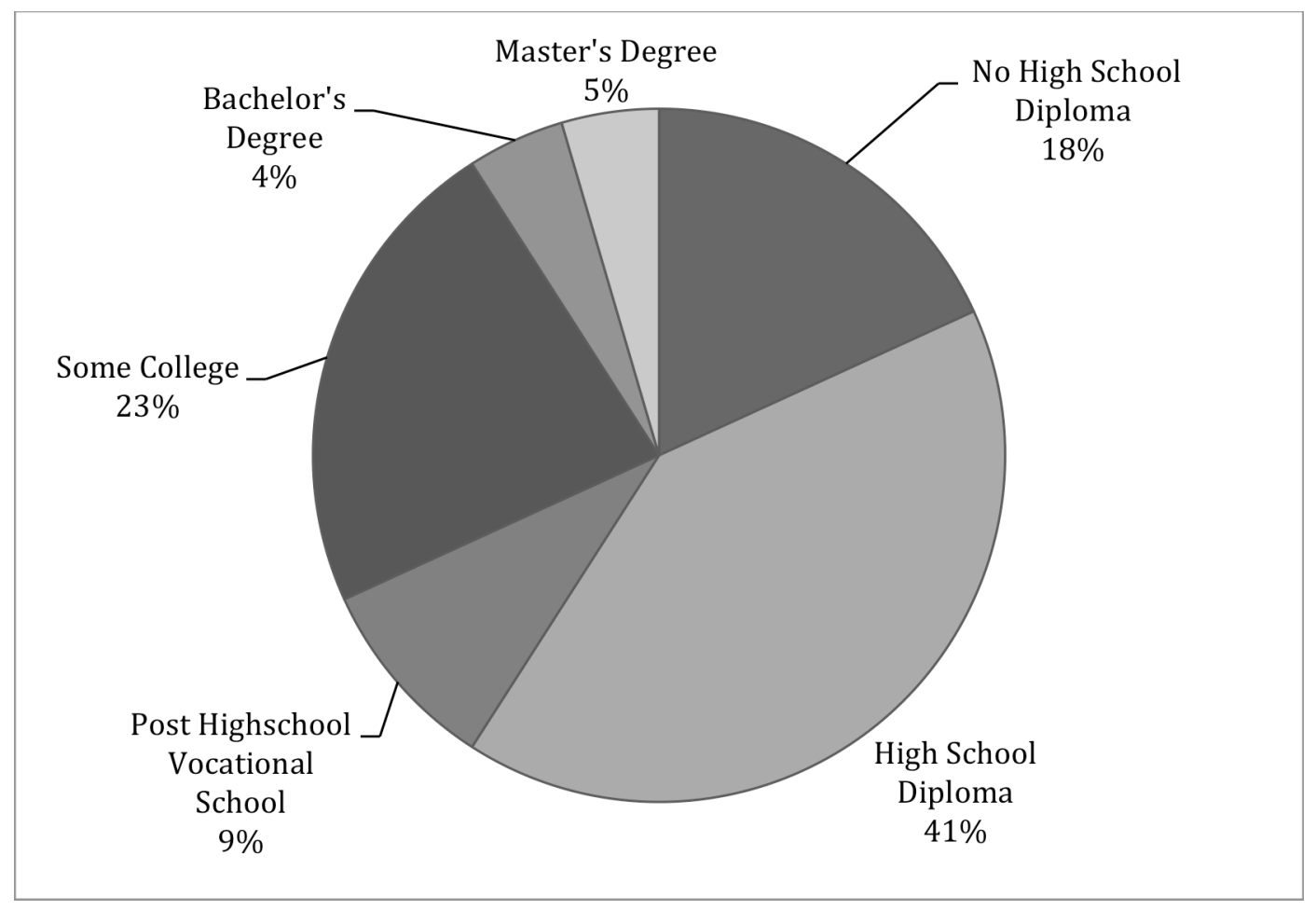


Appendix F: Nuwuvi Religio-Spiritual Orientation ( $\mathrm{N}=\mathbf{2 2})$

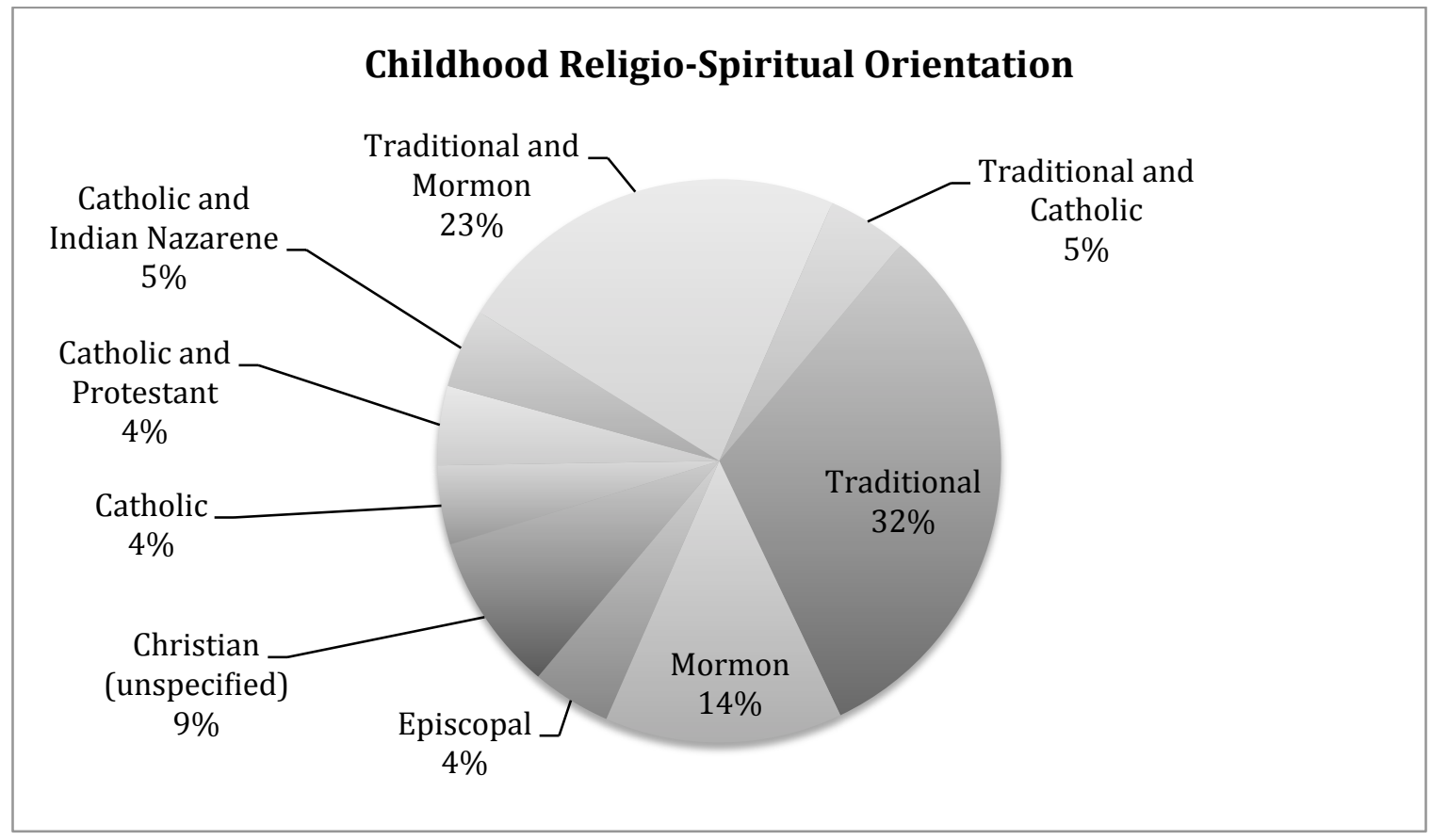

\section{Religio-Spiritual Orientation at Time of Study}

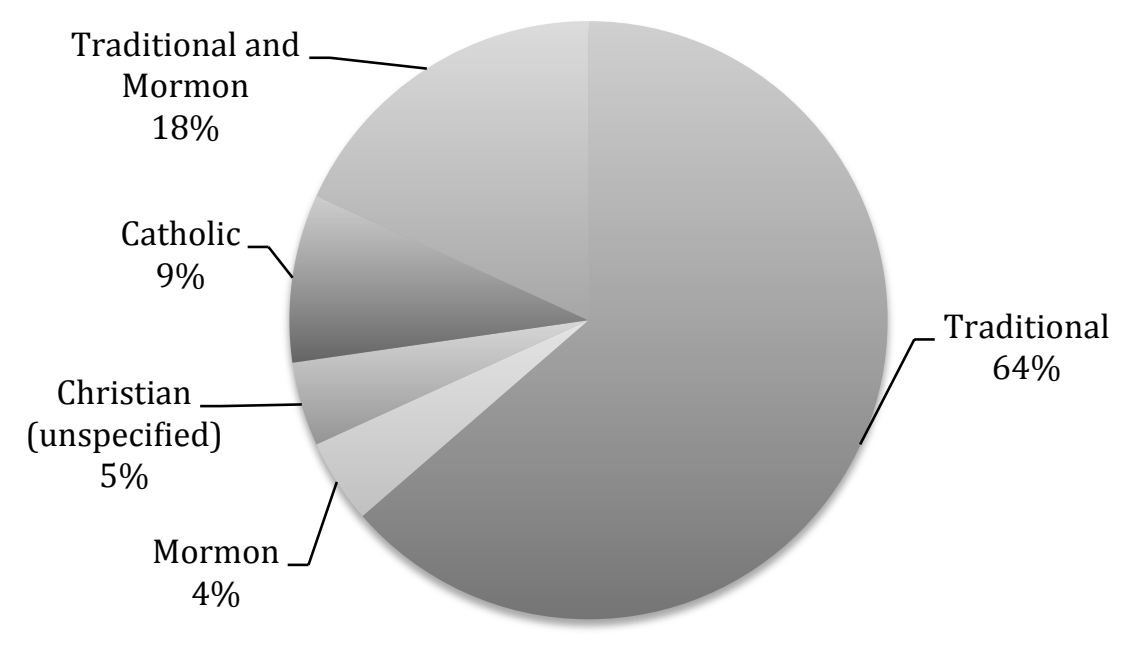




\section{Appendix G: Nuwuvi Disturbance-Based Management Practices in Piñon-Juniper Woodlands}

\begin{tabular}{|c|c|c|}
\hline \multicolumn{2}{|c|}{ MANAGEMENT METHOD } & POTENTIAL ENVIRONMENTAL FUNCTIONS \\
\hline \multirow{4}{*}{ Pruning } & $\begin{array}{l}\text { Selective } \\
\text { harvesting of } \\
\text { aerial portions }\end{array}$ & $\begin{array}{l}\text { - Stimulates growth } \\
\text { - Leaves sufficient material for continued growth and reproduction } \\
\text { - Leaves food for animals }\end{array}$ \\
\hline & Coppicing & $\begin{array}{l}\text { - Stimulates production of unbranched whips, for basketry and other utilitarian } \\
\text { functions }\end{array}$ \\
\hline & Whipping/shaking & $\begin{array}{l}\text { - Dislodges pine nuts, cones, dead material } \\
\text { - Stimulates and frees up space for new growth } \\
\end{array}$ \\
\hline & Foot traffic & $\begin{array}{l}\text { - Speed nutrient cycling } \\
\text { - Reduces fire ladders through mulching }\end{array}$ \\
\hline \multirow{3}{*}{ Burning } & Tidying & $\begin{array}{l}\text { - Reduces catastrophic fire danger } \\
\text { - Reduces fuel ladders } \\
\text { - Controls insect and mistletoe populations } \\
\text { - Reduces spread of mistletoe } \\
\text { - Improves accessibility } \\
\text { - Produces Nuwuvi aesthetic of a tended landscape }\end{array}$ \\
\hline & Patch burning & $\begin{array}{l}\text { - Reduces catastrophic fire danger } \\
\text { - Stimulates production of long, straight, unbranched whips of Salix spp., Rhus trilobata, } \\
\text { and other spp. for use in basketry, etc. } \\
\text { - Controls insect populations } \\
\text { - Improves accessibility to resources } \\
\text { - Stimulates germination of Nicotiana attenuata, and seed plants such as Mentzelia spp., } \\
\text { etc. }\end{array}$ \\
\hline & $\begin{array}{l}\text { Animal drives } \\
\text { (rabbit, deer, } \\
\text { antelope) }\end{array}$ & $\begin{array}{l}\text { - Soil disturbance } \\
\text { - Stimulates disturbance-evolved plant species }\end{array}$ \\
\hline \multirow[b]{2}{*}{$\begin{array}{l}\text { Broadcast } \\
\text { Seeding }\end{array}$} & Intentional & $\begin{array}{l}\text { - Increased presence of tobacco Nicotiana attenuata, and seed plants such as Mentzelia } \\
\text { spp., etc. } \\
\text { - Often used in conjunction with patch burning } \\
\text { - Aids seed dispersal }\end{array}$ \\
\hline & Unintentional & $\begin{array}{l}\text { - Occurring as a by-product of harvesting } \\
\text { - Assists inflorescence shattering } \\
\text { - Aids seed dispersal } \\
\text { - Seeds are buried and protected from predators by inadvertent trampling } \\
\text { - Often used in conjunction with patch burning }\end{array}$ \\
\hline \multirow{2}{*}{ Digging } & Harvesting & $\begin{array}{l}\text { - Aerates soil } \\
\text { - Utilizes natural erosive processes to ease harvesting and limit impact } \\
\text { - Stimulated growth of clonal pups left in situ and aids expansion of a patch } \\
\end{array}$ \\
\hline & Transplanting & $\begin{array}{l}\text { - Stimulates vegetative growth of mother plant and new plant } \\
\text { - Increases range and distribution of plants } \\
\text { - Creates new species diversity } \\
\end{array}$ \\
\hline \multirow{4}{*}{$\begin{array}{l}\text { Spring } \\
\text { Maintenance }\end{array}$} & Pruning & \multirow{4}{*}{$\begin{array}{l}\text { - Opens access } \\
\text { - Maintains water purity } \\
\text { - Increases water-holding capacity of basin } \\
\text { - Prevents spring from drying or closing up } \\
\text { - Ensures water for humans and animals } \\
\text { - Avoids large-scale disturbance and water diversion, minimizing impacts to springsnails } \\
\text { and sensitive vegetation }\end{array}$} \\
\hline & $\begin{array}{l}\text { Removing animal } \\
\text { carcasses }\end{array}$ & \\
\hline & Removing algae & \\
\hline & Removing silt & \\
\hline
\end{tabular}




\section{Appendix H: Reported Nuwuvi Vegetative Propagation Methods for Select Taxa}

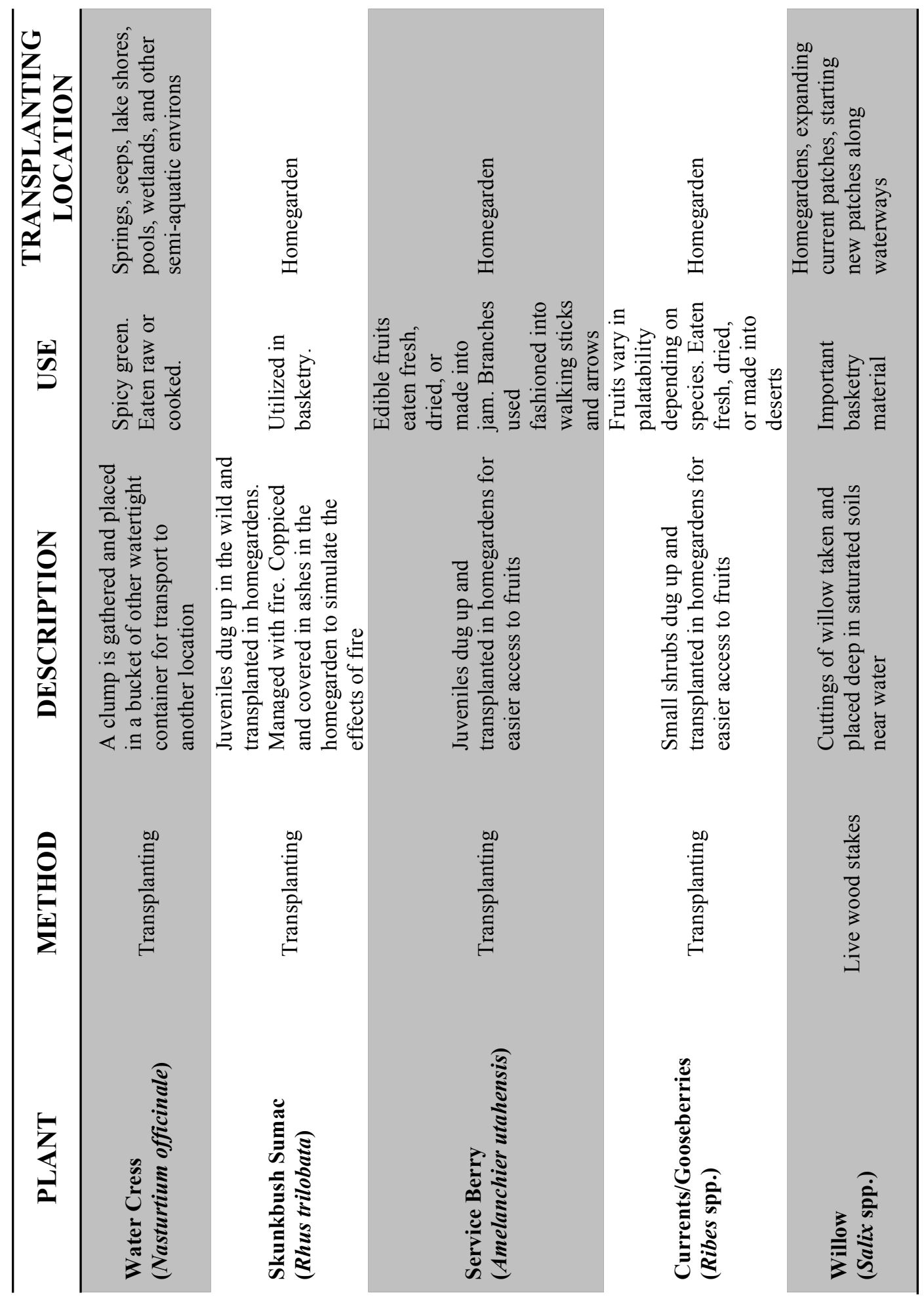


Appendix I: Special Status Faunal Species Potentially Benefitting from Nuwuvi Taboos in Piñon-Juniper Woodlands ${ }^{1}$

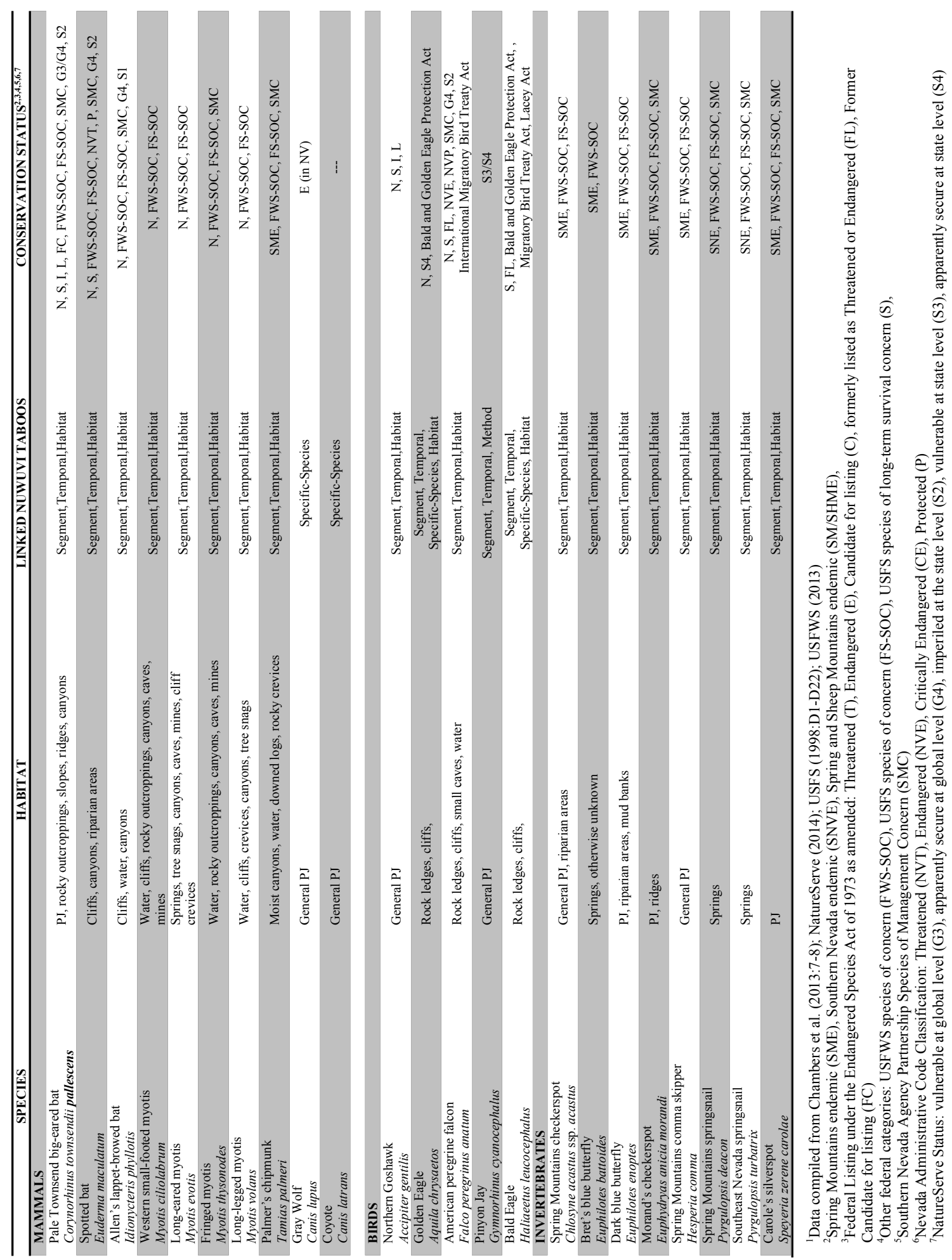




\section{Appendix J: Special Status Botanical Species Potentially Benefitting from Nuwuvi Taboos in Piñon-Juniper Woodlands ${ }^{1}$}

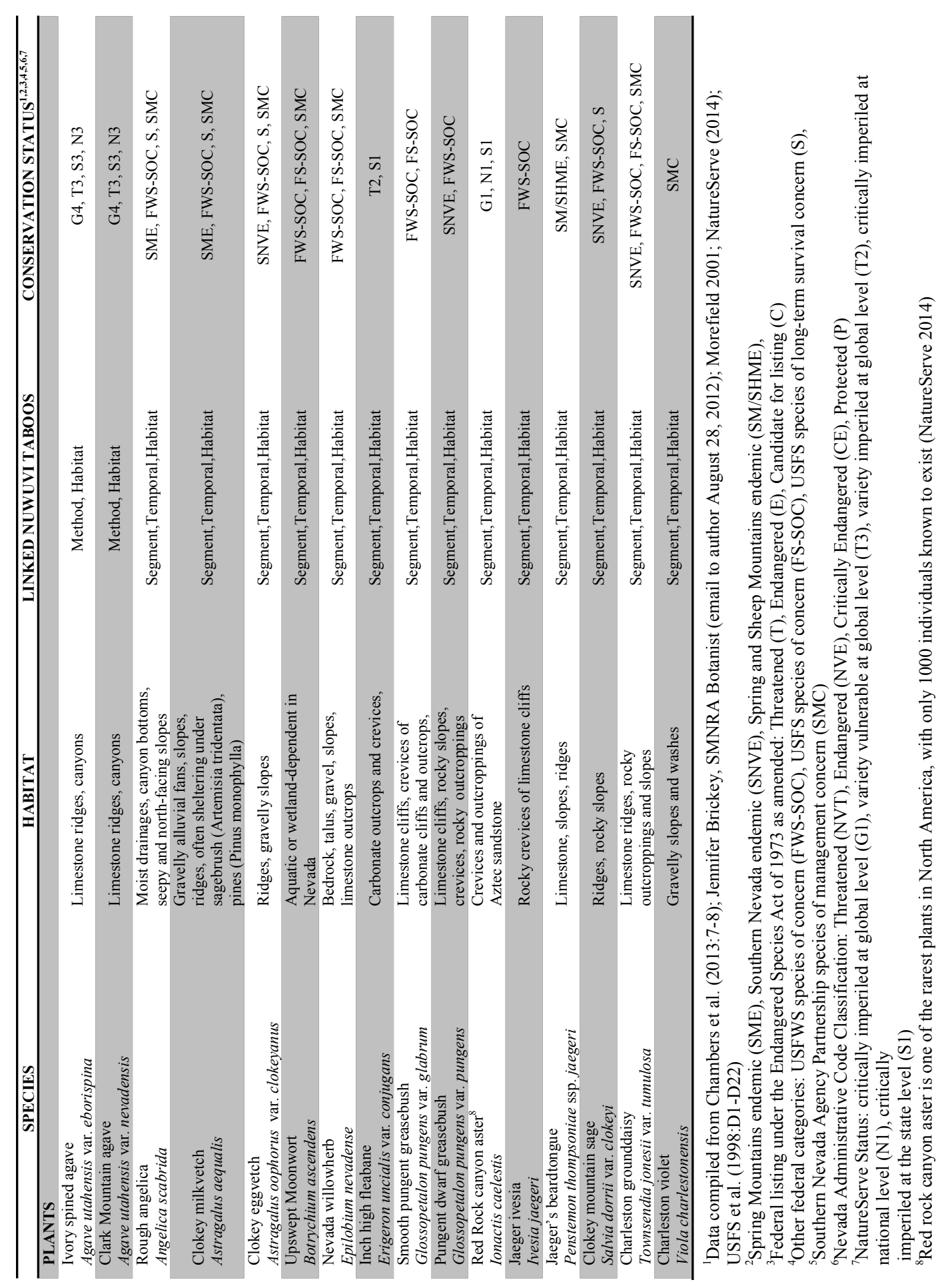




\section{Appendix K: \\ Summary of Recommendations for Collaborative Resource Stewardship Projects in Piñon-Juniper Woodlands}

Collaborative Resource Stewardship refers to cooperative and participatory engagements between federal agencies and Nuwuvi Nations that hybridize indigenous knowledge, practices, and social institutions with Western science-based approaches to achieve mutually agreeable goals (Spoon et al. 2013). This summary of recommendations is geared towards protected area cultural and natural resource managers. Although also providing a model for similar engagements in other contexts, this summary is specifically oriented toward collaborative resource stewardship between Nuwuvi, the USFS, and the USFWS within piñon-juniper woodlands in the Spring Mountains National Recreation Area and the Desert National Wildlife Refuge, Nevada. The first section provides recommendations and cautions for integrating Nuwuvi ecological knowledge (NEK) and Western science, while the second section describes suggestions, including several collected directly from Nuwuvi consultants, for creating collaborative resource stewardship projects in piñon-juniper woodlands.

Integrating local ecological knowledge with Western science

Despite fundamental epistemological and methodological differences among Nuwuvi, USFS, and USFWS approaches to piñon-juniper management, many corollaries are apparent. In fact, Nuwuvi management approaches even align with ecosystem management guidelines established for the SMNRA, which aim to:

1. Maintain viable populations of native species,

2. Maintain native ecosystems,

3. Maintain evolutionary and ecological processes including disturbance regimes,

4. Manage over long durations of time, and

5. Accommodate human use and habitation (USFS et al. 1998:7-8).

Collaborative resource stewardship is best characterized as an iterative process rather than an end product. It consists of both knowledge sharing and relationship building between diverse stakeholders and partners in resource conservation. Collaborative resource stewardship seeks to identify common goals, while acknowledging differences of opinion and worldview. The following cautions are offered to ensure successful and socially equitable collaborations: 
1. Avoid treating Western science as a gold standard to judge and evaluate the accuracy and validity of indigenous knowledge and management practices against.

2. Avoid indigenous knowledge appropriation by working collaboratively with indigenous partners.

3. Involve Native American partners in all stages of project development, from project design and scoping, to project implementation.

\section{$\underline{\text { Recommendations for Creating Collaborative Resource Stewardship Projects }}^{39}$}

- Provide opportunities for effective and meaningful consultation with traditionally associated Native Americans for all natural and cultural resource management activities.

- Perform ethnographic research with tribal partners aimed at identifying indigenous knowledge, management practices, and social institutions linked to relevant ecosystems and resources.

- Integrate both cultural and natural resource managers with tribal partners to achieve an interdisciplinary and intercultural approach to resource management.

- Avoid culturally offensive and toxic practices (e.g., herbicide use, fire retardant application) in cultural use areas. ${ }^{40}$

- Design collaborative stewardship projects to focus on Cultural Keystone Species such as piñon pines as rallying points. ${ }^{41}$

- Identify resource and habitat taboos that overlap with agency management policies use these points of agreements as a foundation for building collaborative partnerships.

- Collaboratively identify and protect culturally significant piñon pine groves and create exclusive use areas for Nuwuvi tribal members.

- Document and list ${ }^{42}$ select piñon groves with demonstrated continuity of use as traditional cultural properties (TCPs) on the National Register of Historic Places.

- Manage select piñon-juniper woodlands as non-industrial nut orchards, while also providing for other non-timber forest products (NTFPs). ${ }^{43}$

\footnotetext{
${ }^{39}$ Several of these ideas were also suggested in Spoon et al. (2013) and/or have been conducted as part of the NKTA project.

${ }^{40}$ See Anderson (2005:319-320) and LeBeau (1998:39) for more information about the cultural impacts and health risks to Native American non-timber forest product (NTFP) harvesters from chemical applications on public lands.

${ }^{41}$ See Higgs (2005:180) for a description of similar approaches.

${ }^{42}$ The listing of a TCP on the National Register of Historic Places does not ensure its protection. It does however; compel agencies to consider their impacts on such "properties" (King 2003).

${ }^{43}$ This idea has also been suggested by McLain and Frazier (2008).
} 
- Maintain sensitivity to Nuwuvi concerns about agency regulation or monitoring of cultural activities in light of historic marginalization and forced removal from ancestral lands. $^{44}$

- Initiate participatory monitoring programs that investigate the effects of Nuwuvi disturbance-based management regimes on the ecological health, productivity, and biodiversity on piñon-juniper woodlands using a series of control and test plots. ${ }^{45}$ Avoid privileging Western science when analyzing the results.

- Collaborate on rare plant monitoring, restoration, re-vegetation, and fire management activities.

- Offer training, scholarships, and employment opportunities in natural and cultural resource management to interested Nuwuvi tribal members. Positions with ecological monitoring, archaeology, and fire crews, and with education and interpretation programs are particularly relevant.

\footnotetext{
${ }^{44}$ McClain's (2008) piece on the panopticon nation-state surveillance of non-timber forest product (NTFP) harvesting is especially pertinent to this Nuwuvi concern. She describes three methods of surveillanceincluding categorization, monitoring, and tracking — utilized by the USFS that effectively transform cultural practices, such as NTFP gathering, into regulated work activities.

${ }^{45}$ See Fowler et al. (2003) for a similar approach.
} 